\title{
Planejamento Bayesiano de Ensaios Clínicos Sequenciais
}

\section{Patrícia Cáceres Klarmann}

\author{
Dissertação apresentada ao \\ Instituto de Matemática e Estatística \\ da Universidade de São Paulo \\ para a obtenção do grau de \\ Mestre em Estatística
}

\section{Área de Concentração: Estatística Bayesiana Orientador: Sérgio Wechsler}

São Paulo, setembro de 1996 


\title{
Planejamento Bayesiano \\ de \\ Ensaios Clínicos Sequenciais
}

\author{
Este exemplar corresponde à redação \\ final da dissertação devidamente corrigida \\ e apresentada por Patrícia Cáceres Klarmann e aprovada \\ pela Comissão Julgadora.
}

São Paulo, 01 de novembro de 1996.

Banca Examinadora:

- Prof. Dr. Sérgio Wechsler (Orientador) - IME-USP

- Prof. Dr. José Galvão Leite - IME-USP

- Prof. Dr. Josemar Rodrigues - ICMSC-USP 


\section{Sumário}

Agradecimentos $\quad$ V

Abstract e Resumo viii

Introdução

1 Estudos Clínicos $\quad 4$

1.1 Estudos Controlados .................. . . 5

1.2 Estudos Clínicos Observacionais . . . . . . . . . . . . 5

1.3 Ensaios Clínicos . . . . . . . . . . . . . . . . . 7

1.4 Ensaios Clínicos na Área Farmacêutica . . . . . . . . . . . . . 8

1.5 Ensaios Clínicos Controlados . . . . . . . . . . . . . . . 12

1.6 Tipos de Controles . . . . . . . . . . . . . . . . . . 13

1.6.1 Controles Concorrentes . . . . . . . . . . . . . . . 13 
1.6.2 Controles Históricos . . . . . . . . . . . . . . . . . . . . 14

1.7 Alocação de Tratamentos . . . . . . . . . . . . . . . . . . 15

1.8 Tipos de Planejamentos . . . . . . . . . . . . . . . . . . 19

1.8.1 Ensaios Não-Sequenciais . . . . . . . . . . . . . . . . . 19

1.8.2 Ensaios Sequenciais . . . . . . . . . . . . . . . . 21

1.9 Abordagem Clássica Versus Abordagem Bayesiana e o Princípio da Verossimilhança ... . . . . . . . . . . . . . . . 24

1.10 Questões Éticas . . . . . . . . . . . . . . . . . . 29

2 Problemas de Decisão $\quad 35$

2.1 Problema de Decisão Puro . . . . . . . . . . . . . . . . . . . . . 37

2.2 Problema de Decisão Estatística com Tamanho de Amostra Fixo . 42

2.3 Análise Pós-Experimental de um Problema de Decisão Estatística 44

2.4 Análise Pré-Experimental de um Problema de Decisão Estatística 46

2.5 Tamanho Ótimo da Amostra . . . . . . . . . . . . . . . . 49

2.6 Problemas de Decisão Estatística com Amostragem Sequencial . . 50

2.7 O Risco de um Procedimento Sequencial . . . . . . . . . . . . . 56

2.8 Procedimentos de Decisão Sequenciais de Bayes . . . . . . . . . . 58

2.9 Procedimento de Decisão Sequencial M-truncado de Bayes . . 64 
2.10 Determinação do Tamanho Máximo da Amostra . . . . . . . . . 70

2.11 Problemas de Decisão Estatística com Amostragem Sequencial em Grupos . . . . . . . . . . . . . . . . . . . . . . . . . . . 73

$\begin{array}{lll}3 & \text { Aplicação } & 75\end{array}$

3.1 Apresentação do Problema . . . . . . . . . . . . . . . . 75

3.2 Características do Ensaio . . . . . . . . . . . . . . . . 76

3.3 Amplitude de Equivalência . . . . . . . . . . . . . . . . . . . 77

3.4 Informação a Priori . . . . . . . . . . . . . . . . . . . . 78

3.5 Problema Puro Associado . . . . . . . . . . . . . . . . . 79

3.5.1 Espaço Paramétrico . . . . . . . . . . . . . . . . 80

3.5.2 Espaço de Decisões . . . . . . . . . . . . . . . . . . . 80

3.5.3 Função de Perda . . . . . . . . . . . . . . . . . . . . . . . 81

3.5.4 Distribuição a Priori . . . . . . . . . . . . . . . . 82

3.5.5 Solução para o Problema Puro . . . . . . . . . . . . . 82

3.6 Características do Planejamento . . . . . . . . . . . . . . . . . . 84

3.7 Construção do Planejamento . . . . . . . . . . . . . . . 88

$3.7 .1 \quad$ Etapa Inicial . . . . . . . . . . . . . . 88

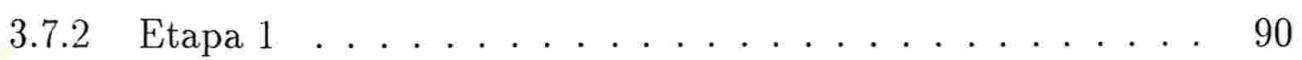




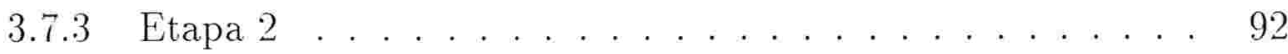

3.7 .4 Etapa $3 \ldots \ldots \ldots \ldots$. . . . . . . . . . . . 96

3.8 Exemplos . . . . . . . . . . . . . . . . . . . . . . . . . . . 99

3.8.1 Exemplo1 . . . . . . . . . . . . . . . . . . 99

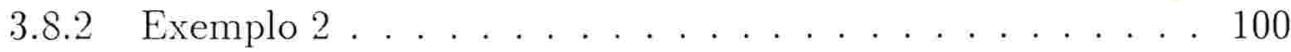

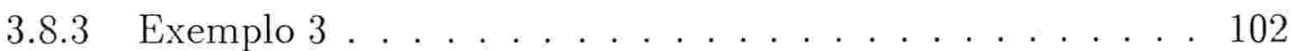

Comentários Finais

Referências Bibliográficas 


\section{Agradecimentos}

Este trabalho é parte final do Programa de Mestrado em Estatística do IMEUSP, programa ao qual dediquei aproximadamente 2 anos e meio da minha vida. Ao longo deste período muitas pessoas compartilharam comigo momentos de alegrias, ansiedade e desânimo que estiveram presentes. Tentarei deixar, aqui, meu agradecimento a todas elas.

- Ao meu orientador Professor Sérgio Wechsler por toda a sua atenção, ensinamentos, paciência, estímulos e momentos de descontração.

- À professora Jandyra Fachel do IM-UFRGS por ter sido minha maior incentivadora para o início do mestrado.

- A todos os professores do IME-USP com quem tive algum contato. Em especial a Clélia Tolói e a Vladimir Belitsky por todo apoio e incentivo no início do mestrado.

- A todos os colegas do IME-USP pelos momentos de trabalho, choradeiras e descontrações.

- A todos os funcionários do IME-USP que sempre colaboraram comigo.

- Ao CNPQ pelo apoio financeiro. 
- Ao meu noivo Flávio pela surpresa maravilhosa de ter vindo junto comigo fazer este mestrado. Pelo seu companheirismo, amor, carinho e paciência. Pela ajuda e pelas nossas trocas de idéias. Sem ele não sei como teria enfrentado todo este período.

- Aos meus pais, irmãos, cunhados e sobrinhos que, juntamente comigo, sentiram a distância, estando, porém, sempre presentes através de demonstrações de carinho e apoio.

- Aos meus sogros, seus filhos, genro, noras e netos por terem me recebido tão bem.

- Aos meus amigos de Porto Alegre pela amizade e por estarem presentes, da forma que podiam, neste período.

- A Eliana e sua família pelo carinho. 
Dedico este trabalho ao Flávio. 


\section{Abstract}

We present an alternative way of designing, monitoring and analising a clinical trial. The aim is to use a group sequential design in a Bayesian context of Decision Theory. The main advantages of this kind of design are the flexibility with regard to possible interruptions of the trial and the possibility of incorporating subjective opinions and preferences, as usual in the medical field. We discuss some aspects of "Ethics and Clinical Trials" and present concepts of Decision Theory. Furthermore, we formally develop a design for the problem of comparing the efficacy of two drugs and present some examples of how to conduct and analyse the proposed trial.

\section{Resumo}

Neste trabalho, apresentamos uma maneira alternativa de planejar, monitorar e analisar um ensaio clínico. A proposta é utilizar de um planejamento sequencial em grupos dentro de um contexto bayesiano de Teoria de Decisão. As principais vantagens deste tipo de planejamento são a sua flexibilidade quanto a possíveis interrupções do ensaio e a possibilidade de incorporação de opiniões e preferências subjetivas tão comuns na área médica. Discutimos alguns aspectos sobre "Ética e Ensaios Clínicos" e apresentamos conceitos de Teoria de Decisão. Além disso, desenvolvemos formalmente um planejamento para o problema de comparar a eficácia de duas drogas e apresentamos exemplos de como conduzir e analisar o ensaio proposto. 


\section{Introdução}

A investigação clínica é um processo altamente dinâmico, onde mudanças acontecem a cada momento. Com o decorrer do tempo, tem sido contínuo o aumento do número de informações quantitativas em estudos clínicos. A preocupação em entender e analisar essas informações tem aumentado o interesse pela Estatística como caminho para promover métodos cada vez mais dinâmicos que conduzam a análises cada vez mais precisas. Ensaios clínicos são experimentos planejados em seres humanos e, por esse motivo, questões éticas surgem naturalmente e devem ser consideradas no seu planejamento.

As técnicas estatísticas mais difundidas e utilizadas para planejamento, monitorização e interpretação de ensaios clínicos controlados têm sido baseadas na teoria clássica de testes de hipóteses de Neyman e Pearson. Para acompanhar a natureza dinâmica da área médica, cada vez mais tem-se utilizado ensaios sequenciais, que incluem a possibilidade de análises intermediárias ( permitindo que um ensaio seja interrompido tão logo os resultados se mostrem "significantes"). A abordagem clássica de testes de hipóteses em ensaios sequenciais é totalmente dependente do planejamento estatístico determinado, sendo assim muito pouco flexível.

O nosso objetivo principal com este trabalho é apresentar uma maneira mais 
dinâmica e flexível de planejar. monitorizar e analisar um ensaio clínico, dando uma maior ênfase para ensaios clínicos na área farmacêutica. Nossa proposta subordina-se à abordagem bayesiana. a qual permite o uso de evidências externas ao ensaio através da atualização de probabilidades (subjetivas). Além disso, ela é mais flexível para tratar com as questões éticas associadas à alocação dos tratamentos entre os pacientes e às interrupções ou prosseguimentos de ensaios com protocolos ditados pelo planejamento estatístico.

Seguindo esta mesma linha. Spiegelhalter et. al. (1994) apresentaram o uso da teoria de inferência estatística bayesiana para a análise de ensaios clínicos. A proposta deles é analisar um ensaio clínico "contemplando" a distribuição a posteriori para os parâmetros de interesse. Por outro lado, Lewis e Berry (1994) apresentaram uma abordagem bayesiana para o planejamento de ensaios clínicos através da incorporação de Teoria de Decisão em ensaios sequenciais. Comparando-se o planejamento bayesiano proposto com os planejamentos sequenciais clássicos em grupos de Pocock (1977) e de O'Brien e Fleming (1979) através de critérios frequentistas, concluiu-se que, principalmente quando muitas análises intermediárias são feitas, o tamanho médio amostral do planejamento bayesiano proposto é usualmente menor.

A nossa sugestão é utilizar um ensaio controlado sequencial em grupos dentro de um contexto bayesiano de Teoria de Decisão (com incorporação de opiniões e preferências subjetivas) para planejamento e análise de um ensaio clínico.

No capítulo 1, apresentamos algumas idéias sobre Estudos Clínicos, procurando citar os aspectos mais importantes que devem ser considerados no planejamento. Também destacamos diversas vantagens dos métodos bayesianos, além de discutirmos alguns aspectos de "Ética e Ensaios Clínicos". O intuito deste capítulo também é possibilitar a familiarização com alguns termos e conceitos 
médicos e estatísticos.

No capítulo 2, desenvolvemos a parte teórica de Teoria de Decisão. Primeiramente, introduzimos alguns conceitos básicos envolvendo Problema de Decisão Puro e Problema de Decisão Estatística, os quais diferem basicamente pela possibilidade, no segundo caso, de se observar uma amostra. Posteriormente, apresentamos o Problema de Decisão Estatística com amostragem sequencial, que tem como característica a possibilidade de interromper o ensaio tão logo os dados sugiram que uma decisão deva ser escolhida. Por fim, desenvolvemos uma maneira de aproximação para o Procedimento de Decisão Sequencial Ótimo através do Procedimento de Decisão Sequencial M-truncado Ótimo.

No capítulo 3, descrevemos um problema bastante comum na área farmacêutica, que é o de comparação da "eficácia de duas drogas". Aplicamos a Teoria de Decisão estudada no capítulo 2 para a construção formal e completa de um Procedimento de Decisão Sequencial M-truncado de Bayes para o problema apresentado. Finalmente, escolhemos três das possibilidades para a amostra e apresentamos em forma de exemplo como conduzir e analisar o ensaio proposto. 


\section{Capítulo 1}

\section{Estudos Clínicos}

Estudos clínicos são pesquisas planejadas em seres humanos com o propósito de servir como base científica da Medicina. Eles são comumente diferenciados em dois tipos: Ensaios Clínicos e Estudos Clínicos Observacionais. A grande diferença entre eles é que ensaios clínicos envolvem experimentação, enquanto estudos clínicos observacionais envolvem apenas observação. Um aspecto comum é que geralmente ambos envolvem um grupo "experimental" e um grupo "controle".

Neste capítulo, primeiramente definiremos estudos controlados e apresentaremos uma breve descrição de estudos clínicos observacionais. Posteriormente apresentaremos algumas idéias sobre ensaios clínicos com enfoque na área farmacêutica. Por fim, devido ao fato que ensaios clínicos envolvem experimentação em seres humanos, discutiremos alguns aspectos da ética médica. 


\subsection{Estudos Controlados}

O principal objetivo de qualquer estudo clínico é buscar associações ou relações de causa-efeito entre tratamentos e doenças. O caminho mais natural para que estes estudos sirvam como base científica da Medicina é a comparação da resposta de um grupo experimental com a de um grupo controle. A principal razão para a inclusão de um grupo controle é obter um padrão com o qual o grupo experimental possa ser comparado. Um Estudo Controlado (ou Estudo Comparativo) possui duas interpretações: ${ }^{1}$

- Qualquer estudo que inclui um grupo controle (pacientes que são submetidos ao tratamento controle), além do grupo experimental (pacientes que são submetidos ao tratamento experimental).

- Qualquer estudo que além de incluir um grupo controle e um grupo experimental, determine que o pesquisador deva exercer o controle através da especificação da maneira com que será feita a alocação (ver seção 1.5) dos tratamentos por esses grupos.

\subsection{Estudos Clínicos Observacionais}

São pesquisas conduzidas por observação de seres humanos. Geralmente são utilizados para buscar associação entre tratamentos e doenças. Em estudos observacionais não é permitido ao pesquisador atribuir os tratamentos às pessoas

\footnotetext{
${ }^{1}$ Ambas são consistentes com a palavra "controlado" (Berry(1990)) e são consideradas legítimas (Berry(1996)).
} 
envolvidas. Neste tipo de estudo, tratamentos podem ser características (sexo, idade, ...), hábitos ou sintomas dos pacientes. Por exemplo. em um estudo sobre câncer no pulmão, a resposta a ser observada pode ser a presença ou não de enfisema pulmonar. O tratamento experimental pode ser o hábito de fumar e o tratamento controle o hábito de não fumar. Devido a sua natureza observacional, este tipo de estudo não é considerado um experimento, mas uma pesquisa que investiga associações. Ele pode ser controlado no sentido da primeira interpretação da seção anterior, mas jamais será controlado no sentido da segunda interpretação. Como Berry (1996) ressalta, estudos observacionais podem mostrar associações, mas não podem inferir relações de causalidade.

Estudos Observacionais Retrospectivos: São estudos observacionais que, como o próprio nome indica, envolvem uma volta no tempo. Iniciam-se com a separação dos pacientes de acordo com a resposta observada, para então o pesquisador voltar no tempo e obter a história de cada pessoa do estudo objetivando buscar possíveis características associadas com a resposta. Por exemplo, se o estudo sobre câncer no pulmão anteriormente citado fosse um estudo observacional retrospectivo, deveríamos iniciar separando pessoas sem enfisema pulmonar e pessoas com enfisema pulmonar, para depois investigar o passado destas pessoas em relação ao hábito de fumar. Neste caso, as conclusões a que poderíamos chegar seriam sobre associação entre câncer no pulmão e tabagismo. Este tipo de estudo é muito utilizado na área de Epidemiologia para investigar associação entre uma doença rara e possíveis causas. Nesta área, estudos observacionais retrospectivos são mais conhecidos como estudos caso-controle.

Estudos Observacionais Prospectivos: São estudos observacionais que, ao contrário do caso anterior, envolvem um acompanhamento ao longo do tempo. Iniciam-se com a separação em grupos controle e experimental de acordo com as características que o pesquisador suspeita serem associadas com a resposta. 
Em seguida, o pesquisador acompanha as pessoas do estudo por um determinado tempo para observar suas respostas. Apesar deste tipo de estudo não ser muito utilizado em epidemiologia, nesta área, estudos observacionais prospectivos são mais conhecidos por estudos de "coorte". O estudo sobre câncer no pulmão realizado por Doll e Hill (1951), por ser o primeiro estudo prospectivo em larga escala para investigar a associação entre câncer no pulmão e tabagismo, é um exemplo clássico. Através da investigação de vários fatores relacionados com o tabagismo, foram separadas 41.000 pessoas em fumantes e não fumantes. Após 4 anos e meio, foi investigado quais destas pessoas haviam morrido e, restringindo a atenção para homens com mais de 35 anos, registrou-se 84 casos de morte por câncer no pulmão. Então, foi verificado quantos destes 84 casos pertenciam ao grupo de fumantes, e a conclusão foi clara em afirmar que existe associação entre fumo e câncer no pulmão.

Estudos observacionais são extremamente importantes quando ensaios clínicos não são possíveis. Para mais detalhes ver, por exemplo, Colton(1974). Para detalhamento de planejamento, condução e análise de estudos observacionais retrospectivos, ver Schlesselman (1982).

\subsection{Ensaios Clínicos}

Ensaios clínicos são pesquisas conduzidas através de experimentos em seres humanos. Geralmente são planejados para avaliar a eficiência de uma ou mais formas de tratamento. Aqui, o termo tratamento tem o significado mais usual de intervenção do pesquisador. É o pesquisador quem atribui tratamentos às pessoas do estudo. Por definição, ensaios clínicos são estudos controlados no sentido da segunda interpretação da seção 1.1. 
Neste trabalho, daremos ênfase à área farmacêutica, onde ensaios clínicos são realizados para avaliar o efeito de diferentes tipos de drogas (tratamentos) em relação a determinada doença (resposta). Note-se que na área farmacêutica, estudos clínicos observacionais são praticamente impossíveis, já que há a necessidade da intervenção do pesquisador para atribuir as drogas envolvidas no estudo. Berry (1990) ressalta que, embora um estudo simples seja uma meta desejável, muitos ensaios clínicos farmacêuticos são demasiadamente simplificados. Fatores como dosagem, diagnóstico, variáveis demográficas, uso de drogas concomitantemente, etc., podem ser de grande relevância (no sentido de afetar substancialmente o efeito da droga) e, portanto, merecem uma atenção especial. Chamaremos de fatores prognósticos aqueles fatores que o pesquisador considerar relevantes em relação à resposta. Estudos muito simples envolvendo poucos fatores prognósticos podem resultar extremamente ineficientes. Nosso objetivo com esta e as próximas seções é discutir alguns aspectos importantes que devem ser considerados em ensaios clínicos.

\subsection{Ensaios Clínicos na Área Farmacêutica}

Antes que um ensaio clínico farmacêutico seja iniciado, as drogas envolvidas devem ser usadas em animais como uma tentativa de entender sua ação no sistema animal. Somente quando é suspeitado um possível efeito benéfico em humanos e nenhum efeito tóxico sério constatado, é que estas drogas podem fazer parte de um ensaio clínico farmacêutico. O estudo em animais também produz informação para a dosagem inicial a ser usada na experimentação em seres humanos. Comumente, um ensaio clínico farmacêutico é categorizado em 4 fases: 


\section{Fase I: Farmacologia Clínica e Efeito Tóxico}

Esta fase se inicia com a primeira vez que a nova droga é experimentada em um ser humano. Tem como objetivo determinar a toxicidade em humanos, metabolismo, absorção, eliminação e outras ações farmacológicas, biodisponibilidade e dosagens tentativas de administração. Nesta fase também acontecem estudos de bioequivalência, cujo objetivo é verificar a igualdade das várias formulações (cápsulas, tabletes, líquidos, ... ) que são desenvolvidas para a comercialização de uma mesma droga. Com o objetivo de reduzir o risco de problemas tóxicos e evitar mascaramento entre a doença e os efeitos farmacológicos a serem testados, esta fase envolve apenas pessoas sadias ${ }^{2}$. Esta é uma fase totalmente exploratória.

\section{Fase II: Investigação Clínica Inicial}

É a fase intermediária. Também é considerada fase exploratória, pois é a primeira vez que a nova droga é administrada a pacientes ${ }^{3}$ (nesta fase todas as pessoas envolvidas no ensaio são pacientes). Possui dois objetivos principais: identificar a população que terá benefícios com a nova droga e verificar a eficiência da dosagem determinada na Fase I. Esses dois objetivos estão intimamente relacionados, uma vez que posologias bem definidas podem depender da categoria do fator prognóstico do paciente. Por exemplo, para a categoria de pacientes muito doentes, uma baixa dosagem da droga pode não trazer benefícios, enquanto que uma dosagem mais elevada, sim (outros tipos de categorias que poderíamos considerar: adulto ou criança, pouco ou muito peso, ...).

Em relação ao primeiro objetivo, duas atitudes bastante extremas podem ser consideradas: "Narrow" ou "Broad". Na atitude "Broad", o ensaio admite todas as categorias de pacientes, e suas respostas devem ser analisadas como função

\footnotetext{
${ }^{2}$ Pessoas que não apresentam a doença em questão.

${ }^{3}$ Pessoas que apresentam a doença em questão.
} 
dessas categorias. A idéia aqui é aprender tanto quanto possível sobre o tipo de paciente que terá benefícios com a nova droga. antes de envolver um estudo na fase III. Na atitude "Narrow" o ensaio, primeiramente, só admite pacientes de uma determinada categoria. Vamos pensar, por exemplo. em pacientes com a doença em nível intermediário (as outras possibilidades de categoria seriam pacientes pouco doentes e pacientes muito doentes). Este tipo de atitude evita que os pacientes muito doentes sejam expostos a alguma possível toxicidade da droga e evita, também, a possibilidade de não se conseguir identificar um possível efeito benéfico da droga devido a seu uso em pacientes pouco doentes. Por envolver apenas uma categoria, este tipo de atitude implica em um ensaio com menor número de pacientes que a atitude anterior. `̀ medida que a droga mostre-se efetiva para uma categoria de pacientes, esta categoria passa a fazer parte de ensaios da fase III e outra categoria começa a ser analisada na fase II. Com este tipo de atitude, a regulamentação da nova droga pode ser estabelecida antes mesmo que todas as categorias sejam estudadas. Uma vez que a primeira categoria estudada na fase II passa para a fase III e, para esta categoria, é estabelecida a eficiência da nova droga, então a regulamentação da droga já é proclamada. A princípio, essa regulamentação é restrita a esta primeira categoria, mas conforme as outras categorias passem pela fase III, a restrição pode ir sendo suspendida. A atitude "Narrow" oferece vantagens por envolver menos risco e agilizar o processo regulatório da nova droga. Por essas vantagens, ela é considerada usualmente melhor mas, na prática, uma atitude intermediária é recomendada na literatura. Por exemplo, em ensaios que envolvem doenças raras, a atitude "Broad" se torna necessária devido ao pequeno número disponivel de pacientes com a doença para o estudo.

Em relação ao segundo objetivo, é importante salientar que não devemos pensar que o efeito dos vários tipos de dosagem seja completamente entendido na fase 
I, principalmente porque aquela fase não envolve pacientes. A meta é estabelecer posologias bem definidas para cada categoria de pacientes a serem envolvidos em ensaios da fase III.

Convém salientar que os objetivos acima citados não são exclusivos da fase II, embora seja clara a importância desta fase intermediária. A idéia desta fase é perseguir os objetivos com sentido exploratório, envolvendo apenas a droga experimental, um pequeno número de pacientes e tempo reduzido. Devido a estas características, esta fase permite apenas estimativas relativamente imprecisas a respeito da segurança e eficiência da droga, bem como de reações adversas provocadas por ela. A importância desta fase é explicada por duas vantagens: maior economia para as indústrias farmacêuticas e exposição de menos pacientes ao risco de uma possível ineficiência ou periculosidade.

\section{Fase III: Avaliação do Tratamento em Larga Escala}

Esta é a fase confirmatória. O objetivo é obter estimativas mais precisas para confirmar ou não a segurança e eficiência de cada posologia indicada na fase II, em relação à doença em questão. Devido a isso, é a fase que costuma envolver o maior número de pacientes do estudo e o maior tempo de duração, apesar da população paciente considerada poder ser mais restrita. Por exemplo, se na fase II não detectarmos um possível efeito benéfico da droga (ou mesmo detectarmos um efeito maléfico) para uma determinada categoria de paciente, este tipo de paciente não deve fazer parte da fase III. A maneira mais utilizada de verificar a eficiência de uma droga (indicando que ela oferece contribuição significativa ao tratamento médico e, portanto, deve receber aprovação para comercialização) é compará-la com tratamento controle através de ensaios clínicos controlados (ver seção 1.5). 
Fase IV : Supervisão durante a Comercialização

Esta fase se dá após a aprovação da droga e tem como objetivo detectar e quantificar efeitos adversos da droga que nào foram identificados nas fases anteriores, seja porque esses efeitos ocorrem muito raramente ou porque seu período de latência é muito longo. Dependendo dos resultados desta fase, uma droga deve até perder sua aprovação para comercialização.

Convém salientar que em muitos ensaios clínicos não é possível identificar cada uma destas fases separadamente, pois muitas vezes há grande sobreposição entre elas. Além disso, a classificação das 4 fases nem sempre é muito nítida e a definição delas varia com cada autor. As definições que apresentamos nesta seção são do texto de Berry (1990).

\subsection{Ensaios Clínicos Controlados}

Neste trabalho daremos ênfase aos ensaios clínicos controlados (ou comparativos) que envolvem dois tratamentos e que são comumente utilizados na fase III. Um ensaio clínico controlado é um estudo controlado no sentido da segunda interpretação da seção 1.1. A diferença entre um ensaio clínico controlado e um estudo controlado é que o primeiro necessariamente envolve seres humanos e o segundo não possui esta exigência. Note que todo ensaio clínico é um ensaio clínico controlado.

O principal objetivo dos ensaios relativos à fase III é a comprovação ou não da eficácia da droga experimental. Muitas vezes aproveita-se o mesmo ensaio para comparar a eficácia entre a droga experimental e alguma droga alternativa ou padrão. Dependendo do objetivo do ensaio, diversos tipos de controle podem 
ser considerados (ver seção 1.6).

Segundo Royall (1991), se os médicos envolvidos no estudo estão em estado de indistinção (definido originalmente como estado de "equipoise" por Freedman(1987), como um estado de genuína incerteza a respeito de qual tratamento envolvido no ensaio é melhor), então o ensaio clínico controlado é chamado experimental. Por outro lado, quando o médico está confiante na superioridade de uma das drogas e seu objetivo com o ensaio é a demonstração deste fato, então o ensaio clínico controlado é chamado demonstrativo (ensaios para "conhecer" e para "convencer" respectivamente).

Um aspecto importante no planejamento de um ensaio clínico é a produção de um protocolo, que é um claro e detalhado plano para a condução deste ensaio. Muitas vezes os órgãos regulatórios utilizam o protocolo para avaliar a validade científica do estudo. Um protocolo de um ensaio clínco controlado deve conter, por exemplo, justificativas e objetivos do ensaio, delimitação da amostra, critério de seleção e tamanho da amostra, tratamentos envolvidos, maneira de alocação dos tratamentos entre os pacientes, tipos de controle, tipos de análises estatísticas a serem feitas, etc.. Em muitos países este protocolo deve ser enviado para um comitê competente que aprovará ou não o ensaio. Após a realização do ensaio, o protocolo mantém alguma relevância dependendo da abordagem estatística utilizada (ver seção 1.9).

\subsection{Tipos de Controles}

\subsubsection{Controles Concorrentes}

É o tipo de controle mais comum em ensaios clínicos farmacêuticos. O uso deste 
tipo de controle permite que a eficácia das drogas seja comparada concorrentemente, ou seja, ao mesmo tempo. Controles concorrentes podem receber os seguintes tratamentos:

Tratamento Ativo: Quando qualquer droga já aprovada é administrada ao grupo controle. Quando é administrada uma droga que é comumente utilizada como tratamento da doença em questão, este controle também é chamado de tratamento padrão.

Não-Tratamento: Quando nenhuma droga é administrada ao grupo controle.

Dose-Resposta: Quando o grupo controle recebe a mesma droga experimental, só que com uma dose distinta. É mais utilizado em estudos para comparar diferentes tipos de dosagens e, portanto, não é muito frequente em estudos da fase III.

Placebo: É uma substância inerte, sem ação farmacológica. Quando administrase placebo, os pacientes controle não devem saber que não estão recebendo tratamento ativo. Por que administrar placebo ao invés de Não-Tratamento? A razão principal é o que se chama de Efeito Placebo: a simples ação de receber algum tratamento pode, por razões psicológicas, trazer benefícios ao paciente (mesmo que este tratamento não passe de placebo). Sendo assim, se nenhum tratamento é administrado ao grupo controle, o efeito do tratamento experimental possui em parte o efeito placebo, que não deveria ser considerado na comparação .

\subsubsection{Controles Históricos}

Formado por grupo previamente tratado (no sentido de intervenção do pesquisador) com tratamento ativo alternativo. Controles históricos também deveriam ser 
similares aos pacientes experimentais em todos os aspectos, exceto, evidentemente, quanto ao tratamento usado. Segundo Berry (1990), é importante distinguir dois tipos de controles históricos: aqueles que foram anteriormente tratados na mesma instituição e pelo mesmo médico dos pacientes experimentais e aqueles que foram tratados em diferentes instituições (incluindo aqui aqueles encontrados na literatura). Esta divisão considera que as diferenças entre protocolos, instituiçôes e médicos podem ser tão grandes em pacientes do segundo tipo, que eles não podem ser usados como grupo controle. Mas quanto ao primeiro tipo, Berry não só considera como grupo controle, como destaca algumas vantagens sobre controles concorrentes, tais como: menor custo, maior comparabilidade (pois, normalmente, há muito mais pacientes disponíveis historicamente do que para estudo), remoção de alguns problemas éticos (somente a droga em estudo será ministrada aos pacientes que entrarem no ensaio). Existem também aqueles que não consideram ensaios envolvendo grupos-controle históricos como "realizados sob método científico". Esta linha de pensamento se satisfaz com a comparabilidade obtida pela simultaneidade dos experimentos ou dos locais, sem atentar para a inevitável subjetividade que existe ao determinar quais outros fatores são ou não relevantes.

\subsection{Alocação de Tratamentos}

A principal idéia em ensaios clínicos controlados é comparar grupos de pacientes que difiram somente quanto ao tratamento a eles atribuído. A vantagem de uma comparação deste tipo é a garantia de que o efeito produzido no paciente seja devido exclusivamente à droga administrada. Entretanto, como esta comparabilidade perfeita é na prática inalcançável, a alocação dos tratamentos entre os pacientes torna-se um fator de maior importância. 
Um caminho muito utilizado para alocação de tratamentos é a aleatorização. Segundo Berry (1996). uma estratégia de aleatorização pode ser entendida de uma maneira intuitiva através da seguinte descrição de mecanismo de aleatorização:

Um mecanismo de aleatorização é qualquer mecanismo onde os resultados são simétricos no sentido de que, para você, nenhum deles parece ser mais provável de ocorrer que os outros.

Um ensaio aleatorizado é caracterizado pelo uso de um mecanismo de aleatorização para a alocação dos tratamentos. A aleatorização é feita com o objetivo de evitar vícios na atribuição dos tratamentos. No mecanismo de aleatorização mais utilizado, o tratamento a ser atribuído a cada paciente é determinado por algum mecanismo lotérico. Este esquema permite que cada paciente do estudo receba um ou outro tratamento independentemente das intenções do experimentador, que tem a autonomia de determinar as chances envolvidas no mecanismo aleatório, mas não a efetiva alocação (realizada por "sorteios"). A escolha das chances envolvidas no mecanismo aleatório muitas vezes está relacionada com a proporção do tamanho da amostra desejada para cada tratamento pelo pesquisador. Por exemplo, se o pesquisador deseja amostras balanceadas ${ }^{4}$, a alocação aleatorizada deve envolver a mesma chance para cada tratamento. Porém neste caso, apesar de ser esperada uma amostra balanceada, ela não é garantida. Uma estratégia de aleatorização alternativa, que garante um completo balanceamento, é alocar tratamentos a partir de amostragem sem reposição de uma urna contendo o mesmo número de bolas correspondente a cada tratamento e o total de bolas igual ao tamanho da amostra estabelecido. Com também este propósito, há a alocação em pares (no caso de apenas dois tratamentos) . O tratamento atribuído ao primeiro paciente de cada par é através da alocação aleatória com chance 0.5 para cada tratamento. Ao segundo paciente, atribui-se o tratamento

\footnotetext{
${ }^{4}$ Com o mesmo número de pacientes em cada tratamento.
} 
que não foi sorteado para o primeiro. Neste tipo de estratégia é importante que o pesquisador já tenha determinado cada par ordenado antes que o tratamento do primeiro paciente seja determinado (para evitar que o pesquisador "escolha" o segundo paciente dependendo do tratamento que restou para ele).

Um outro tipo de mecanismo de aleatorização é a alocação sistemática. Como o próprio nome diz, esta alocação é feita por algum processo sistemático. Por exemplo, no caso em que o dia do nascimento do paciente seja um número par (recebe a droga $A$ ) ou ímpar (recebe a droga $B$ ). Neste tipo de estratégia é importante que os pacientes não conheçam o processo sistemático (se isto acontecer, o paciente saberá qual droga receberá e isto poderá influenciar na sua decisão de participar ou não do ensaio ou mesmo provocar algum efeito psicológico que ficará confundido com o efeito do tratamento). A escolha do processo sistemático é feita pelo pesquisador, que deve ter o cuidado de não escolher nenhuma variável de sistematização que guarde alguma relação com a resposta do estudo. Por exemplo, suponha que o pesquisador considere o sexo do paciente um fator prognóstico. Neste caso, um processo sistemático que determine tratamento $A$ para pacientes cujos nomes terminem com a letra $a$ e tratamento $B$ para pacientes cujos nomes terminem com a letra $o$ não deve ser escolhido. Muitos autores não consideram a alocação sistemática como um processo aleatório, preferindo chamá-la de um processo pseudo-aleatório.

Perceba-se que nenhuma das estratégias acima citadas garante balanceamento dos tratamentos nas diferentes categorias dos fatores prognósticos. Um grande desbalanceamento deste tipo pode gerar resultados comprometedores. A alternativa recomendada é que os pacientes sejam primeiramente separados em grupos conforme essas categorias e que depois seja aplicada, dentro de cada grupo, a estratégia de aleatorização escolhida. Esta atitude é conhecida por estratificação. 
O uso da estratificação deve ser cuidadoso. A abordagem clássica determina que a estratificação feita antes da aleatorização deva ser considerada na análise, no sentido que, neste caso, a análise deva ser feita dentro de cada categoria, acarretando um ajuste no nível de significância clássico. E. ainda. se o tamanho da amostra permanece o mesmo, o aumento no número de análises dependendo do número de categorias aumenta a dificuldade de detectar diferenças entre os efeitos das drogas (a idéia aqui é similar à que apresentaremos com mais detalhes na parte de ensaios sequenciais clássicos da seção 1.8.2). Abordagens consistentes com o Princípio da Verossimilhança não sofrem tais dificuldades, estimulando o uso de estratificação.

Um outro caminho para a alocação de tratamentos é a aleatorização adaptativa. A alocação aleatória adaptativa vai modificando sequencialmente as chances no mecanismo lotérico a partir dos dados que vão sendo obtidos com o ensaio (favorecendo o que, até então, se mostra o melhor tratamento). Um exemplo é a regra de aleatorização "Play-the-Winner" proposta por Wei e Durham (1978): Consideremos dois tratamentos $A$ e $B$. Uma bola branca e uma bola preta são colocadas em uma urna. Sorteia-se uma bola e atribui-se o respectivo tratamento ao primeiro paciente. Por exemplo, se a bola branca for sorteada, então o tratamento $A$ será dado ao primeiro paciente. Se este paciente tiver resposta clínica positiva, uma outra bola branca retorna à urna, juntamente com a bola branca que foi sorteada. Caso contrário, esta retornará acompanhada por uma segunda bola preta. Então, sorteia-se uma segunda bola da urna (que agora contém três bolas) e atribui-se o respectivo tratamento ao segundo paciente. Procede-se da mesma maneira sucessivamente até o final do ensaio, aumentando-se sempre o número de bolas na urna de acordo com as respostas clínicas obtidas (ver na seção 1.10 as consequências de aleatorização adaptativa nas discussões sobre ética médica). 
Outro aspecto a considerar é que vícios também podem surgir durante o ensaio. Tanto o paciente como o clínico responsável pelo estudo podem ser afetados se souberem o tipo de droga que está sendo usada e, então, reagir diferenciadamente. Uma maneira usada para minimizar este problema é através de um ensaio "Blind". Um ensaio "double-blind" é aquele em que nem o paciente nem o médico sabem qual o tratamento (incluindo placebo) está sendo usado. Se este desconhecimento for só por parte do paciente o ensaio é chamado de "singleblind" (muitas vezes, um ensaio "double blind" é impossível, como, por exemplo, em casos que envolvem algum tipo de cirurgia).

\subsection{Tipos de Planejamentos}

Nesta seção descreveremos os tipos de planejamentos que mais são utilizados em ensaios clínicos controlados. Separaremos em dois grupos principais.

\subsubsection{Ensaios Não-Sequenciais}

A sua principal característica é que o número total de pacientes, digamos $n$, a ser incluído no ensaio deve ser fixado antes do seu início. Aqui, $n$ pacientes não precisam ser necessariamente tomados de uma única vez, mas conclusões não são estabelecidas antes que todos sejam amostrados. Se algum resultado for conhecido antes do final da amostragem, ele não pode ser utilizado nem para alterar a regra de alocação dos tratamentos para os próximos pacientes, nem para encerrar o ensaio. Em ensaios não-sequenciais, a alocação aleatória adaptativa Play-the-Winner não pode ser utilizada. Os tipos de ensaios não-sequenciais mais utilizados na área farmacêutica são: 
Estudos Utilizando Controles Históricos: Neste tipo de estudo, todo paciente admitido é tratado com a droga experimental. As respostas dos pacientes experimentais são medidas e comparadas com as dos pacientes históricos. A medição das respostas prescrita no protocolo deve ser a mesma para os dois grupos.

Estudos Paralelos: A principal característica é que existe um grupo de pacientes para cada tratamento, ou seja.os grupos de tratamentos são independentes. Aqui, o grupo controle deve ser concorrente, e o mesmo protocolo deve ser seguido para cada um dos grupos.

Estudos Pareados: Este tipo de estudo é utilizado quando o ensaio envolve apenas dois tratamentos. O grupo experimental e o grupo controle são determinados de maneira a assegurar valores similares dos fatores prognósticos. Uma maneira de implementação é a utilização do mesmo paciente para ambos os grupos. Ou seja, o mesmo paciente recebe o tratamento padrão e o tratamento experimental. Neste caso a administração dos tratamentos pode ser feita de duas maneiras: em tempos diferentes (este é um caso particular de estudo "crossover", que veremos adiante) ou ao mesmo tempo (este tipo é mais utilizado em estudos de bioequivalência onde duas formulações são administradas ao mesmo tempo). Outra possibilidade é formar pares de pacientes que são homogêneos segundo os fatores prognósticos. Um de cada par fará parte do grupo controle e o outro do grupo experimental (também costuma-se utilizar gêmeos como pares de pacientes). Neste último caso, os grupos de pacientes são distintos. Estudos pareados também são utilizados para minimizar a variabilidade entre os grupos de pacientes.

Estudos "Crossover": Neste tipo de estudo, o mesmo paciente recebe todos os tratamentos em estudo, porém em tempos diferentes. O caso mais comum envolve dois tratamentos e dois estágios (neste caso, também é considerado um estudo pareado). No primeiro estágio, um grupo recebe o tratamento controle e 
o outro a terapia experimental. enquanto que no segundo estágio há a inversão. Aqui o grupo controle deve ser concorrente e o mesmo protocolo deve ser seguido em cada estágio. Este tipo de estudo é utilizado para minimizar a variabilidade nos pacientes, que são blocos. É importante destacar que antes que cada paciente receba o segundo tratamento, é preciso assegurar que possíveis vestígios do primeiro tratamento não afetem a performance do segundo tratamento. Muitas vezes um período "wash-out" é introduzido entre a administração dos tratamentos, justamente para eliminar efeitos "carry-over" (vestígios do efeito do primeiro tratamento que influenciariam o efeito do segundo tratamento). Note-se que estudos "crossover" podem envolver mais de dois tratamentos.

Estudos Fatoriais: Quando grupos distintos de pacientes são formados e para cada um deles é atribuído uma das possíveis combinações dos fatores de interesse. Por exemplo, digamos que queremos comparar os tratamentos ativos $A$ e $B$ (aqui os tratamentos são considerados fatores) e que cada um deles tenha dois níveis de interesse: administrar o tratamento ou não administrá-lo. Neste caso, temos um ensaio fatorial $2 \times 2$ (pois temos 2 fatores e cada um deles com 2 níveis), acarretando 4 combinações de fatores de interesse e, portanto, 4 grupos distintos de pacientes. Um grupo receberá o tratamento $A$ (combinação de administrar o tratamento $A$ e não administrar o tratamento $B$ ), outro receberá o tratamento $B$, outro receberá os tratamentos $A$ e $B$ ao mesmo tempo e outro receberá placebo ou não-terapia. Este tipo de estudo permite verificar o efeito da interação entre os tratamentos.

\subsubsection{Ensaios Sequenciais}

A principal característica deste tipo de ensaio é que resultados de análises intermediárias (análises feitas no decorrer do ensaio) podem ditar a regra para atribuição 
do tratamento ao próximo paciente e. ainda, permitem que o ensaio seja encerrado após qualquer uma dessas análises intermediárias. Dependendo do tipo de abordagem utilizada, Clássica ou Bayesiana, ensaios sequenciais apresentam algumas outras características bastante distintas.

Ensaios Sequenciais Clássicos: têm como característica principal controlar a taxa de erro tipo I total. A possibilidade de interromper o ensaio após uma análise intermediária "gasta" parte do erro tipo I total (o erro tipo I total é comumente chamado de $\alpha$ total). Dada esta característica, geralmente o número máximo de análises intermediárias a serem feitas é fixado antes do início do ensaio. Um ensaio planejado com, por exemplo, apenas uma análise intermediária prevê dois testes. O primeiro teste é feito depois da observação de um determinado número de observações e o segundo depois de observado o total de observações previamente fixado. Se pensarmos nestes dois testes como testes clássicos não-sequenciais (ou seja, não fazendo parte de um procedimento sequencial) chamamos o valor $\alpha$ de cada teste como $\alpha_{i}$ nominal onde $i$ representa a $i$-ésima etapa do teste sequencial. Armitage et.al (1969) demonstraram que, se testes de significância são feitos repetidamente sobre dados acumulados, o $\alpha$ total será superior ao máximo dos $\alpha_{i}$ 's nominais. E mais, será inferior a soma dos $\alpha_{i}$ 's nominais. A idéia intuitiva é simples: $\alpha$ representa a probabilidade de rejeitar a hipótese nula dada que ela é verdadeira. Em um teste sequencial com duas etapas, onde usualmente o objetivo de análises intermediárias é parar o ensaio tão logo a hipótese nula possa ser rejeitada, pode-se rejeitá-la tanto no primeiro teste quanto no segundo e isto deve ser incorporado no $\alpha$ total. Se o $\alpha$ nominal do primeiro teste é, digamos, 0.02 , então o $\alpha$ total é no mínimo este valor pois ainda falta incorporar a probabilidade de rejeitar a hipótese nula no segundo teste. Portanto, para manter um dado nível $\alpha$ total, o aumento no número de análises intermediárias acarreta numa diminuição dos valores dos $\alpha_{i}$ 's nominais. Além disso, para manter um 
dado $\alpha$ total e um dado poder para o teste, o aumento no número de análises intermediárias acarreta em um aumento no tamanho máximo da amostra (isto é devido ao fato de que os $a_{i}$ s nominais são todos menores que o a total e o ensaio pode ser interrompido após qualquer análise intermediária). Neste caso, se a diferença entre os tratamentos for grande, o aumento no número de análises intermediárias aumenta a possibilidade de que o ensaio seja terminado antes do final e, consequentemente. diminui o tamanho médio amostral esperado. Da mesma maneira, se a diferença for pequena, então o aumento no número de análises intermediárias não aumenta a possibilidade de que o ensaio seja terminado antes, aumentando assim o tamanho médio amostral esperado. Portanto, o número ótimo de análises intermediárias a serem fixadas está totalmente relacionado com a verdadeira diferença no efeito dos tratamentos. Com o objetivo de minimizar o tamanho médio amostral esperado, o trabalho de McPherson (1982) traz uma investigação do número ótimo de análises intermediárias a ser fixado para um ensaio sequencial em grupos clássico. Lewis e Berry (1994) comentam que o número ótimo de análises intermediárias a serem feitas depende da incerteza que temos do tamanho da diferença em efeito dos tratamentos. Os diferentes tipos de planejamentos sequenciais clássicos que existem são diferentes planos para alocar o "gasto" do $\alpha$ total fixado entre as análises interinas planejadas. O planejamento de Pocock (1977), por exemplo, divide o $\alpha$ total de modo que o $\alpha$ nominal de cada teste seja o mesmo. Já o planejamento sequencial de O'Brien e Fleming (1979) estabelece $\alpha_{i}$ 's nominais crescentes em relação às análises intermediárias a serem feitas. Note-se que o planejamento de O'Brien e Fleming é mais conservativo que o de Pocock nas análises intermediárias iniciais, uma vez que no início ele está "gastando" menos do a total. enquanto que nas análise intermediárias finais o planejamento de Pocock é mais conservativo que o de O'Brien e Fleming, uma vez que no final ele está "gastando" mais do $\alpha$ total. 
Ensaios Sequenciais Bayesianos: Têm como característica principal que a escolha do planejamento é situada. como veremos com mais detalhes nos próximos capítulos. em um contexto de Teoria de Decisão. com incorporação de opiniōes e preferências subjetivas. A distribuição para os parâmetros desconhecidos é continuamente atualizada com a chegada de informações e análises intermediárias são feitas com base na corrente distribuição a posteriori. Uma consequência desta postura é que no momento em que a amostragem é encerrada. a análise a ser feita para os parâmetros desconhecidos não depende do número de análises intermediárias realizadas. A próxima seção trata com mais detalhes a comparação entre ensaios sequenciais Clássicos e Bayesianos.

\subsection{Abordagem Clássica Versus Abordagem Bayesiana e o Princípio da Verossimilhança}

O foco da análise bayesiana é a distribuição a posteriori, que é a distribuição corrente dos vários parâmetros desconhecidos, dada a informação fornecida pela amostra. É uma abordagem condicional em relação à amostra, uma vez que trabalha com probabilidades de hipóteses dado um conjunto de dados.

O foco da abordagem clássica são todos os possíveis resultados da amostra, dada uma determinada hipótese. É uma abordagem não-condicional em relação à amostra, uma vez que trabalha com probabilidades de conjunto de dados, dada uma hipótese.

$\mathrm{Na}$ análise bayesiana as medidas calculadas são diretas, enquanto que na análise clássica são indiretas. Por exemplo, se estivéssemos estudando a diferença em eficácia de terapias $A$ e $B$, a análise bayesiana produz a probabilidade 
de haver diferença entre as duas terapias. dado o resultado da amostra (ou, mais rigorosamente, a distribuição de probabilidades para a diferença de efeitos). Já a análise clássica produz, por exemplo. o p-value, que é a probabilidade da diferença amostral ser tão ou mais extrema que o valor observado na amostra, baseada no planejamento do estudo e supondo a hipótese de diferença nula. A distinção entre estas duas probabilidades pode parecer, principalmente para não estatísticos, bastante sutil e talvez por isso. na prática, muitos interpretam o p-value frequentista erroneamente como a probabilidade calculada pela análise bayesiana.

Uma grande controvérsia entre bayesianos e clássicos diz respeito à adoção do Princípio da Verossimilhança.

Definição 1.1 Seja $\omega$ um parâmetro desconhecido, com $\omega \in \Omega$. Seja $X$ uma variável aleatória, com $x$ definido em $S$ onde $S$ é o espaço amostral dos valores para $X$. Seja $\{P(x \mid \omega): \omega \in \Omega\}$ a família de distribuições de probabilidade que caracteriza o modelo. Então:

1. $P(. \mid \omega)$ se chama "distribuição amostral".

2. $P(x \mid$.) se chama "função de verossimilhança gerada por $x$ ".

Na maioria das vezes, a função de verossimilhança acima definida é denotada por $L_{x}(\omega)$. Para amostra de vetores aleatórios, temos

Sejam $x_{1}, \ldots, x_{n}$ realizações das variáveis aleatórias $X_{1}, \ldots, X_{n}$ supostas serem condicionalmente, dadow. independentes e identicamente distribuídas com função de distribuição $F\left(x_{1}, \ldots, x_{n} / \omega\right)$. A Função de Verossimilhança gerada por $x=\left(x_{1}, x_{2}, \ldots, x_{n}\right)$ é:

$$
L_{\boldsymbol{x}}(\omega)= \begin{cases}f\left(x_{1}, \ldots, x_{n} / \omega\right) & \text { se F possui uma densidade } f \\ P\left(x_{1}, \ldots, x_{n} / \omega\right) & \text { se F possui uma função de probabilidade } P\end{cases}
$$


Informalmente, temos:

Princípio da Verossimilhança: A função de verossimilhança $L_{\boldsymbol{x}}($.) contém toda a informação fornecida pelo experimento que é relevante para inferências sobre $\omega$.

Então, de acordo com o Princípio da Verossimilhança, se dois experimentos planejados para inferir sobre uma mesma quantidade $\omega$ produzirem verossimilhanças $L_{\boldsymbol{x}}(\omega)$ e $L_{\boldsymbol{y}}(\omega)$ iguais ou proporcionais $\left(L_{\boldsymbol{x}}(\omega)=c L \boldsymbol{y}(\omega)\right.$, onde $c$ é uma constante que não depende de $\omega$ ), deverão necessariamente obter a mesma inferência para $\omega$.

O exemplo que veremos a seguir foi originalmente apresentado por Berry (1987) e revisto por Inoue (1995).

Exemplo: Suponhamos que $X_{1}, \ldots, X_{n}$ são condicionalmente, dado $\omega$, independentes e identicamente distribuídas com distribuição comum $N(\omega, 1)$, onde $X_{i}$ está associada à diferença em eficácia entre dois tratamentos para o i-ésimo paciente. Neste caso, a verossimilhança é dada por:

$$
\begin{aligned}
L_{\boldsymbol{x}}(\omega) & =\prod_{i=1}^{n} f\left(x_{i} / \omega\right) \\
& =\prod_{i=1}^{n} \frac{\exp \left[-0.5(x i-\omega)^{2}\right]}{\sqrt{2 \pi}} \\
& =\left(\frac{1}{\sqrt{2 \pi}}\right)^{n} \exp \left[-0.5\left(\sum_{i=1}^{n} x_{i}^{2}\right)\right] \exp \left[-0.5\left(n \omega^{2}-2 \omega n \bar{x}\right)\right]
\end{aligned}
$$

Suponhamos que um teste de hipóteses seja realizado para testar $H_{0}: \omega=0$ contra $H_{a}: \omega \neq 0$. Consideremos os seguintes procedimentos estabelecidos para uma amostra de tamanho máximo 200, seguindo a abordagem clássica de testes de hipóteses. 
1. Pegar 100 observações:

Se $\left|\sqrt{100} \bar{X}_{100}\right|>k_{1}$, parar a amostragem e rejeitar $H_{0}$

Se $\left|\sqrt{100} \bar{X}_{100}\right| \leq k_{1}$. continuar a amostragem pegando mais 100 observações.

Caso a amostragem seja continuada:

Se $\left|\sqrt{200} \quad \bar{X}_{200}\right|>k_{2}$, parar a amostragem e rejeitar $H_{0}$

Se $\left|\sqrt{200} \bar{X}_{200}\right| \leq k_{2}$, parar a amostragem e nào rejeitar $H_{0}$

2. Pegar 200 observações:

Se $\left|\sqrt{200} \quad \bar{X}_{200}\right|>k$, parar a amostragem e rejeitar $H_{0}$

Se $\left|\sqrt{200} \quad \bar{X}_{200}\right| \leq k$, parar a amostragem e não rejeitar $H_{0}$

Obs: O primeiro procedimento é um planejamento sequencial em grupos de tamanho $100 \mathrm{com} 2$ etapas. Os valores para $k_{1}$ e $k_{2}$ dependem do $\alpha$ total a ser fixado e da maneira com que ele será "gasto" entre as duas etapas planejadas. O segundo é um planejamento não sequencial com amostra de tamanho 200 fixado de antemão.

Suponhamos que o pesquisador tenha escolhido o planejamento descrito no procedimento 1 com $\alpha$ total para o teste fixado em 0.05. Suponhamos também que tenha sido escolhida a abordagem proposta por Pocock (1977) para a determinação dos $\alpha_{i}^{\prime}$ s nominais. Neste caso, o $\alpha_{i}$ nominal para cada teste deve ser 0.0294 , correspondendo a $k_{1}=k_{2}=2.18$

Digamos que as primeiras 100 observações tenham sido tomadas, resultando uma média $\bar{x}_{100}=0.14$. Assim, como $\sqrt{100} \bar{x}_{100}=\sqrt{100} 0.14=1.4<2.18$, a conclusão para a primeira análise intermediária é que a amostragem deve ser continuada, pois a hipótese nula não pode ser rejeitada. 
Digamos agora que as próximas 100 observacões sejam tomadas e que, juntandose ao resultado obtido com as primeiras 100 observações, se tenha obtido uma média $\bar{x}_{200}=0.15$. Assim, como $\sqrt{200} \bar{x}_{200}=2.12<2.18$, a cónclusào para a análise final é não rejeitar $H_{0}$.

Agora, suponhamos que o pesquisador tenha escolhido o mesmo planejamento que o descrito anteriormente, mas que, por algum motivo alheio ao ensaio, ele não pôde verificar os resultados depois das 100 primeiras observações. Neste caso, a análise a ser feita não deve ser com base no procedimento 1, mas sim com base no procedimento 2 (pois o fato de ele não ter verificado os resultados após as 100 primeiras observações descaracterizaria um ensaio sequencial). Digamos que a mesma amostra tenha sido observada, ou seja, que $\bar{x}_{200}=0.15$. Neste caso, como $\sqrt{200} \bar{x}_{200}=2.12>1.96$, a conclusão para o ensaio é rejeitar $H_{0}$ !

Note-se que, devido ao fato dos valores das 200 observações tomadas terem sido os mesmos nas duas situações descritas, o valor da função de verossimilhança é idêntico. Também é fácil ver (equação 1.1) que, mesmo que os valores das 200 observações não tivessem sido os mesmos, mas permitissem que o valor para a estatística suficiente para o teste ( a média $\bar{X}_{200}$ ) fosse idêntico nas duas situações, os valores das funções de verossimilhança seriam proporcionais. Sendo assim, para ser condizente com o Princípio da Verossimilhança, a inferência feita para $\omega$ deveria ser a mesma.

Mas o que vimos com o exemplo foi que, apesar de verossimilhanças idênticas, a inferência clássica feita para $\omega$ foi totalmente influenciada pelo tipo de planejamento estabelecido, causando violação do Princípio da Verossimilhança. O mais intrigante é pensar que as conclusões a serem tiradas após um ensaio que tomou um dado número de observações (no caso do exemplo, 200) podem ser contrárias entre si, dependendo de fatores que, geralmente, são totalmente alheios a $\omega$ (como 
o caso de não ter sido verificado o resultado no decorrer do ensaio porque não houve tempo, ou o pesquisador ficou com preguiça, ou ...).

Por outro lado, uma análise para $\omega$ feita seguindo uma abordagem bayesiana é totalmente condizente com o Princípio da Verossimilhança, uma vez que é baseada na corrente distribuição a posteriori para $\omega$, condicionada aos dados observados. A posteriori pode ser atualizada sempre que um novo dado for obtido, não sofrendo nenhuma alteração devido ao número de atualizações feitas. Por exemplo, atualizar a priori somente depois de observar $X_{1}=x_{1}$, e $X_{2}=x_{2}$ é equivalente a primeiro atualizar a priori depois de observar $X_{1}=x_{1}$, resultando em uma posteriori, e depois atualizar esta posteriori com a informação $X_{2}=x_{2}$.

Um detalhamento sobre o Princípio da Verossimilhança e suas implicações pode ser visto no trabalho de Inoue (1995).

\subsection{Questões Éticas}

Ao planejarem um experimento, estatísticos e cientistas em geral direcionam sua atenção para que este experimento seja estatisticamente bem planejado e monitorado. Em ensaios clínicos, os experimentos envolvem seres humanos e, por esse motivo, um outro contexto que deve ser considerado com importância é o que diz respeito a ética médica. Nesta seção, discutiremos algumas questões relacionadas com a ética médica individual e coletiva. A maior parte das idéias que aqui serão colocadas são baseadas no trabalho de Royall (1991).

A ética médica individual é sugerida pelo dever dos médicos de sempre fazerem o melhor pela saúde de seu paciente. A Associação Médica Mundial de Geneva é explícita em seu estabelecimento: "a saúde de meu paciente será a minha primei- 
ra consideração". O juramento de Hipócrates diz que "Quaisquer casas que eu poderei visitar, eu irei pelo benefício da saúde ..." Para tratar de assuntos relacionados com estas consideraçòes, diversos nomes sào encontrados na literatura. Por exemplo, Veatch (1981) refere-se ao "Princípio de Hipócrates" , Marquis (1983) trata por "Obrigação Terapêutica". Neste trabalho seguiremos Royall (1991) e Fried (1974) ao chamarmos de "Princípio da Atenção Pessoal". Este princípio impôe que a primeira preocupação de um médico deve ser a saúde de seu paciente e, sendo assim, ele sempre deve fazer o que considera melhor para cada um deles. Para este julgamento, o médico deve levar em consideração toda a informação disponível sobre os possíveis tratamentos. A relação médico-paciente tem mudado muito com o tempo. Até 1940, a situação dominante era de paternalismo, onde a decisão do tratamento era exclusiva do médico. Atualmente, tem crescido cada vez mais a imagem de autonomia, onde o médico propõe o que considera melhor (seguindo o Princípio da Atenção Pessoal), mas é o paciente quem decide seu tratàmento. Outro dever de um médico é ter competência médica, no sentido que ele deve possuir adequados conhecimentos e habilidades profissionais que assegurem que ele seja suficientemente capaz de discernir qual tratamento realmente deve produzir melhores resultados para o seu paciente. Uma ação médica condizente com a ética médica deve atentar tanto para o Princípio da Atenção Pessoal quanto para a Competência Médica.

Já a ética médica coletiva engloba os pacientes e a Humanidade como um todo. Segundo princípios de ética coletiva, o médico tem a obrigação de fazer o que lhe for possivel em benefício da saúde da sociedade e das gerações futuras. Porém nem sempre a ética individual vai de encontro com a ética coletiva. Suponhamos que, ao longo de um ensaio sequencial para comparar droga $A$ com droga $B$, o médico vá atribuindo ao próximo paciente aquela droga que ele considera estar se mostrando, até então, mais eficaz. Possivelmente ele terá, ao final do ensaio, um 
grande desbalanceamento entre o número de pacientes tratados com cada droga. Este grande desbalanceamento diminui a habilidade do estatístico (principalmente se de formação frequentista) de "escolher" a mais eficiente. Neste caso, o médico está de acordo com a ética individual, porém em desacordo com a ética coletiva, uma vez que o resultado do ensaio está comprometido pelo desbalanceamento. E é aqui que surge um grande dilema em relação a ensaios clínicos: o conflito natural entre a ética individual e a ética coletiva.

Ensaios clínicos que utilizam alocação aleatória são considerados por alguns autores a abordagem mais "científica" para estudos controlados. A questão é que a alocação aleatória obviamente viola o compromisso com a ética individual! Os defensores da aleatorização apresentam dois argumentos para justificar o seu uso em ensaios clínicos controlados demonstrativos: o primeiro, supostamente de natureza prática, sustenta que a perda por estar violando a ética individual é superada pelo ganho em benefício da ética coletiva. O segundo, de suposta natureza epistemológica, argumenta que um médico somente realiza um ensaio clínico se ele não conhece qual dos tratamentos é melhor. Ele pode até acreditar na superioridade de um dos tratamentos, mas esta crença, por não possuir base científica (se possuísse, não haveria necessidade de ensaio), não é vista como um julgamento medicamente competente, não havendo, consequentemente, uma violação do Princípio da Atenção Pessoal. Mas será que para um julgamento ser medicamente competente é necessário ter havido um ensaio? Em um ensaio clínico controlado experimental, os mesmos defensores são diretos: este tipo de ensaio só é iniciado se os clínicos envolvidos estão em estado de indistinção e isto torna a alocação aleatória totalmente ética. Mas, por outro lado, será que o estado de indistinção existe na prática? Será que ele não varia com o paciente? Ou seja, será que é possível um clínico não ter nenhuma "preferência"? Será que esta "preferência" não pode ser considerada um julgamento medicamente competente? 
E, mesmo admitindo-se um estado de indistinçào no início do ensaio, até quando este estado permanece? Examinando-se os resultados que vão surgindo com o ensaio, até quando um médico consegue permanecer em estado de "equipoise"? Se o médico não "olhar" os resultados antes do final do ensaio, o estado de indistinçào pode ser mantido. Mas é ético desconsiderar estas informações que chegam com o decorrer do ensaio?

Métodos de aleatorização adaptativos tais como a regra "Play-the-Winner" são métodos de alocação alternativos para evitar vícios na atribuição de tratamentos e que ajudam a amenizar este dilema ético. Uma desvantagem do uso da regra "Play-the-Winner" é que ela só pode ser utilizada em ensaios sequenciais. Outra alternativa é utilizar Aleatorização "Informed Consent": o clínico explica ao seu paciente toda a situação do caso bem como os possíveis tratamentos com suas respectivas vantagens e desvantagens. Se, depois disso, o paciente aceitar participar de um ensaio aleatorizado envolvendo os tratamentos em questão, ele será considerado "Informed Consent". Aleatorização "Informed Consent" se dá quando utiliza-se alocação aleatória apenas entre pacientes "Informed Consent". A aleatorização "Informed Consent" apresenta algumas dificuldades tais como: a população de pacientes é mais restrita, uma vez que crianças, idosos e pacientes inconscientes não podem ser considerados (aqui há controvérsia, pois alguns clínicos consideram que para estes tipos de pacientes seus responsáveis poderiam responder por eles); a dificuldade, por parte dos clínicos, de serem imparciais ao prestar a informação; a dificuldade de fazer a proposta em casos onde a resposta pode ser muito maléfica (como o óbito); a dificuldade de estabelecer quando um paciente pode ser considerado "Informed Consent", .... A aleatorização "Informed Consent" deveria sempre ser utilizada (seguindo a ética individual) ao invés da aleatorização sem "Informed Consent", mas, devido às dificuldades acima citadas, isto nem sempre acontece. 
Nào pretendemos, neste trabalho, entrar em maiores discussões a respeito de questões éticas propriamente. mas deixar claro que as influências e consequências éticas da aleatorização (introduzida para evitar vícios na alocação de tratamentos) são consideradas nas análises frequentistas, onde a aleatorização é indispensável. Por outro lado, em análises bayesianas a aleatorização não é considerada. "Aleatorização em ensaios clínicos permanece como o mais confiável método para avaliar a eficácia entre terapias" (Byar et al., (1976)), mas isto não implica que estudos que utilizam controles históricos ou concorrentes não aleatorizados tenham pouco ou nenhum valor científico. "Nós podemos aprender sem aleatorização" (Royall, (1991)). Além do mais, o que é valor "científico"?

A questão da especificação do tamanho de amostra também é polêmica. Por questões éticas, um ensaio clínico deve ser interrompido tão logo os dados evidenciem uma clara diferença ou equivalência dos tratamentos, para assim evitar que mais pacientes sejam expostos à terapia inferior (ética individual) e também evitar um retardamento na aplicação dos resultados a pacientes futuros (ética coletiva). Uma maneira de resolver este problema é a utilização de ensaios sequenciais. Um problema de ensaios sequenciais é que o uso formal destes tipos de ensaios pode acabar originando mais problemas práticos, sem necessariamente resolver o problema ético.

Os ensaios sequenciais clássicos apresentam duas grandes desvantagens:

- O aumento no número de análises intermediárias pode aumentar o tamanho médio amostral esperado. Sendo assim, ensaios sequenciais clássicos com muitas análises intermediárias fixadas não são recomendados e, portanto, a possibilidade de interromper um ensaio tão logo os dados evidenciem uma clara diferença entre os tratamentos fica comprometida. 
- A abordagem clássica para ensaios sequenciais não é condizente com o Princípio da Verossimilhança. uma rez que as análises a serem feitas são totalmente dependentes do protocolo. Dependendo do tipo de planejamento, ou mesmo do tipo de alocaçào feita. as inferências podem ser distintas. Se, por motivos alheios ao ensaio. ele for interrompido antes da primeira análise intermediária fixada. nenhuma conclusào pode ser obtida. Se a interrupçào for entre duas análises intermediárias previamente fixadas, como por exemplo, entre a primeira e a segunda, o resultado da análise deverá levar em consideração somente as respostas dos pacientes que entraram no ensaio até a primeira análise intermediária e as outras devem ser desconsideradas! Concluindo, a interrupção de um ensaio clássico entra em choque com a teoria que o determina. Em outras palavras, medidas como nível de significância, coeficiente de confiança etc... não podem ser calculadas após a interrupção. A fidelidade a estas teorias e, consequentemente, aos protocolos impediria a análise após alguma interrupção não-planejada.

Os ensaios sequenciais bayesianos são bem mais flexíveis, pois mesmo que ocorra uma quebra no protocolo, eles permitem que inferências sejam feitas. A abordagem bayesiana para ensaios sequenciais é totalmente condizente com o Princípio da Verossimilhança, uma vez que a inferência a ser feita para os parâmetros desconhecidos depende somente dos dados observados, não dependendo do número de análises intermediárias feitas, ou do tipo de alocação utilizado, ou dos motivos da interrupção. Deste modo, nenhuma resposta de paciente observado precisa ser desperdiçada. 


\section{Capítulo 2}

\section{Problemas de Decisão}

Neste capítulo consideraremos os conceitos básicos de Teoria da Decisão essenciais para o entendimento e desenvolvimento de problemas de decisào sequencial. Este capítulo tem como base o texto de De Groot (1970), sendo que muito também é aproveitado de Berger (1980) e de Raiffa e Schlaifer (1961).

Um problema de decisão interessante envolve incerteza e. como o próprio nome diz, tomada de decisào. Essa incerteza provém de algo que, para você, é desconhecido. Neste trabalho, assim como na maioria dos problemas práticos. consideraremos que essa incerteza é a respeito do valor de uma quantidade numérica representada por w. u' é comumente chamado de "Estado da Natureza" e $\Omega$ denotará o conjunto de todos os possíveis estados da natureza (A rigor, $\Omega$ é o conjunto de todos os possíveis valores para o estado da natureza. Da mesma forma, quando nào houver confusào, usaremos $\omega$ tanto para representar o estado da natureza quanto um dos seus possíveis valores). A Teoria da Decisão formaliza as diferentes possíveis decisòes $d_{1}, d_{2}, \ldots$ (decisòes também sào chamadas, na literatura, de açòes) a serem tomadas (denotaremos por $D$ o conjunto de todas as 
decisòes disponiveis) e. trabalhando com w desconhecido. considera que alguma informaçào sobre ele pode ser obtida através de experimentaçào. Na maioria das situaçòes. a experimentaçào realizada envolve observaçoes que sào supostas serem distribuidas de acordo com alguma distribuiģào de probabilidade dependente de $\omega$ ' (por exemplo. a distribuição das observaçòes pode possuir parâmetro w. Xestes casos. $\omega$ pode ser chamado de parâmetro e $\Omega$ de Espaço Paramétrico). As inferências estatísticas clássicas consideram apenas a informaçào amostral (obtida com a experimentaçào) para fazer inferência a respeito de w. Na Teoria da Decisào, a informaçào amostral é combinada com a introduçào explícita de uma medida numérica. a Função Perda, que representa a preferência pelas possiveis consequências (ou "perdas") de cada possivel decisão para cada estado da natureza. O objetivo da Teoria da Decisào é estabelecer como "escolher" qual decisào deve ser tomada. Princípios tais como Princípio Minimax. Princípio da Invariância e Princípio de Bayes sào os critérios mais utilizados para resolver esta questão. Neste trabalho consideraremos apenas o Princípio de Bayes. A utilização do princípio de Bayes exige que a informação amostral. além de ser combinada com a funçào perda, seja também combinada com o que chamamos de informaçào a priori. A informação a priori incorpora todo o conhecimento disponível sobre w que nào seja proveniente da experimentaçào estatística e deve sempre ser probabilística (isto é. uma distribuiçào de probabilidade sobre (?). Uma decisào pode ser estabelecida sem que uma experimentaçio estatística seja realizada. Este tipo de problema chamaremos de Problema de Decisão Puro. Quando o problema envolver experimentação estatística propriamente. chamaremos de Problema de Decisão Estatística (note-se que todo o problema de decisão estatística possui um problema de decisào puro associado). 


\subsection{Problema de Decisão Puro}

É caracterizado pelo fato de que una decisào d deve ser escolhida dentre o conjunto $D=\left\{d_{1}, d_{2} \ldots\right\}$ de todas as decisòes disponiveis com base na distribuiçào a priori para w e na funçào de perda estabelecida (que representa as preferèncias pelas consequências de $\left.\left(\omega \cdot d_{i}\right)\right)$.

Definição 2.1 lim Problema de Decisão Puro $\epsilon$ definido pelos elementos $(D, \Omega, L)$. onde:

(i) $D$ é o "espaço de decisóes". $D \neq \varnothing$.

(ii) $\Omega$ é o espaço de todos os possiveis para w "estado da natureza". $\Omega \neq \varnothing$.

(iii) $L$ é a "função perda" associada. $L$ é definida no cartesiano $\Omega \times D$.

(iv) A distribuição a priori para o parâmetrow será representada por $\xi($.$) (e será$ uma densidade ou funçio de probabilidade).

Para qualquer ponto $(\omega, d) \in \Omega \times D$, o número $L(\omega, d)$ representa a perda associada quando o valor do estado da natureza é $\omega$ e a decisão escolhida é $d$. Supòe-se que. para cada $d \in D$. a perda $L(., d)$ é uma funçào mensurável no espaço $\Omega$. Assumese também que $L: \Omega \times D$ é uma funçào nào-negativa, isto é. $L: D \times \Omega \rightarrow[0 . \infty)$ (ver resultado 2.2 ).

Definição 2.2 A Perda Esperada (ou Risco) $\mathrm{em}$ um problema (D. $\Omega . L$ ) $d \epsilon$ qualquer decisio $d \in D$ contra a priori $\xi($.$) para \omega$. denotada por $\rho(\xi$.d). é definida por:

$$
\begin{aligned}
\rho(\xi, d) & =\mathbb{E}[L(\omega, d)] \\
& = \begin{cases}\int_{\Omega} L(\omega . d) \xi(\omega) d \omega & \text { se } \omega \text { tem densidade } \xi \\
\sum_{i} L\left(\omega_{i}, d\right) \xi\left(\omega_{i}\right) & \text { se } \omega \text { tem função de probabilidade } \xi\end{cases}
\end{aligned}
$$


É suposto que a integral e o somatório acima são finitos para todo $d \in D$.

Obs: Para simplificar. sempre utilizaremos a mesma notaçào para representar uma densidade ou uma funçào de probabilidade. Da mesma maneira. sempre utilizaremos o simbolo $\int$ para representar a integral da funçào densidade ou a soma da funçào de probabilidade.

O Princípio de Bayes: Lima decisào $d$ é preferivel a $d^{\prime}$ sempre que $\rho(\xi . d)<$ $\rho\left(\xi, d^{\prime}\right)$. Portanto, de acordo com o Princípio de Bayes, a "melhor" decisào contra a priori $\xi($.$) para \omega$ seria aquela que minimizasse $\rho(\xi . d)$ em relaçào a torlas ac decisões $d \in D$.

Obs: O Princípio de Bayes possui justificação axiomática. Ver. por exemplo, Lindley (1971) ou De Groot (1970).

Definição 2.3 O Risco de Bayes (ou Risco de Decisão Ótima) contra a priori $\xi($.$) para \omega$, denotado por $\rho^{*}(\xi)$, é definido por

$$
\rho^{\times}(\xi)=\inf _{d \in D} \rho(\xi, d)
$$

Definição 2.4 lima Decisão de Bayes (ou Decisão Ótima) contra a priori $\xi($.$) , denotada por d^{x}$. é qualquer decisào cujo risco $\rho\left(\xi . d^{*}\right)$ i igual a $\rho^{*}(\xi)($ Em outras palauras. é uma decisâo que "minimiza" o risco).

Obs: É importante observar que. em algumas situaçòes onde o espaço de decisòes $D$ não é finito. o Risco de Bayes $\rho^{\star}(\xi)$ dentre todos os $d \in D$ pode não corresponder, exatamente. a nenhum $d \in D$. Nestas situaçòes nenhuma decisào no espaço $D$ será uma decisão de Bayes (A saída. na prática, para continuar utilizando o Princípio de Bayes é escolher uma decisào $d \in D$ para a qual seu risco $\rho(\xi . d)$ seja suficientemente próximo do Risco de Bayes). Nas situaçòes onde os riscos de 
duas ou mais decisòes forem iguais ao Risco de Bayes. estas duas ou mais decisòes serào todas decisòes de Bayes.

Definição 2.5 L'ma decisào $d \in D$ é chamada admissível quando nào triste nenhuma outra decisào $d^{\prime} \in D$ tal que

$$
L\left(\omega, d^{\prime}\right) \leq L(\omega \cdot d) \quad \text { para todo } \omega \in \Omega
$$

com a desigualdade acima estritamente satisfeita para pelo menos algum valor $\omega \in \Omega$. Caso contrário. dizemos que dé inadmissível (e que d" "domina" d).

Obs: Note-se que, seguindo o Princípio de Bayes, considerar decisoes inadmissiveis é perda de tempo. Portanto, daqui para diante só consideraremos as decisões admissiveis em cada problema de decisão.

Definição 2.6 Uma Deciscio d $d_{M}$ Ć chamada Mista ou Aleatorizada quando usamos algum mecanismo lotérico para sortear uma decisaio do conjunto D. As "probabilidades" deste mecanismo lotérico devem ser independentes da priori $\xi$ (e da distribuiçào dos dados). Neste caso. a perda associada à decisào aleatorizada $d_{M}$ para um dado ponto $\omega \in \Omega$ deve satisfazer

$$
L\left(\omega, d_{M}\right)=\sum_{d \in D} p_{d} L(\omega, d)
$$

onde $p_{d}$ é a "probabilidade" de sortear-se a decisâo d.

Resultado 2.1 Seja Mo conjunto de todas as possive is decisócs aleatorizadas $d_{M}$ de um dado problema. Chamemos de decisóes puras (ou rígidas) todas as decisões $d \in D$. Note-se que uma decisào pura d pode ser vista como uma decisão aleatorizada onde dé selecionada com probabilidade $I$ (e $d_{M} \neq d$ é selecionada 
com probabilidade igual a zero). Deste modo. $D \subset . M$. Pela definiçào (2.6) sabese que o risco $\rho\left(\xi . d_{M}\right)$ para uma decisio aleatorizada pode ser calculado como uma média ponderada dos riscos $\rho(\xi$.d) das decisós puras d. Isto é.

$$
\begin{aligned}
\rho\left(\xi . d_{M}\right) & =\mathbb{E}\left\{L\left(\omega \cdot d_{M}\right)\right\} \\
& =\mathbb{E}\left\{\sum_{d \in D} p_{d} L(\omega \cdot d)\right\} \\
& =\sum_{d \in D} p_{d} \mathbb{E}\{L(\omega \cdot d)\} \\
& =\sum_{d \in D} p_{d} \rho(\xi, d)
\end{aligned}
$$

Portanto, segue que:

$$
\begin{aligned}
\inf _{d_{M} \in M} \rho\left(\xi, d_{M}\right) & =\inf _{d_{M} \in M} \sum_{d \in D} p_{d} \rho(\xi, d) \\
& \geq \sum_{d \in D} p_{d} \inf _{d_{M} \in M} \rho(\xi, d) \\
& =\sum_{d \in D} p_{d} \inf _{d \in D} \rho(\xi, d) \\
& =\inf _{d \in D} \rho(\xi, d) \sum_{d \in D} p_{d} \\
& =\inf _{d \in D} \rho(\xi, d) \\
& =\rho^{*}(\xi)
\end{aligned}
$$

Ou seja, para toda decisào aleatorizada existe pelo menos uma decisào pura com risco menor ou igual.

Obs: Portanto, seguindo o Principio de Bayes, considerar decisóes aleatorizadas é irrelevante. Sendo assim, daqui para diante só consideraremos as decisões puras dos problemas. Observe-se, também, que o resultado 2.1 corresponde ao bom senso das pessoas (que indica desconsiderar decisòes tomadas através de sorteios).

Resultado 2.2 Considere uma nova função perda $L_{0}$ dada por:

$$
L_{0}(\omega \cdot d)=L(\omega, d)-\inf _{d \in D} L(\omega \cdot d)
$$


Lma decisào d ${ }^{*}$ é uma Decisào de Bayes contra $\varepsilon$ com funçào perda $L$ se. e somente se. dx também é uma Decisào de Bayess contra E com funçào de perda $L_{0}$.

De fato. para qualquer valor $\omega \in \Omega$ e $d \in D$. a funçào de perda $L_{0}$ possui a seguinte propriedade:

$$
L_{0}(\omega, d) \geq 0
$$

Portanto. neste trabalho iremos supor. sem perda de generalidade. que $L(\omega, d)$ satisfaz a relaçào $(2.2)$.

A determinação da funçào perda. na prática. é muitas vezes difícil. A preocupação que devemos ter é que ela deve ser construída ou escolhida para refletir a "verdadeira" perda do problema associado. O caminho para isto é fazer uma análise de utilidade no problema (ver Berger (1980)). Muitas vezes. entretanto, problemas de decisão sào desenvolvidos para certas funçòes de perda convencionais, tais como a perda quadrática, a perda linear e a perda "0-1", perdas assimétricas, dentre outras. Vale ressaltar que esses desenvolvimentos possuem grande interesse teórico.

Definição 2.7 Sé eja l'm problema de decisào onde o espaço de decisóes é $D=$ $\left\{d_{1}, d_{2}\right\}$, o espaço "paramétrico" é $\Omega=\left\{\omega_{1}, \omega_{2}\right\}$. A funçào perda ()-I para este problema é dada por:

$$
L\left(\omega, d_{i}\right)=\left\{\begin{array}{l}
0 \quad \text { se } \omega=\omega_{i} \\
1 \text { se } \omega=\omega_{j}(j \neq i)
\end{array}\right.
$$

Isto é, interpreta-se que a decisào $d_{1}$ é "correta" caso $\omega=\omega_{1} \in$ a decisão $d_{2} e^{e}$ "correta" caso $\omega=\omega_{2}$. 
Lima extensaío da perda "()-L" é dada pela perda "()-k" que é definida por:

$$
L\left(\omega^{\prime} \cdot d_{i}\right)= \begin{cases}0 & \text { se } \omega^{\prime}=\omega_{i} \\ k & \text { st } \omega^{\prime}=\omega_{j}(j \neq i)\end{cases}
$$

Obs: Aqui. $k>0$.

Note-se que o teste de hipóteses simples clássico $H_{0}: \omega=\omega_{1}$ versus $H_{1}$ : $\omega=\omega_{2}$ corresponde ao problema de decisào que utiliza a função perda descrita na equaçào (2.3).

\subsection{Problema de Decisão Estatística com Tama- nho de Amostra Fixo}

Um problema de decisão estatística é caracterizado pela oportunidade de se observar o valor de uma variável aleatória $X^{\prime}$ ou vetor aleatório $X$ relacionado com o estado da natureza $\omega$ antes da escolha de uma decisão $d \in D$. Trabalharemos, inicialmente, com X representando uma variável aleatória real. A adaptaçào para um vetor aleatório de tamanho $n$ é direta.

As possiveis decisões a serem tomadas são as mesmas $d_{1}, d_{2}, \ldots$ do problema puro associado, mas agora a escolha da melhor decisão também depende do valor a ser observado de $X^{\prime}$ e, por esse motivo, as decisões serão notadas por $\delta(x)$. $\delta(x)$ é a decisão $d \in D$ escolhida caso o resultado $x \in S$ seja observado. A especificação de $\delta(x)$ para cada $x \in X$ é a regra de decisão $\delta$. A funçào de perda associada agora depende, além de $\theta=\left(\omega, X^{\prime}\right)$ e da regra de decisào $\delta$. do custo de conduzir e analisar o experimento. Sem perda de generalidade, vamos supor que o custo de analisar o experimento está incluído no custo de conduzir o experimento e 
chamaremos este custo de Custo Amostral. O custo amostral pode depender de muitos fatores. Iremos considerar o caso em que ele depende apenas do número de observaçòes da amostra, nào sendo afetado pelo valor de w' ou pela magnitude do valor observado de $X$, nem pela maneira como a amostragem é realizada. Mais ainda, o custo amostral será suposto constante igual a $c$ para cada unidade da amostra. Consideraremos ainda que a perda total é a soma da perda que depende de $\theta$ e $\delta$ (que chamaremos de perda de decisão e é a mesma função de perda do problema puro associado) e do custo amostral. Temos então a seguinte definição:

Definição 2.8 Sob as condiçôes acima, a função de perda total que denotaremos por $L_{t}$ passa a ser:

$$
\begin{aligned}
L_{t}(\delta, \theta, c) & =L(\delta ; X, \omega ; c) \\
& =L(\delta ; X, \omega)+c \\
& =L[\delta(X), \omega]+c
\end{aligned}
$$

Obs: No caso do vetor aleatório $\boldsymbol{X}$ com $n$ variáveis aleatórias a função de perda total é dada por:

$$
L_{t}(\delta, \theta, c, n)=L[\delta(\boldsymbol{X}), \omega]+c n
$$

Definição 2.9 Um Problema de Decisão Estatística é definido pelos elementos $(\triangle, \Omega, S, L)$, onde:

(i) $\Delta$ é o espaço de todas as "Regras de Decisão" $\delta$ de $S \mathrm{em}$ D. Uma regra de decisão $\delta($.$) especifica para cada valor x \in S$ uma decisão $\delta(x)$ em $D$. Ś é o espaço amostral dos valores para a observaçâo $X$.

(ii) $\Theta=\Omega \times S$ é o espaço de todos os valores para $\left(\omega, X^{\prime}\right)$.

(iii) $L_{t}$ é a função de perda total associada. L té a soma da funçâo de perda $L e$ do custo amostral. L é definida no cartesiano $\Theta \times \Delta$. 
(iv) A distribuiçào a priori conjunta para $\theta=(\omega, X)$ será representada por $h(.,$.$) (será utilizada para densidade ou funçào de probabilidade), onde h(\omega, x)=$ $f(x \mid \omega) \xi(\omega)$ ( com $f(. \mid \omega)$ representando a marginal condicional de $X \mid \omega \in \xi($. a priori para o parâmetro $\omega)$.

\subsection{Análise Pós-Experimental de um Problema de Decisão Estatística}

Neste tipo de análise, primeiro observa-se a amostra $X$ e depois, com base no específico resultado $x$, é feita a escolha $d \in D$ que minimiza o risco de decisào. Observe-se que aqui precisamos apenas determinar a decisào de Bayes contra a "priori" $\xi_{x}$ (ver notação abaixo), ressaltando-se que a regra de decisão $\delta$ nào precisa ser determinada por inteiro.

Notação: Suponhamos que uma amostra tenha sido tomada e $x \in S$ tenha sido observado. Denotaremos por $\xi_{x}($.$) a distribuição a posteriori para \omega$ dado $X=x$ (sendo $h(.,$.$) a priori para \left(\omega, X^{\prime}\right)$ ). Então,

$$
\begin{aligned}
\xi_{x}(.) & =\xi(. \mid X=x) \\
& =\frac{h(., x)}{\int_{\Omega} h(\omega, x) d \omega}
\end{aligned}
$$

Definição 2.10 A Perda Esperada ou Risco de qualquer decisão $\delta(x) \in D$ contra a posteriori $\xi_{x}$, denotado por $\rho\left[\xi_{x}, \delta(x)\right]$, é simplesmente o risco de $\delta(x)$ contra a posteriori $\xi_{x}$ considerada como priori no problema puro $(D, \Omega, L)$, ou seja,

$$
\begin{aligned}
\rho\left[\xi_{x}, \delta(x)\right] & =\mathbb{E}\{L[\omega, \delta(x)]\} \\
& =\int_{\Omega} L[\omega, \delta(x)] \xi_{x}(\omega) \mathrm{d} \omega
\end{aligned}
$$


Definição 2.11 O Risco de Bayes contra a posteriori $\xi_{x}$ para w. denotado por $\rho^{*}\left(\xi_{x}\right)$ é definido por:

$$
\rho^{*}\left(\xi_{x}\right)=\inf _{\delta(x) \in D} \rho\left[\xi_{x}, \delta(x)\right]
$$

Obs: Este risco também é chamado de Risco de Bayes a Posteriori.

Definição 2.12 Uma Decisão de Bayes contra a posteriori $\xi_{x}$, denotada por $\delta^{*}(x)$, é qualquer decisão cujo risco $\rho\left[\xi_{x}, \delta^{*}(x)\right]$ é igual a $\rho^{*}\left(\xi_{x}\right)$.

Definição 2.13 O Risco Total de Decisão de Bayes será denotado por $R^{*}\left(\xi_{x}\right)$, onde

$$
\begin{aligned}
R^{*}\left(\xi_{x}\right) & =\inf _{\delta(x) \in D}\{\mathbb{E}\{L[\omega, \delta(x)]\}+c\} \\
& =\rho^{*}\left(\xi_{x}\right)+c
\end{aligned}
$$

Obs: Este risco também é chamado de Risco Total de Bayes a Posteriori e segue de (2.4) e de (2.6).

Convém salientar que a análise pós-experimental é mais simples e é utilizada quando a amostragem é feita com certeza. No entanto, em problemas onde a decisão de se tomar uma amostra depende de um possível decréscimo no Risco Total de Bayes (perceba que o Risco Total de Bayes no problema puro é simplesmente $\left.\rho^{\star}(\xi)\right)$ a análise pré-experimental é a mais adequada. O restante do desenvolvimento da teoria será feito em termos de análise pré-experimental, que descreveremos na seção posterior. 


\subsection{Análise Pré-Experimental de um Problema de Decisão Estatística}

Neste tipo de análise, primeiro determina-se a regra de decisão de Bayes $\delta^{*}$. Este tipo de análise é mais utilizado na fase de planejamento do experimento, quando primeiro queremos avaliar o "ganho" que teremos com a observação da amostra $X$ para então decidir se iremos ou não observá-la. Entre os bayesianos, a Análise Pré-Experimental é mais conhecida por Análise Pré-Posterior.

Definição 2.14 A Perda Esperada ou Risco em um problema $(\Delta, \Omega, S, L)$ de qualquer regra de decisão $\delta \in \Delta$ contra a priori $h(. .$.$) para \theta$, denotado por $\rho(h, \delta)$, é definido por:

$$
\begin{aligned}
\rho(h, \delta) & =\mathbb{E}\left\{L\left[\omega, \delta\left(X^{\prime}\right)\right]\right\} \\
& \left.=\int_{\Omega} \int_{S} L[\omega, \delta(x))\right] f(x \mid \omega) \xi(\omega) \mathrm{d} x \mathrm{~d} \omega
\end{aligned}
$$

Obs: Note-se que a esperança na equação (2.8) é em relação à priori $h(.,$.$) para$ $(\omega, X)$.

Definição 2.15 O Risco de Bayes contra a priori $h(. .$.$) para \theta$, denotado por $\rho^{*}(h)$, é dado por:

$$
\rho^{*}(h)=\inf _{\delta \in \Delta} \rho(h, \delta)
$$

Obs: Este risco também é chamado de Risco de Bayes a Priori.

Definição 2.16 Uma Regra de Decisão de Bayes contra a priori h(.,.), denotada por $\delta^{*}$, é qualquer regra de decisão cujo risco $\rho\left(h . \delta^{*}\right)$ é igual a $\rho^{*}(h)$. 
Definição 2.17 O Risco Total de Bayes a Priori. denotado por $R^{\star}(h)$, é dado por:

$$
R^{\times}(h)=c+\rho^{\times}(h)
$$

Notação: Seja $\xi($.$) uma priori para \omega \in \Omega$. Seja X uma variável aleatória com distribuição condicional $f(. \mid \omega)$. Denotaremos por $f(. \mid \xi)$ a distribuição marginal (não condicional) ou preditiva para $X$, Então,

$$
f(. \mid \xi)=\int_{\Omega} f(x \mid \omega) \xi(\omega) \mathrm{d} \omega
$$

e, a distribuição a priori conjunta para $\left(\omega, X^{\prime}\right)$ pode ser fatorada por

$$
h(\omega, x)=\xi_{x}(\omega) f(x \mid \xi)
$$

A minimização do risco $\rho(h, \delta)$ diretamente em relação a $\delta$ é chamada a Forma Normal para encontrar uma regra de decisão de Bayes. Esta maneira muitas vezes se torna um problema computacionalmente difícil.

Um método alternativo é dado quando notamos que na equaçào abaixo

$$
\begin{aligned}
\rho(h, \delta) & =\mathbb{E}\{L[\omega, \delta(X)]\} \\
& =\int_{\Omega} \int_{S} L[\omega, \delta(x)] h(\omega, x) \mathrm{d} x \mathrm{~d} \omega \\
& =\int_{S}\left\{\int_{\Omega} L[\omega, \delta(x)] f(x \mid \omega) \xi(\omega) \mathrm{d} \omega\right\} \mathrm{d} x
\end{aligned}
$$

a minimização de $\rho(h, \delta)$ em relação a $\delta$ em $\Delta$ é equivalente à minimização da integral interna da equação (2.13) para cada $x \in S$.

A mudança na ordem de integração na equação (2.12) é válida pelo teorema de Fubini, uma vez que $L(\omega, d) \geq 0$. 
Desenvolvendo a equação (2.13), temos:

$$
\begin{aligned}
\rho(h, \delta) & =\int_{S}\left\{\int_{\Omega} L[\omega \cdot \delta(x)] h(\omega, x) \mathrm{d} \omega\right\} \mathrm{d} x \\
& =\int_{S}\left\{\int_{\Omega} L[\omega, \delta(x)] f(x \mid \omega) \xi_{\beta}(\omega) \mathrm{d} \omega\right\} \mathrm{d} x \\
& =\text { (ver equação 2.11) } \\
& =\int_{S}\left\{\int_{\Omega} L[\omega, \delta(x)] \xi_{x}(\omega) \mathrm{d} \omega\right\} f(x \mid \xi) \mathrm{d} x \\
& =\int_{S} \rho\left[\xi_{x}, \delta(x)\right] f(x \mid \xi) \mathrm{d} x
\end{aligned}
$$

Ou seja, para cada $x \in S$, minimiza-se $(\operatorname{em~} D) \rho\left[\xi_{x}, \delta(x)\right]$.

Demostramos então o seguinte teorema:

Teorema 2.1 Uma regra de decisão de Bayes $\delta^{*}$ pode ser encontrada escolhendo, para cada $x \in S$, uma decisão que minimize o risco a posteriori, ou seja, que atinja

$$
\inf _{\delta(x) \in D} \int_{\Omega} L(\delta(x), \omega) \xi_{x}(\omega) \mathrm{d} \omega
$$

Este método é chamado de Forma Extensiva para encontrar uma regra de decisão de Bayes. Em outras palavras, resolve-se o problema como se fosse um problema de decisão puro, sendo no entanto usada a distribuiçào a posteriori $\xi_{x}$ ao invés da priori $\xi$ para $\omega$.

Em resumo provamos que a Forma Normal e a Forma Extensiva para resolver um problema de decisão são equivalentes, ou seja, requerem exatamente as mesmas informações de entrada e, apesar de terem passos intermediários distintos, conduzem à mesma solução ótima. 
O teorema acima é bastante intuitivo: uma vez que $X^{\prime}=x$ tenha sido observado, nada mais natural que atualizar a informaçào a priori com a informaçào obtida com a amostra através da fórmula de Bayes, caindo assim na mesma situaçào de um problema puro. diferindo-se apenas na substituição da distribuição a priori para $\theta$ pela distribuição a posteriori para $\omega$ dado $X=x$. E, então, o resultado garante que $\delta^{*}(x)$ é uma decisào de Bayes contra a distribuição a posteriori $\xi_{x}$ para $\omega$ (onde $\delta^{*}($ ) é a regra de decisão de Bayes contra a priori $h(, .)$,$) .$

Através do teorema (2.1) podemos ver, claramente, que o princípio de Bayes satisfaz o Princípio dia Verossimilhança, uma vez que ao minimizar $\int_{\Omega} L(\omega, \delta(x)) \xi_{x}(\omega) d \omega$ para cada $x \in S$, a única função dos dados utilizada é a função de verossimilhança gerada pelo ponto $x$ observado. Por outro lado, esta conclusão é natural, pois o Princípio da Verossimilhança não proíbe a integração no espaço amostral antes da ámostragem (como na situação de planejamento do experimento. Nesta altura $X$ é tão aleatório quanto $\omega$ ).

Resultado 2.3 Segue da equação (2.14) que o Risco Total contra h(.,.) para qualquer regra de decisão $\delta \in \Delta$ é dado por:

$$
\begin{aligned}
R^{*}(h) & =c+\int_{S} \rho\left[\xi_{x}, \delta(x)\right] f(x \mid \xi) \mathrm{d} x \\
& =c+\mathbb{E}\left\{\rho\left[\xi_{X}, \delta\left(X^{\prime}\right)\right]\right\}
\end{aligned}
$$

\subsection{Tamanho Ótimo da Amostra}

A abordagem para um problema de decisão estatística que vimos anteriormente estabelece uma amostra de tamanho fixo. Note que o tamanho da amostra a ser tomada deve ser fixado antes do início do ensaio. A maneira utilizada para determinar o tamanho ótimo da amostra $n^{*}$ é dada pela minimização em relação 
a $n$ do Risco Total de Bayes a Priori. A idéia é, então, tomar as $n^{*}$ observaçòes desde que o Risco Total de Bayes a Priori para uma amostra de tamanho $n^{*}$ seja menor que o Risco Total de Bayes com nenhuma observação (que corresponde ao Risco de Bayes do problema puro associado).

A seguir, descreveremos outra abordagem, que en muitos aspectos é mais vantajosa que a determinação a priori do tamanho amostral.

\subsection{Problemas de Decisão Estatística com Amos- tragem Sequencial}

Consideremos agora problemas que envolvem amostragem sequencial, ou seja, situaçōes onde as observações $X_{1}, X_{2}, \ldots$ são tomadas uma de cada vez. Após cada observação $X_{n}$, atualizamos a informação sobre $\omega$ obtida com a observação de $x_{1}, x_{2}, \ldots, x_{n}$, e entào decidimos se queremos continuar o processo de amostragem (tomando, então uma nova observação $X_{n+1}$ ) ou se queremos terminar o processo de amostragem escolhendo uma decisão "terminal" $d \in D$ com base na informação obtida com $X_{1}=x_{1}, \ldots, X_{n}=x_{n}$.

Notação: Uma amostra sequencial $X$ é um processo estocástico $X=\left(X_{1}, X_{2}, \ldots\right)$. $\boldsymbol{X}_{n}=\left(X_{1}, \ldots, X_{n}\right)$ representará uma amostra sequencial de tamanho $n$.

Neste trabalho iremos supor que $X_{1}, X_{2}, \ldots \mid \omega$ são condicionalmente (dado $\omega$ ) independentes e identicamente distribuídas com distribuiçào comum $f_{X_{1}}(. \mid \omega)$.

Um problema de decisão sequencial possui duas componentes: Plano Amostral ou Regra de Parada e Regra de Decisão Sequencial.

1) Plano Amostral ou Regra de Parada: Inicialmente, decide-se se uma 
decisão $d \in D$ deve ser escolhida sem que nenhuma observaçào seja tomada ou se a amostragem deve ser iniciada. Caso a amostragem seja iniciada, especificase para cada possível conjunto de valores $X_{1}=x_{1}, \ldots . X_{n}=x_{n}(n \geq 1)$ se a amostragem deve parar (e uma decisào terminal $d \in D$ ser escolhida com base nesses dados) ou se uma nova observação $X_{n+1}$ deve ser tomada. Formalmente, temos:

Definição 2.18 Uma Regra de Parada associada a uma amostra sequencial $\boldsymbol{X}$ é uma sequência de funçôes $\tau=\left(\tau_{0}, \tau_{1}, \ldots\right)$ satisfazendo:

i) $\tau_{n} \in\{0,1\}, n=0,1,2 \ldots$

ii) $\tau_{n}=\tau_{n}\left(X_{1}, \ldots, X_{n}\right)$, para $n=1, \mathscr{D}, \ldots$

iii) Se $\tau_{n}=1$ então $\tau_{n+1}=1$, para todo $n=0,1, \ldots$

Obs: "1" simboliza "pare a amostragem" e "0" simboliza "continue a amostragem".

2) Regra de Decisão: Especifica a decisão terminal $d \in D$ que deve ser escolhida caso a regra de parada determine que nenhuma observação deva ser tomada. Por outro lado, se a amostragem deve ser iniciada, especifica a decisão terminal $\delta_{n}\left(x_{1}, \ldots, x_{n}\right) \in \mathrm{D}$ que deve ser escolhida para cada conjunto de valores observados antes que a amostragem seja terminada. Formalmente temos:

Definição 2.19 Uma Regra de Decisão Sequencial é uma sŁquência de funçôes $\delta=\left(\delta_{0}, \delta_{1}, \ldots\right)$, onde $\delta_{0} \in D$ e $\delta_{n}=\delta_{n}\left(X_{1}, \ldots, X_{n}\right) \in D$ para todo $n=1, \mathscr{Q}, \ldots$

Em outras palavras, se $S$ é o espaço amostral de $X_{1}$ (e de $X_{2}$, e de $X_{3}, \ldots$ ) $e \underbrace{S \times S \times \ldots \times S}_{n}=S^{n}$, temos:

$\delta_{0} \in D \quad e \quad \delta_{n}: S^{n} \rightarrow D$. 
Obs: $S^{n}=\underbrace{S \times S \times \ldots \times S}_{n}=$ Espaço Amostral de $X_{n}=\left(X_{1}, \ldots, X_{n}\right)$

$$
S^{\infty}=S \times S \times \ldots=\text { Espaço Amostral de } X=\left(X_{1}, X_{2} \ldots\right) \text {. }
$$

Definição 2.20 O tamanho da amostra associado a uma regra de parada $\tau$ é a variável aleatória

$$
N_{\tau}=\min _{n \geq 0}\left\{n: \tau_{n}=1\right\}
$$

Definição 2.21 Seja $X=\left(X_{1}, X_{2}, \ldots\right)$ uma amostra sequencial, $\tau$ uma regra de parada associada a $\boldsymbol{X}, N_{\tau}$ o tamanho da amostra associado a $\tau$. As Regiões de Parada associadas à regra $\tau$ são os subconjuntos $\left(B_{1}, B_{2}, \ldots\right)$ onde

$$
B_{n}=\tau_{n}^{-1}(\{1\}) \subset S^{n}, n=1,2, \ldots
$$

Em outras palavras,

$$
B_{n}=\left\{\left(x_{1}, \ldots, x_{n}\right) \in S^{n}: \tau_{n}\left(x_{1}, \ldots, x_{n}\right)=1\right\}
$$

(Note-se que, caso $\tau_{0}=1$, a respectiva região de parada é $B_{0}=S^{\infty}$ ).

Resultado 2.4 Da definiçáo de regra de parada temos para $n=0,1, \ldots$ :

$$
\left(x_{1}, \ldots, x_{n}\right) \in B_{n} \Rightarrow\left(x_{1}, \ldots, x_{n}, y\right) \in B_{n+1},
$$

qualquer que seja $y \in S$.

Às vezes, é conveniente considerar $B_{n}=\tau_{n}^{-1}(\{1\}) \subset S^{\infty}$ isto é, $B_{n}=\left\{\left(x_{1}, \ldots\right) \in\right.$ $\left.S^{\infty}: \tau_{n}\left(X_{1}, \ldots\right)=1\right\}$. Neste caso o resultado acima implica:

$$
B_{n} \subset B_{n+1}, \quad n=1,2, \ldots
$$


Definição 2.22 O evento $\left\{N_{\tau}=n\right\}$ representa todas as sequências que conduzem a um tamanho de amostra $N_{\tau}=n \in$ é definido por:

$$
\{N=n\}=\left\{\left(x_{1}, \ldots\right) \in S^{\infty}: N_{\tau}\left(x_{1}, \ldots\right)=n\right\}
$$

para $n=1,2, \ldots$

Fato: Suponhamos que $\tau_{0}=0$. Então, pela definição 2.22 temos:

$$
\begin{aligned}
\left\{N_{\tau}=1\right\}= & \left\{\left(x_{1}, x_{2}, \ldots\right) \in S^{\infty}: N_{\tau}\left(x_{1}, x_{2}, \ldots\right)=1\right\} \\
= & \left\{\left(x_{1}, x_{2}, \ldots\right) \in S^{\infty}: \tau_{1}\left(x_{1}\right)=1\right\}=B_{1} \\
\left\{N_{\tau}=n\right\}= & \left\{\left(x_{1}, x_{2}, \ldots\right) \in S^{\infty}: N_{\tau}\left(x_{1}, x_{2}, \ldots\right)=n\right\} \\
= & \left\{\left(x_{1}, x_{2}, \ldots\right) \in S^{\infty}: \tau_{1}\left(x_{1}\right)=0 \wedge \ldots \wedge \tau_{n-1}\left(x_{1}, \ldots, x_{n-1}\right)=0 \wedge\right. \\
& \left.\tau_{n}\left(x_{1}, \ldots, x_{n}\right)=1\right\} \\
= & \overline{B_{1}} \cap \overline{B_{2}} \cap \ldots \cap \overline{B_{n-1}} \cap B_{n} \\
= & \left(\overline{B_{1} \cup B_{2} \cup \ldots \cup B_{n-1}}\right) \cap B_{n} \\
= & \overline{B_{n-1}} \cap B_{n}
\end{aligned}
$$

A última igualdade vale pela equação (2.16).

Obs: Note que é necessário escrever o evento $\{N=n\}$ como $\overline{B_{n-1}} \cap B_{n}$ e não somente $B_{n}$, pois

$$
\left(x_{1}, \ldots, x_{n}\right) \in B_{n} \nRightarrow\left(x_{1}, \ldots, x_{n-1}\right) \notin B_{n-1}
$$

\section{Notação}

- Seja $\xi($.$) uma priori para \omega \in \Omega$ e $\boldsymbol{X}_{n}$ uma amostra com distribuição condicional conjunta $f_{n}\left(x_{1}, \ldots, x_{n} \mid \omega\right)$. Denotaremos por $f_{n}\left(x_{1}, \ldots, x_{n} \mid \xi\right)$ a preditiva para $\boldsymbol{X}_{n}$. Então,

$$
f_{n}\left(x_{1}, \ldots, x_{n} \mid \xi\right)=\int_{\Omega} f\left(x_{1}, \ldots, x_{n} \mid \omega\right) \xi(\omega) \mathrm{d} \omega
$$




$$
\begin{aligned}
& =\text { (se forem condicionalmente i.i.d.) } \\
& =\int_{\Omega} f\left(x_{1} \mid \omega\right) f\left(x_{2} \mid \omega\right) \ldots f\left(x_{n} \mid \omega\right) \xi(\omega) \mathrm{d} \omega \\
& =\int_{\Omega}\left[\prod_{i=1}^{n} f\left(x_{i} \mid \omega\right)\right] \xi(\omega) \mathrm{d} \omega
\end{aligned}
$$

- Suponhamos que uma amostra $\boldsymbol{X}_{n}$ tenha sido tomada e que $\boldsymbol{x}_{n}=$ $\left(x_{1}, \ldots, x_{n}\right) \in S^{n}$ tenha sido observado. Denotaremos por $\xi_{n}($.$) a distribuição$ a posteriori para $\omega$ dado que $X_{1}=x_{1}, \ldots, X_{n}=x_{n}\left(\operatorname{com} g_{n}(.\right.$,$) a priori para$ $\left.\left(\omega, \boldsymbol{X}_{n}\right)\right)$.

- Se $f_{n}\left(x_{1}, \ldots, x_{n} \mid \xi\right)$ é a preditiva para $\boldsymbol{X}_{n}(\operatorname{com} \xi($.$) a priori para \omega)$ e $\xi_{n}($.$) a posteriori para \omega$ dado $X_{1}=x_{1}, \ldots, X_{n}=x_{n}$, então, a distribuição a priori conjunta para $\left(\omega, \boldsymbol{X}_{n}\right)$, que será denotada por $g_{n}\left(\omega, x_{1}, \ldots, x_{n}\right)$, pode ser fatorada por:

$$
g_{n}\left(\omega, x_{1}, \ldots, x_{n}\right)=\xi_{n}(\omega) f_{n}\left(x_{1}, \ldots, x_{n} \mid \xi\right)
$$

- Para $A \subset S^{n}$

$$
\mathbb{P}\left\{\left(x_{1}, \ldots, x_{n}\right) \in A\right\}=\int_{A} f_{n}\left(x_{1}, \ldots, x_{n} \mid \xi\right) \mathrm{d} x_{1} \ldots \mathrm{d} x_{n}
$$

Portanto, (supondo $\tau_{0}=0$ )

$$
\begin{aligned}
\mathbb{P}\left\{N_{\tau} \leq n\right\} & =\sum_{j=1}^{n} \mathbb{P}\left\{N_{\tau}=j\right\} \\
& =\sum_{j=1}^{n} \mathbb{P}\left\{\overline{B_{j-1}} \cap B_{j}\right\} \\
& =\sum_{j=1}^{n}\left\{\int_{\left\{N_{\tau}=j\right\}} f_{j}\left(x_{1}, \ldots x_{j} \mid \xi\right) \mathrm{d} x_{1} \ldots \mathrm{d} x_{j}\right\} \\
& =\sum_{j=1}^{n}\left\{\int_{\left\{N_{\tau}=j\right\}}\left[\int_{\Omega} \prod_{i=1}^{j} f\left(x_{i}\right)(\omega) \xi(\omega) \mathrm{d} \omega\right] \mathrm{d} \boldsymbol{x}_{j}\right\}
\end{aligned}
$$


A função de perda total que consideraremos para o problema de decisão com amostragem sequencial seguirá as mesmas condiçòes da definição 2.i para o problema de decisão sequencial com tamanho de amostra fixo. Aqui uma adaptação é necessária devido ao fato da regra de decisão depender da amostra e, agora, o tamanho da amostra também ser uma variável aleatória associada a regra de parada $\tau$. Temos entào:

Definição 2.23 A função de perda total $L_{t}$ do problema de decisão sequencial é dada por:

$$
L_{t}[\delta, \tau, \theta, c, n)=L\left[\delta_{N_{\tau}}\left(\omega, X_{1}, \ldots, X_{N_{\tau}}\right]+c N_{\tau}\right.
$$

Definição $2.24 \mathrm{Um}$ procedimento de decisão sequencial $\gamma$ é próprio quando $\mathbb{P}\left(N_{\tau}<\infty\right)=\lim _{n \rightarrow \infty} \mathbb{P}(N \leq n)=1$.

Obs: Neste trabalho consideraremos apenas procedimentos de decisão sequenciais próprios.

Definição 2.25 Um Problema de Decisão Sequencial é um problema definido pelos elementos $\left(\Gamma, \Omega, S^{\infty}, L\right)$, onde:

i) Г é o espaço de todos os "Procedimentos de Decisão Sequenciais" ?.

ii) $\Theta=\Omega \times S^{\infty}$ é o espaço de todos os valores para $(\omega, \boldsymbol{X})$.

iii) $L_{t}$ é a função de perda total associada. $L_{t}$ é a soma da função de perda $L e$ do custo amostral. L é definida no cartesiano $\Gamma \times \Theta$.

iv) A distribuição a priori conjunta para $(\omega, \boldsymbol{X})$ será representada por $g(.,$.$) (será utilizada para densidade ou função de probabilidade), g(\omega, \boldsymbol{X})=$ $\xi(\omega) \prod_{i=1}^{N_{\tau}} f\left(X_{i} \mid \omega\right)$. 
Definição 2.26 Um procedimento de decisão sequencial $\gamma \in \Gamma$ é o par $(\delta, \tau)$ onde $\tau$ representa Plano Amostral ou Regra de Parada $\epsilon \delta$ representa a Regra de Decisão Sequencial.

\subsection{O Risco de um Procedimento Sequencial}

Definição 2.27 Suponha-se $\tau_{0}=0$ (ou seja, que pelo menos uma observaçào deve ser tomada). A Perda Esperada Total ou Risco Total em um problema $\left(\Gamma, \Omega, S^{\infty}, L\right)$ de qualquer procedimento de decisâo sequencial $\gamma \in \Gamma$ contra a priori $g(.,$.$) , denotado por R(g, \gamma)$, é definido por:

$$
R(g, \gamma)=\mathbb{E}\left\{L\left[\omega ; \delta_{N_{\tau}}\left(X_{1}, \ldots, X_{N_{\tau}}\right)\right]+c N_{\tau}\right\}
$$

Desenvolvendo a equação acima temos:

$$
\begin{aligned}
R(g, \gamma) & =\mathbb{E}\left\{L\left[\omega ; \delta_{N_{\tau}}\left(X_{1}, \ldots, X_{N_{\tau}}\right)\right]+c N_{\tau}\right\} \\
& =\mathbb{E}\left\{c N_{\tau}\right\}+\mathbb{E}\left\{L\left[\omega ; \delta_{N_{\tau}}\left(X_{1}, \ldots, X_{N_{\tau}}\right)\right]\right\} \\
& =c \sum_{n=1}^{\infty} n \mathbb{P}\left\{N_{\tau}=n\right\} \\
& +\sum_{n=1}^{\infty} \mathbb{E}\left\{L\left[\omega ; \delta_{N_{\tau}}\left(X_{1}, \ldots, X_{N_{\tau}}\right)\right] \mid N_{\tau}=n\right\} \mathbb{P}\left\{N_{\tau}=n\right\}
\end{aligned}
$$

Mas, supondo as variáveis discretas (para simplicidade) 


$$
\begin{aligned}
\mathbb{E}\{ & \left.L\left[\omega ; \delta_{N_{\tau}}\left(X_{1}, \ldots, X_{N_{\tau}}\right)\right] \mid N_{\tau}=n\right\}= \\
& =\int_{\Omega} \int_{S^{n}} L\left[\omega ; \delta_{n}\left(x_{1}, \ldots, x_{n}\right)\right] g_{n}\left\{\omega ; x_{1}, \ldots, x_{n} \mid N_{\tau}=n\right) \mathrm{d} \omega \mathrm{d} \boldsymbol{x}_{n} \\
& =\int_{S^{n}} \int_{\Omega} L\left[\omega ; \delta_{n}\left(x_{1}, \ldots, x_{n}\right)\right] g_{n}\left(\omega ; x_{1}, \ldots, x_{n} \mid N_{\tau}=n\right) \mathrm{d} \omega \mathrm{d} \boldsymbol{x}_{n} \\
& =\int_{S^{n}} \int_{\Omega} L\left[\omega ; \delta_{n}\left(x_{1}, \ldots, x_{n}\right)\right] \frac{g_{n}\left(\omega ; x_{1}, \ldots, x_{n} ; N_{\tau}=n\right)}{\mathbb{P}\left\{N_{\tau}=n\right\}} \mathrm{d} \omega \mathrm{d} \boldsymbol{x}_{n} \\
& =\int_{\left\{N_{\tau}=n\right\}} \int_{\Omega} L\left[\omega ; \delta_{n}\left(x_{1}, \ldots, x_{n}\right)\right] \frac{g_{n}\left(\omega ; x_{1}, \ldots, x_{n}\right)}{\mathbb{P}\left\{N_{\tau}=n\right\}} \mathrm{d} \omega \mathrm{d} \boldsymbol{x}_{n} \\
& =(\text { notação, pg } 54) \\
& =\int_{\left\{N_{\tau}=n\right\}} \int_{\Omega} L\left[\omega ; \delta_{n}\left(x_{1}, \ldots, x_{n}\right)\right] \frac{\xi_{n}(\omega) f_{n}\left(x_{1}, \ldots, x_{n} \mid \xi\right)}{\mathbb{P}\left\{N_{\tau}=n\right\}} \mathrm{d} \omega \mathrm{d} \boldsymbol{x}_{n}
\end{aligned}
$$

Substituindo o resultado da equação(2.20) na equação(2.19) temos:

$$
\begin{aligned}
& R(g, \gamma)= \\
& \quad=c \sum_{n=1}^{\infty} n \mathbb{P}\left\{N_{\tau}=n\right\}+ \\
& \quad \sum_{n=1}^{\infty}\left\{\int_{\left\{N_{\tau}=n\right\}} \int_{\Omega} L\left[\omega ; \delta_{n}\left(x_{1}, \ldots, x_{n}\right)\right] \frac{\xi_{n}(\omega) f_{n}\left(x_{1}, \ldots, x_{n} \mid \xi\right)}{\mathbb{P}\left\{N_{\tau}=n\right\}} \mathrm{d} \omega \mathrm{d} \boldsymbol{x}_{n} \mathbb{P}\left\{N_{\tau}=n\right\}\right\} \\
& \quad=c \sum_{n=1}^{\infty} n \mathbb{P}\left\{N_{\tau}=n\right\}+
\end{aligned}
$$




$$
\begin{aligned}
& \sum_{n=1}^{\infty} \int_{\left\{N_{\tau}=n\right\}}\left\{\int_{\Omega} L\left[\omega ; \delta_{n}\left(x_{1}, \ldots, x_{n}\right)\right] \xi_{n}(\omega) d \omega\right\} f_{n}\left(x_{1}, \ldots, x_{n} \mid \xi\right) d \boldsymbol{x}_{n} \\
& =\sum_{n=1}^{\infty}\left\{c n \mathbb{P}\left\{N_{\tau}=n\right\}+\int_{\left\{N_{\tau}=n\right\}} \rho\left[\xi_{n}, \delta_{n}\left(\boldsymbol{x}_{n}\right)\right] f_{n}\left(\boldsymbol{x}_{n} \mid \xi\right) \mathrm{d} \boldsymbol{x}_{n}\right\} \\
& =\mathbb{E}\left\{c N_{\tau}+\rho\left[\xi_{N_{\tau}}, \delta_{N_{\tau}}\left(X_{1}, \ldots, X_{N_{\tau}}\right)\right]\right\}
\end{aligned}
$$

A equação (2.22) será útil no teorema 2.2.

\subsection{Procedimentos de Decisão Sequenciais de Bayes}

Definição 2.28 O Risco Total de Bayes a Priori de um problema de decisão sequencial $\left(\Gamma, \Omega, S^{\infty}, L\right)$ com priori $g(.,$.$) para (\omega, \boldsymbol{X})$, denotado por $R^{*}(g)$, é dado por:

$$
R^{*}(g)=\inf _{\gamma \in \Gamma} R(g, \gamma)
$$

Definição 2.29 Um Procedimento de Decisão Sequencial de Bayes contra a priori $g(.,$.$) , denotado por \gamma^{*}$, é qualquer procedimento cujo risco $R\left(g, \gamma^{*}\right)$ é igual a $R^{*}(g)$.

O objetivo desta seção é encontrar $\gamma^{*}$. Minimizar $R^{*}(g)$ diretamente para todos os procedimentos $\gamma \in \Gamma$ é uma tarefa não muito simples devido a infinidade de procedimentos que surgem com a amostragem sequencial. O teorema seguinte mostra como facilitar esta tarefa. 
Teorema 2.2 Se $\gamma^{*}=\left(\delta^{+}, \tau^{+}\right)=\left[\left(\delta_{0}^{+}, \tau_{0}^{+}\right),\left(\delta_{1}^{+}, \tau_{1}^{+}\right) \ldots\right]^{*}$ é um procedimento de decisão sequencial ótimo contra a priori $g(.$,$) para (\omega, X)$. então, para todo $n=$ $1,2, \ldots$ e para (quase) todo $\left(x_{1}, \ldots, x_{n}\right) \in S^{n}, \delta_{n}^{+}\left(x_{1}, \ldots, x_{n}\right)$ é uma decisâo de Bayes contra a posteriori $\xi_{n}$.

Prova: A demonstraçào deste teorema formaliza a idéia intuitiva que apresentaremos.

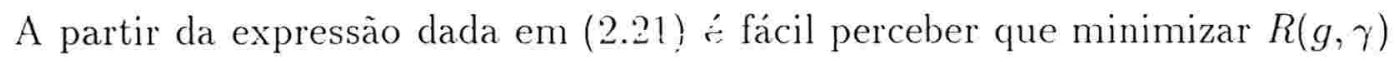
em relação a todos $\gamma \in \Gamma$ é equivalente a minimizar, para cada $n$, a expressão entre chaves. Ao fixar $n$ a primeira parcela $\sum_{i=1}^{n} c_{i} \mathbb{P}\left\{N_{\tau}=n\right\}$ é constante. Minimizar a segunda parcela é equivalente a minimizar, para cada $\boldsymbol{x}_{n} \in\left\{N_{\tau}=n\right\}$ o risco a posteriori $\rho\left[\xi_{n}, \delta_{n}\left(\boldsymbol{x}_{n}\right)\right]$ que é exatamerte o que faríamos para encontrar uma regra de decisão de Bayes no caso de uma amostra de tamanho fixo $n$. Deste modo, para todo $n$ a regra de decisão $\delta_{n}\left(\boldsymbol{X}_{n}\right)$ é uma regra de decisão de Bayes e o teorema está demonstrado.

Em outras palavras, temos como resultado do teorema 2.2 que, para todo $n=0,1,2, \ldots$, a regra de decisão $\delta_{n}$ do procedimento de decisão sequencial de Bayes é uma regra de decisão de Bayes para o problema de decisão estatística com amostra de tamanho $n$ fixado.

Uma consequência direta do teorema acima é que para contruírmos um procedimento de decisão sequencial de Bayes $\delta^{\star}$ podemos sempre desprezar $\delta_{n}\left(\boldsymbol{X}_{n}\right)$ que não são regras de decisão de Bayes para os problemas não sequenciais intermediários. Assim, a determinação do procedimento de decisão sequencial de Bayes fica reduzida a determinar-se a regra de parada ótima, pois uma vez que esta regra determine a parada do experimento na etapa $n(n=0,1, \ldots)$, a decisão a ser tomada deve ser a decisão de Bayes contra a posteriori $\xi_{n}$ e, portanto, o 
Risco Total a Posteriori de ter parado o ensaio na etapa $n$ será o Risco de Bayes a Posteriori $R^{\star}\left(\xi_{n}\right)=\rho^{\star}\left(\xi_{n}\right)+n c($ análogo à equaçào $(2 . \imath))$.

Com o objetivo de simplificaçào passaremos a utilizar a seguinte notaçào:

- $\rho_{0}\left(\xi_{0}\right) \equiv$ Risco de Bayes contra a priori $\xi_{0}$ para $\omega$ do problema puro.

$$
\rho_{0}\left(\xi_{0}\right)=\inf _{d \in D} \int_{\Omega} L(\omega, d) \xi_{0}(\omega) \mathrm{d} \omega
$$

- $\rho_{0}\left(\xi_{n}\right) \equiv$ Risco de Bayes a Posteriori contra $\xi_{n}$. Então:

$$
\rho_{0}\left(\xi_{n}\right)=\inf _{d \in D} \int_{\Omega} L(\omega, d) \xi_{n}(\omega) \mathrm{d} \omega
$$

- $R_{0}\left(\xi_{n}\right) \equiv$ Risco Total de Bayes a Posteriori contra $\xi_{n}$ para $\omega$. Então:

$$
R_{0}\left(\xi_{n}\right)= \begin{cases}\rho_{0}\left(\xi_{0}\right) & \text { para } n=0 \\ \rho_{0}\left(\xi_{n}\right)+n c & \text { para } n=1,2, \ldots\end{cases}
$$

- $R_{0}(g) \equiv$ Risco Total de Bayes a Priori contra $g(. .$.$) para (\omega, X)$.

Portanto, o Risco Total de Bayes a Priori contra a priori $g(\ldots)$ para $(\omega, \boldsymbol{X})$. é a esperança, em relação ao evento $\left\{\Lambda_{\tau}=n\right\}$, dos Riscos Totais de Bayes a Posteriori, ou seja

$$
\begin{aligned}
R_{0}(g) & =\mathbb{E}\left\{R_{0}\left(\xi_{n}\right)\right\} \\
& = \begin{cases}\rho_{0}\left(\xi_{0}\right) \mathbb{P}\left\{N_{\tau}=0\right\} & \text { se } n=0 \\
\mathbb{E}\left\{\rho_{0}\left(\xi_{N_{\tau}}\right)+c N_{\tau}\right\} & \text { se } n=1,2, \ldots\end{cases} \\
& = \begin{cases}\rho_{0}\left(\xi_{0}\right) & \text { se } n=0 \\
\mathbb{E}\left\{\rho_{0}\left(\xi_{N_{\tau}}\right)+c N_{\tau}\right\} & \text { se } n=1,2, \ldots\end{cases}
\end{aligned}
$$


Sendo assim, daqui para diante a preocupaçào será encontrar a regra de parada ótima. sem que seja mencionada explicitamente a regra de decisão.

$\mathrm{Na}$ construção da regra de parada ótima. a primeira preocupação deve ser em determinar se alguma amostra deve ou nào ser observada. A idéia aqui é avaliar o benefício que teremus se observarmos a amostra. Como a anostragem é sequencial, devemos primeiramente avaliar o benefício que teremos se observarmos $X_{1}$ (a primeira observação da amostra). É evidente que nessa avaliação devemos considerar todos os possíveis resultados para $X_{1}$ e, além disso, devemos considerar a possibilidade de, após observarmos $X_{1}=x_{1}$, ou pararmos a amostragem ou observarmos $X_{2}$. Entretanto, para decidir se "vale a pena" observar $X_{2}$, também devemos considerar que, após observarmos $X_{1}=x_{1}$ e $X_{2}=x_{2}$, poderemos decidir por parar ou continuar a amostragem observando $X_{3}$. E assim indefinidamente. Então, como avaliar o proveito que teremos caso a amostragem seja iniciada? A dificuldade está justamente no fato de que para essa avaliaçào devemos considerar uma infinidade de possibilidades futuras. Uma alternativa é limitar o número máximo de observações a serem tomadas em, digamos. $M$. Ao fixarmos $M$, a cadeia de perguntas acima se repete somente até a etapa $M$. Nesta etapa, a pergunta seria a seguinte: Após observarmos $X_{1}=x_{1}, \ldots, X_{M-1}=x_{M-1}, X_{M}=x_{M}$, qual a decisão terminal que deve ser escolhida? Aqui a resposta não depende dos possíveis valores para $X_{M+1}$ e nem da possibilidade de depois observarmos $X_{M+2}, X_{M+3}, \ldots$, pois, devido ao limite $M$, não consideraremos estas possibilidades. A determinação do valor para $M$ será discutida na seçào (2.10).

Suponhamos então, que o número de observações a serem tomadas é limitado em $M$, ou seja, $M$ é o número máximo de etapas do procedimento sequencial a ser considerado. Suponhamos, também, que a amostragem tenha seguido até a etapa $M-1$, tendo sido observados $X_{1}=x_{1}, \ldots, X_{M-1}=x_{M-1}$. Agora, sabendo que a amostragem será terminada no máximo na etapa $M$. só temos dois ca- 
minhos possíveis a seguir: parar a amostragem e escolher $d \in D$ com base nas informações $x_{1} \ldots . x_{M-1}$. ou observar $X_{M}$ e escolher $d \in D$ com base nas informações $x_{1}, \ldots, x_{M}$. Pelo teorema 2.2, sabemos que se a amostragem terminar agora, a decisão a ser tomada deve ser a decisão de Bayes do problema puro associado, com priori $\xi_{M-1}$ e risco de decisão de Bayes a posteriori $\rho^{\star}\left(\xi_{M-1}\right)$. Por outro lado, considerando o problema como um problema de decisào estatística para $u m$ tamanho de amostra fixo $\mathrm{n}=1$, com priori $\xi_{M-1}$ para $\omega$. calculamos o risco total de Bayes para o caso em que a amostragem seja continuada. Seguindo o Princípio de Bayes, o caminho a ser seguido é o correspondente ao mínimo entre estes dois riscos, o qual chamaremos de risco de continuaçào ótima na etapa $M-1$ após observarmos $X_{1}=x_{1}, \ldots, X_{M-1}=x_{M-1}$. Chamaremos de continuação ótima o caminho tomada seguindo o Princípio de Bayes.. Se procedermos desta maneira para todos os possíveis valores de $X_{1}, \ldots, X_{M-1}$, teremos as respectivas continuações ótimas, juntamente com seus riscos.

Agora, voltamos uma etapa, ou seja, iremos supor que a amostragem só tenha prosseguido até a etapa $M-2$ e que tenham sido observados $X_{1}=x_{1}, \ldots, X_{M-2}=$ $x_{M-2}$. A determinação a respeito da amostragem parar ou nào depende, agora, do benefício que teremos se observarmos $X_{M-1}$ que depende de todos os seus possíveis valores e também da possibilidade de após observarmos ainda $X_{M}$. Sendo que já calculamos o risco de continuação ótima para todos os possíveis valores de $X_{1}, \ldots, X_{M-1}$,essa avaliaçào é fácil. Como já calculamos o risco de continuação ótima para todas as possibilidades de $X_{1}=x_{1}, \ldots, X_{M-2}=x_{M-2} . X_{M-1}$ (perceba que aqui estamos considerando $x_{1}, \ldots, x_{M-2}$ como valores fixados e somente $X_{M-1}$ como variável aleatória), então basta ponderar estes riscos pela distribuição preditiva para $X_{M-1} \mid X_{1}=x_{1}, \ldots, X_{M-2}=x_{M-2}$ e somar com o custo amostral de observar $X_{M-1}$ para obter o risco total de Bayes a priori caso a amostragem seja continuada depois de terem sido observados $X_{1}=x_{1}, \ldots X_{M-2}=x_{M-2}$. 
Perceba-se que, de acordo com o princípio de otimazação que veremos adiante. esta quantidade é equivalente ao risco total do procedimento sequencial de Bayes para o problema com priori $\xi_{M-2}$ e amostra limitada em, no máximo, duas observações (a possibilidade de parar ou não a amostragem na etapa $M-1$ dependendo dos possíveis valores para $X_{1}=x_{1}, \ldots, X_{M-2}=x_{M-2}, X_{M-1}$ já está incorporada nos riscos de continuação ótima considerados para a etapa M-1). O mínimo entre este risco e o risco do problema puro associado com priori $\xi_{M-2}$ determina o risco de continuação ótima na etapa $M-2$ após observar $X_{1}=x_{1}, \ldots, X_{M-2}=x_{M-2}$. Procedendo desta maneira para cada possivel valor de $X_{1}, \ldots . X_{M-2}$, obteremos os respectivos riscos de continuação ótima na etapa $M-2$. E, assim. voltamos uma etapa de cada vez repetindo o procedimento acima para cada uma delas, até chegarmos na etapa 1 , onde, supondo termos observado $X_{1}=x_{1}$. calculamos o risco de continuação ótima na etapa 1 para cada possível valor de $X_{1}$. Ponderando este risco pela distribuição preditiva de $X_{1}$ e somando o custo amostral de observar $X_{1}$, obteremos o risco total do procedimento sequencial de Bayes limitado na etapa $M$. O mínimo entre este risco e o risco de Bayes com priori $\xi$ para $\omega$ do problema puro associado é o risco de continuação ótima da etapa inicial (quando determina se a amostragem deve ou não ser iniciada).

Esta técnica de primeiramente supor estar na etapa final e, entào, ir retornando até a etapa inicial é chamada de Técnica de Indução Backward. Os procedimentos de decisão sequenciais que possuem um limite máximo para o tamanho da amostra são chamados de Procedimentos de Decisão Sequencial Truncados. A determinação da continuaçào ótima utilizando a técnica de induçào Backward em cada etapa especifica a regra de parada do procedimento de decisão sequencial de Bayes quando o número máximo de observaçòes é $M$. DeGroot (1970) salienta que a construção do procedimento M-truncado de Bayes utilizando a técnica de indução backward, ilustra o princípio da otimização desenvolvido 
por Bellman (195i) que estabelece o seguinte: em qualquer etapa de um procedimento de decisào sequencial de Bayes, se os valores $X_{1}=x_{1} \ldots \ldots X_{j}=x_{j}(j<M)$ tiverem sido observados. a determinação da continuação da amostragem deve ser equivalente ao procedimento de decisão sequencial de Bayes para o problema com priori $\xi_{j}$ para $\omega$ e número máximo de observações a serem tomadas limitado em $(\mathrm{M}-\mathrm{j})$.

Definição 2.30 Um Procedimento de Decisâo S'equencial $\gamma$ é chamado Mtruncado e será denotado por $\gamma^{M}$ quando existe um inteiro positivo $M$ tal que $\mathbb{P}\left\{N_{\tau} \leq M\right\}=1$, onde $N_{\tau}$ é o tamanho da amostra sequencial.

Definição 2.31 O Risco Total de Bayes a Priori de um problema de decisâo sequencial $M$-truncado $\left(\Gamma^{M}, \Omega, L\right)$ com priori $g_{M}(.,$.$) para \left(\omega, \boldsymbol{X}_{M}\right)$ : denotado por $R^{*}\left(g_{M}\right)$, é:

$$
R^{*}\left(g_{M}\right)=\inf _{\gamma^{M} \in \Gamma^{M}} R\left(g_{M}\right)
$$

onde $\Gamma^{M}$ é o espaço de todos os possíveis procedimentos de decisào sequenciais M-truncados.

Definição 2.32 Um Procedimento de Decisão Sequencial M-truncado de Bayes contra a priori $g_{M}(.,$.$) denotado por \gamma^{M *}$, é qualquer $\gamma^{M}$ cujo risco é igual a $R^{*}\left(g_{M}\right)$.

\subsection{Procedimento de Decisão Sequencial M-truncado de Bayes}

Na seção anterior descrevemos a construção de um procedimento de decisão sequencial $M$-truncado de Bayes pela técnica de induçào backward. Nesta seçào, 
apresentaremos o desenvolvimento matemático da construçào.

Estamos considerando um problema de decisão com potencial amostra sequencial $\left(X_{1}, \ldots, X_{M}\right)$ de variáveis aleatórias condicionalmente (dado $\omega$ ) independentes e identicamente distribuídas com densidade comum $f_{X_{1}}(. \mid \omega)$, função de perda total $L\left[\omega ; \delta_{N_{\tau}}\left(X_{1}, \ldots, X_{N_{\tau}}\right)\right]$ (dado como na equação (2.17) e custo constante c por observação.

Se a distribuição a priori para $\left(\omega, X_{n}\right)$ é $g_{n}(.,$.$) e se \rho_{0}\left(\xi_{0}\right)$ é definido como em (2.23) então, para $n=0,1 \ldots . M-1$, a distribuição preditiva para $X_{n+1}$ dado que $X_{1}=x_{1}, \ldots, X_{n}=x_{n}$ é dada por:

$$
f\left(x_{n+1} \mid \xi_{n}\right)=\int_{\Omega} f\left(x_{n+1} \mid \omega\right) \xi_{n}(\omega) \mathrm{d} \omega
$$

e, dado que $\xi_{n}\left(X_{n+1}\right)$, denoła a distribuição a posteriori dados $X_{1}=x_{1}, \ldots, X_{n}=$ $x_{n}$ observados e $X_{n+1}$ variável aleatória, $\operatorname{com} \rho_{0}\left(\xi_{n+1}\right)$ definido como na equação (2.24), temos:

$$
\mathbb{E}\left\{\rho_{0}\left[\xi_{n}\left(X_{n+1}\right)\right]\right\}=\int_{S} \rho_{0}\left(\xi_{n+1}\right) f\left(x_{n+1} \mid \xi_{n}\right) \mathrm{d} x_{n}
$$

Vamos agora descrever o algoritmo de construçào do procedimento sequencial $M$-truncado de Bayes:

1. Primeiro Passo: O início da técnica de indução backward é localizado na última etapa do problema que neste caso é $M$. Suponhamos que na etapa $M$ tenham sido observados $X_{1}=x_{1}, \ldots, X_{M}=x_{M}$. Devido ao truncamento em $M$ a continuação ótima nesta etapa é parar a amostragem e a decisão terminal é escolhida em $D$ com base nos valores $x_{1}, \ldots, x_{M}$ observados. $\mathrm{O}$ risco da continuação ótima nesta etapa dados $X_{1}=x_{1}, \ldots . X_{M}=x_{M}$ é $\rho_{0}\left(\xi_{M}\right)$ (equação $\left.(2.24)\right)$. 
2. Segundo Passo: Voltar uma etapa. Suponhando que na etapa $M-1$ foram observados $X_{1}=x_{1}, \ldots . X_{M-1}=x_{M-1}$. devemos decidir se paramos a amostragem ou se observamos $X_{M}$ (considerando que após observar $X_{M}$ mais nenhuma observação será tomada). Calculamos o risco $\rho_{0}\left(\xi_{M-1}\right)$ se pararmos a amostragem (equação (2.24)) e u risco $\mathbb{E}\left\{\rho_{0}\left[\xi_{M-1}\left(X_{M}\right)\right]\right\}+c$ se prosseguirmos a amostragem observando $X_{M}$ (equação (2.29). Repetimos? este procedimento para todas as possibilidades de $X_{1}, \ldots, X_{M-1}$. Então, a regra de parada do procedimento de decisão sequencial $M$-truncado de Bayes, caso seja atinjida a etapa $M-1$, estabelece que:

- Se $\rho_{0}\left(\xi_{M-1}\right) \leq \mathbb{E}\left\{\rho_{0}\left[\xi_{M-1}\left(X_{M}\right)\right]\right\}+c$, a continuação ótima é parar a amostragem e a decisão terminal é escolhida em $D$ com base nos valores $x_{1}, \ldots, x_{M-1}$ observados.

- Se $\rho_{0}\left(\xi_{M-1}\right)>\mathbb{E}\left\{\rho_{0}\left[\xi_{M-1}\left(X_{M}\right)\right]\right\}+c$, a continuação ótima é observar $X_{M}$ e a decisão terminal é escolhida em $D$ com base nos valores $x_{1}, \ldots, x_{M}$ observados.

Obs: Note-se que o custo das primeiras M-1 observações não foram considerados pois, como ele entraria nos dois lados da desigualdade, a parcela referente a ele se anularia na comparaçào (a decisão a essa altura não incorpora o gasto amostral já efetuado).

O risco da continuação ótima nesta etapa dados $X_{1}=x_{1}, \ldots, X_{M-1}=x_{M-1}$ é:

$$
\rho_{1}\left(\xi_{M-1}\right)=\min \left[\rho_{0}\left(\xi_{M-1}\right), \mathbb{E}\left\{\rho_{0}\left[\xi_{M-1}\left(X_{M}\right)\right]\right\}+c\right]
$$

3. Terceiro Passo: Voltar outra etapa. Suponhando que na etapa $M-2$ foram observados $\mathrm{X}_{1}=x_{1}, \ldots, \mathrm{X}_{M-2}=x_{M-2}$, devemos decidir se paramos 
a amostragem ou se observamos $X_{M-1}$ (considerando que. após observar $X_{M-1}$, ainda será possivel observar $\left.X_{M}\right)$. Calculamos o risco $\rho_{0}\left(\xi_{M-2}\right)$ se a amostragem for finalizada na etapa $M-2$ (equação $(2.24)$ ) e o risco $\mathbb{E}\left\{\rho_{1}\left[\xi_{M-2}\left(X_{M-1}\right)\right]\right\}+c$ se prosseguirmos a amostragem observando $X_{M-1}$ (e considerando que após observar $X_{1:-1}$ ainda podemos observar $\left.X_{M}\right)$ através de:

$$
\mathbb{E}\left\{\rho_{1}\left[\xi_{M-2}\left(X_{M-1}\right)\right]\right\}=\int_{S} \rho_{1}\left[\xi_{M-1}\right] f\left(x_{M-1} \mid \xi_{M-2}\right) \mathrm{d} x_{M-1}
$$

onde $\rho_{1}\left[\xi_{M-1}\right]$ é o respectivo risco da continuaçào ótima na etapa $M-1$ calculado em (2.30).

Repetimos este procedimento para todas as possibilidades de $X_{1}, \ldots, X_{M-2}$. Então, a regra de parada do procedimento de decisão sequencial $M$-truncado de Bayes caso a etapa $M-2$ seja atinjida estabelece:

- Se $\rho_{0}\left(\xi_{M-2}\right) \leq \mathbb{E}\left\{\rho_{1}\left[\xi_{M-2}\left(X_{M-1}\right)\right]\right\}+c$, a continuaçào ótima é parar a amostragem e a decisão terminal é escolhida em $D$ com base nos valores $x_{1}, \ldots, x_{M-2}$ observados.

- Se $\rho_{0}\left(\xi_{M-2}\right)>\mathbb{E}\left\{\rho_{1}\left[\xi_{M-2}\left(X_{M-1}\right)\right]\right\}+c$, a continuaçào ótima é prosseguir a amostragem, observando $X_{M-1}$ (seguindo, depois, o estabelecido por $\left.\tau\left(X_{1}^{\prime}, \ldots, X_{M-1}^{\prime}\right)\right)$.

Pelo mesmo motivo que no passo anterior, o custo amostral das primeiras $M-2$ observações não foi considerado na comparação.

$\mathrm{O}$ risco da continuação ótima nesta etapa dados $\mathrm{X}_{1}=x_{1}, \ldots . \mathrm{X}_{M-2}=x_{M-2}$ é:

$$
\rho_{2}\left(\xi_{M-2}\right)=\min \left[\rho_{0}\left(\xi_{M-2}\right), \mathbb{E}\left\{\rho_{1}\left[\xi_{M-2}\left(X_{M-1}\right)\right]\right\}+c\right]
$$


4. Quarto Passo: Voltar mais uma etapa e repetir o mesmo procedimento das etapas anteriores. Agora iremos comparar $\rho_{0}\left(\xi_{M-3}\right)$ com $\mathbb{E}\left\{\rho_{2}\left[\xi_{M-3}\left(X_{M-2}\right)\right]\right\}+c$. A regra de parada é cosntruída analogamente aos passos anteriores e o risco da continuaçào ótima nesta etapa dados $X_{1}=x_{1}, \ldots, X_{M-3}=x_{M-3}$ é:

$$
\rho_{3}\left(\xi_{M-3}\right)=\min \left[\rho_{0}\left(\xi_{M-3}\right), \mathbb{E}\left\{\rho_{2}\left[\xi_{M-3}\left(X_{M-2}\right)\right]\right\}+c\right]
$$

5. Passos Seguintes: E assim sucessivamente, até a etapa inicial, onde será comparado $\rho_{0}(\xi)$ com $\mathbb{E}\left\{\rho_{M-1}\left[\xi_{0}\left(X_{1}\right)\right]\right\}+c$, sendo o risco da continuaçào ótima na etapa inicial dado por:

$$
\rho_{M}\left(\xi_{0}\right)=\min \left[\rho_{0}\left(\xi_{0}\right), \mathbb{E}\left\{\rho_{M-1}\left[\xi_{0}\left(X_{1}\right)\right]\right\}+c\right]
$$

Em resumo, um procedimento de decisão sequencial $M$-truncado de Bayes possui riscos de continuação ótima dados por $\rho_{M}\left(\xi_{0}\right), \rho_{M-1}\left(\xi_{1}\right), \quad \ldots \quad$, $\rho_{1}\left(\xi_{M-1}\right), \rho_{0}\left(\xi_{M}\right) . \quad \rho_{0}\left(\xi_{M}\right)$ é calculado pela equação (2.24) e os outros podem ser calculados recursivamente através da seguinte relação, que facilita grandemente a sequência de computação:

$$
\begin{aligned}
\rho_{j+1}\left(\xi_{k}\right)= & \min \left[\rho_{0}\left(\xi_{k}\right) ; \mathbb{E}\left\{\rho_{j}\left[\xi_{k}\left(X_{k+1}\right)\right]\right\}+c\right] \\
& \text { para } j=0, \ldots, M-1 \text { e } k=M-j-1 .
\end{aligned}
$$

Resultado 2.5 Pelo Princípio de Otimizaçâo de Belmann (19.57) em qualquer etapa $n(n<M)$ de um procedimento de decisão sequencial M-truncado de Bayes, a seguinte relaçâo é válida:

$$
\rho_{M-n}\left(\xi_{n}\right)=R^{\times}\left(g_{M-n}\right)
$$

onde 
- $\rho_{M-n}\left(\xi_{n}\right)$ é o risco da continuaçio ótima na etapa $n$ dados $X_{1}=x_{1} \ldots, X_{n}=$ $x_{n}$ de um problema de decisão sequencial M-truncado de Bayes com priori $g_{M}(.,.) \operatorname{para}\left(\omega \cdot \boldsymbol{X}_{M}\right)$.

- $R^{*}\left(g_{M-n}\right)$ é o Risco Totai de Bayes a Priori de um problema de cíecisão sequencial de Bayes $(M-n)$-truncado com priori $\xi_{n}($.$) para \omega$ e $g_{M-n}(.,$. $\operatorname{para}\left(\omega, \boldsymbol{X}_{M-n}\right)$.

Do resultado do teorema 2.2 e dos resultados desta seçào, podemos fin!alınente estabelecer o procedimento de decisão sequencial $M$-truncado de Bayes. através do seguinte:

Resultado 2.6 O procedimento de decisão sequencial $M$-truncado de Bayes estabelece que:

1. Na etapa inicial do problema,

- Se $\rho_{0}\left(\xi_{0}\right)=\rho_{M}\left(\xi_{0}\right)$, entâo a continuaçâo ótima é não iniciar a amostragem e uma decisão terminal de Bayes $d^{*}$ é escolhida em D sem que observação alguma seja tomada.

- Se $\rho_{0}\left(\xi_{0}\right)>\rho_{M}\left(\xi_{0}\right)$. entào $X_{1}$ deve ser observada.

2. Sucessivamente, para as etapas $j(j=1, \ldots, M-1)$ e supondo que $X_{1}=$ $x_{1}, \ldots, X_{j}=x_{j}$ tenham sido observados

- Se $\rho_{0}\left(\xi_{j}\right)=\rho_{M-j}\left(\xi_{j}\right)$, então a continuaçào ótima é interromper a amostragem nesta etapa $j$ e uma decisâo terminal de Bayes contra $\xi_{j}$ é escolhida em D. 
- Se $\rho_{0}\left(\xi_{j}\right)>\rho_{. Y-, j}\left(\xi_{i}\right)$. entào $X_{j+1}$ de è ser observada.

3. Se a amostragem prosseguir até a etapa . H. a continuaçaio ótima é interromper a amostragem nesta ctapa (após a observaçào de $X_{. y}$ e independente do valer observado) e uma decisaio terminal de Bayes contra $\xi_{M}$ é escolhida em $D$

No resultado acima. a consideração de possibilidades $\rho_{0}\left(\xi_{j}\right)<\rho_{M-j}\left(\xi_{j}\right)$ nào foi necessária devido ao seguinte:

Teorema 2.3 Para qualqur distribuiçào $\xi_{k}$ para u. temos:

$$
\rho_{j}\left(\xi_{k}\right) \geq \rho_{j+1}\left(\xi_{k}\right) \quad \operatorname{para} j=0,1 \ldots
$$

Prova: Segundo a equaçào (2.33) $\rho_{j}\left(\xi_{k}\right)$ é igual a $R^{\times}\left(g_{j}\right)$ que é o Risco Total de Bayes a Priori (o menor risco dentre todos os procedimentos de decisào sequencial que terminam a amostragem. no máximo, em $j$ etapas) do procedimento de decisão sequencial $j$-truncado com priori $\xi_{k}$ para $\omega$, enquanto, $\rho_{j+1}\left(\xi_{k}\right)$ é a $R^{\star}\left(g_{j+1}\right)$ que é o Risco Total de Bayes a Priori do procedimento de decisào sequencial $(j+1)$-truncado com priori $\xi_{k}$ para $\omega$. Como $j+1>j$. o teorema fica demonstrado.

\subsection{Determinação do Tamanho Máximo da Amostra}

A utilização de um procedimento de decisão sequencial de Bayes construído segundo a técnica de induçào backward, formalmente desenvolvida na seçào ante- 
rior, pressupòe a fixaçào de um tamanho máximo de amostra. 1/. Nesta seçào discutiremos a determinaçào .1 .

Um primeiro aspecto a ser considerado é que. em muitos casos. o limite máximo para a amostra vem determinado juntamente com o problema inicial. Sào casos onde. por exemplo. o tempo e ou a verba destinados à pesquisa impòem este limite máximo. Quando isto nào acontece, alguns critérios para a determinação de $M$ devem ser considerados.

Conforme o desenvolvimento descrito na seçào anterior. nào é difícil perceber que os cálculos para $\rho_{M-j}\left(\xi_{j}\right)$ vão se tornando complicados a medida que $M$ aumenta. A dificuldade, muitas vezes. nào reside nas contas em si. mas na determinaçào de todas as possibilidades para a amostra, as quais. evidentemente, crescem com o aumento de $M$. Sendo assim, fixar $M$ muito grande pode tornar o problema difícil de ser resolvido computacionalmente. Por outro lado, o nosso objetivo inicial era construir o procedimento de decisào sequencial (não truncado) de Bayes. O limite $M$ foi introduzido apenas para auxiliar nesta tarefa. Com ele, o que conseguimos é o procedimento sequencial $M$-truncado de Bayes. que pode ser visto como uma aproximação para o procedimento sequencial ótimo não-limitado. Vejamos o seguinte resultado:

Resultado 2.7 Para qualquer problema de decisào sequencial. a seguinte relaçào é válida:

$$
\lim _{M \rightarrow \infty} R^{\times}\left(g_{M}\right)=R_{0}(g)
$$

O resultado 2.7 é direto e segue do resultado 2.5 e do teorema 2.3. pois a sequencia de riscos totais de Bayes de procedimentos truncados é não crescente.

Pelo resultado 2.i. devemos escolher $M$ suficientemente grande para que a aproximação seja boa. Uma discussào a respeito da precisào dessa aproximaçào 
nào será feita neste trabalho (ver. por exemplo. Berger (1980)). Aqui. trabalharemos com o fato de em muitos casos. o procedimento sequencial (nào truncado) de Bayes ser. na verdade. .M-truncado:

Condição 2.1 Se o risco de decisào de Bayes a posteriori na clapa k satisfaz à relação

$$
\rho_{0}\left(\xi_{k}\right)<c
$$

para todo $\left(x_{1}, \ldots x_{k}\right) \in S^{k}$ e se $M$ é o menor valor de $k$ tal que esta relação seja verdadeira entâo o procedimento sequencial ótimo é o sequencial M-limitado ótimo.

Prova: Esta condiçào é bastante intuitiva. Suponhamos que estào sendo considerados todos os possíveis procedimentos sequenciais não-truncados e que a amostragem tenha prosseguido até a etapa $M$. Suponhamos também que $X_{1}=$ $x_{1}, \ldots, X_{M}=x_{M}$ tenham sido observados. Como já foi visto, o Risco de Bayes a Posteriori na etapa $M$ é $\rho_{0}\left(\xi_{M}\right)$. O risco de continuar a amostragem depende de, se após observarmos $X_{M+1}$ iremos observar $X_{M+2}$ e depois $X_{M+3}, \ldots$. Sem um limite máximo para a amostragem, não vimos como calcular este risco. Entretanto, sabemos que devemos considerar que ao menos a observaçào $X_{M+1}$ será tomada. Assim, este risco será, no mínimo, o custo de observar $X_{M+1}$, que é $c$. Então, dada a hipótese da condiçào 2.1 e tendo observado $X_{1}=x_{1}, \ldots, X_{M}=x_{M}$, o risco de continuar a amostragem é maior que o risco de tomar uma decisào imediatamente, para qualquer que seja o valor de $\left(x_{1}, \ldots, x_{M}\right)$.

Nem sempre é possível encontrar $M$ que satisfaça a relação dada na equação (2.35) e, mesmo quando isto é possível, ele nem sempre será suficientemente pequeno a ponto de tornar o problema computacionalmente conveniente. Condiçòes menos restritivas do que as da condição 2.1 geralmente conduzem a um valor de $M$ menor. 
Condição 2.2 Suponha quc. para todo $j \geq k \in \operatorname{todo}\left(x_{1} \ldots \ldots x_{j}\right) \in S^{j}$. a seguinte relação é satisfeita

$$
\rho_{0}\left(\xi_{j}\right) \leq \mathbb{E}\left\{\rho_{0}\left[\xi_{j}\left(X_{i+1}\right)\right]\right\}+c
$$

Se $M$ é o menor valor de ki tal que esta relaçâo seja verdadeira entào. o procedimento sequencial de Bayes é o procedimento sequencial M-truncado de Bayes.

Prova: Esta condiçào nào é tào forte quanto a primeira. uma vez que o lado direito da desigualdade (2.36). considera, além do custo de observar $X_{j+1}$, a $\mathbb{E}\left\{\rho_{0}\left[\xi_{j}\left(X_{j+1}\right)\right]\right\}$. Ela $\dot{e}$ mais trabalhosa pois. devemos verificá-la para todo $j \geq$ M. A razào disto é que como vimos na equaçào (2.34).

$$
\rho_{1}\left(\xi_{j}\right)=\min \left[\rho_{0}\left(\xi_{j}\right): \mathbb{E}\left\{\rho_{0}\left[\xi_{j}\left(X_{j+1}\right)\right]\right\}+c\right]
$$

pode ser maior que $\rho_{2}\left(\xi_{j}\right)$. significando que, o risco $\rho_{0}\left(\xi_{j}\right)$ de parar o ensaio na etapa $j$ ser menor ou igual ao risco $\mathbb{E}\left\{\rho_{0}\left[\xi_{j}\left(X_{j+1}\right)\right]\right\}$ de continuar a amostragem tomando somente mais uma observaçào, nao implica em ele ser menor ou igual ao risco $\mathbb{E}\left\{\rho_{z}\left[\xi_{j}\left(x_{j+1}\right)\right]\right\}$ de continuar a amostragem tomando mais $z(z>0)$ observações. Mas, se garantirmos a validade da relaçào dada na equaçào(2.36) para todo $j \geq M$ (e lembrando da recursividade para calcular $\rho_{z}\left(\xi_{j+1}\right)$ dada na equação (2.32), estamos garantindo que o risco de parar a amostragem na etapa $j$ é menor ou igual ao risco de continuar a amostragem sendo ela tào grande quanto se queira tomar.

\subsection{Problemas de Decisão Estatística com Amostragem Sequencial em Grupos}

Este tipo de abordagem é uma variante do problema de decisào estatística com amostragem sequencial. A variante é que, aqui, ao invés de irmos tomando uma 
observaçào de cada vez. tomamos un grupo de tamanho $N$ fixado de cada vez. A característica principal deste tipo de ensaio é que ele pode ser interrompido depois da observaçào de qualquer grupo de pacientes. A adaptaçào dos resultados obtidos nas seções anteriores é direta. 


\section{Capítulo 3}

\section{Aplicação}

Neste capítulo. trabalharemos com as idéias e conceitos tratados nos capitulos 1 e 2 através da apresentaçào de um exemplo de ensaio clínico farmacêutico. Primeiramente, faremos um detalhamento do problema a ser tratado: apresentaremos e discutiremos os aspectos relacionados com o planejamento do ensaio. Posteriormente. mostraremos como conduzir o ensaio. monitorá-lo e também. como analisar os dados obtidos através de situações hipotéticas. O planejamento que apresentaremos foi inspirado no trabalho de Berry (1994).

\subsection{Apresentação do Problema}

Suponhamos que uma certa indústria farmacêutica seja responsável pela fabricação de uma droga. a qual chamaremos de droga $A$. Digamos que a droga $A$ esteja sendo utilizada para o tratamento de uma certa doença e que. até entào, esteja se mostrando eficiente. Suponhamos, também, que uma nova droga, que chamaremos de droga $B$. indicada para o tratamento dessa mesma doença esteja sendo 
desenvolvida por esta indústria. Admitiremos que a droga A possui aprovaçào para comercialização pelos órgãos competentes e a chamaremos de droga-padrão (o tratamento utilizando a droga-padrào scrá chamado de tratamento-padrào). A droga $B$, que ainda necessita de aprovação para comercializaçào. chamaremos de droga-experimental (o tratamento utilizando a droga experimental será chamado de tratamento-experimental). O objetivo da indústria é fabricar apenas a droga que se mostrar mais eficiente.

\subsection{Características do Ensaio}

Primeiramente, iremos supor que ensaios relativos às fases 1 e 2. descritas no capítulo 1 , tenham sido realizados para a droga $B$, e que ela esteja apto a passai para a fase 3. Dadas as características descritas na seçào anterior, a opçào escolhida para a fase 3 é um ensaio comparativo com grupo controle recebendo tratamento ativo.

Para cada paciente do estudo será ministrada uma das drogas. Chamaremos de "sucesso" aquele paciente que depois de receber a droga que the foi selecionada, responder clinicamente positivo ao tratamento. O caso em que a resposta for clinicamente negativa será chamado de "fracasso". Consideraremos ser funçào do médico o estabelecimento do que seja "uma resposta clinicamente positiva" e. portanto, nào nos preocuparemos com este tipo de questào. A proporçào amostral de sucessos sob o tratamento $A$ será denotada por $p_{A}$ e a do tratamento $B, p_{B}$. $P_{A}$ é a proporção de sucessos entre toda a população paciente. se esta fosse tratada $\operatorname{com} A . P_{B}$ é a proporçào de sucessos entre toda a populaçào paciente, se essa fosse tratada com $B$. O nosso parâmetro de interessa será a diferença entre essas proporções e será denotado por $\omega=P_{B}-P_{A}$. Portanto, valores positivos para 
u' significam que a proporçào de sucessos sob tratamento $B$ é maior do que sob o tratamento $A$. enquanto valores negativos indicam que a proporçào de sucessos de $A$ é maior.

A nossa proposta para o problema é trabalhar com um ensaio sequencial em blocos, utilizando a teoria de decisão juntamente com o Princípio de Bayes para o planejamento.

\subsection{Amplitude de Equivalência}

Antes do planejamento do ensaio. um importante conceito a ser trabalhado é o de amplitude de equivalência (Spiegelhalter et. al. (1994)). A idéia básica é que nem sempre os tratamentos envolvidos no estudo possuem o mesmo "custo". Aqui, estamos chamando de custo todos os aspectos do tipo: reaçòes adversas provocadas pela droga (efeitos colaterais). dificuldade de aplicaçào, custo monetário, etc.. Se este custo nào é o mesmo para diferentes tratamentos. é natural pensarmos que, para considerarmos um tratamento superior ao outro. será necessário um certo valor mínimo para a diferença em eficácia. Tendo em mente esta idéia, a noçào de amplitude de equiralência foi criada. Ela é representada pelo intervalo $\left(D_{I} . D_{S}\right)$ e significa que. se $u \in\left(D_{I} . D_{S}\right)$. entào nào somos capazes de preferiri um dos tratamentos. ou seja. neste intervalo. eles sào considerados equivalentes. Se $\omega<D_{I}$, entào consideramos o tratamento-padrão superior. e, se $\omega>D_{S}$, o tratamento-experimental é considerado superior. Na literatura. o limite $D_{S}$ é comumente chamado de "benefício mínimo clinicamente significante". A especificação do intervalo $\left(D_{I}, D_{S}\right)$ é, obviamente, subjetiva e depende da interação entre estatístico e médico, além do conhecimento prévio a respeito dos tratamentos. Segundo Spiegelhalter et. al. (1994). é bastante razoável que a 
amplitude de equivalência vá mudando conforme se aumente o aprendizado sobre os tratamentos com o progresso do ensaio.

A especificaşão $D_{I}=0$ é comum para muitos tipos de problemas. Neste caso. estamos considerando que o custo do tratamento experimental é maior. Entào:

1. Se $\omega<0$. além do custo com o tratamento-padrào ser menor. os benefícios são melhores e. portanto. ele deve ser considerado superior.

2. Se $\omega \in\left[0, D_{S}\right)$. o melhor benefício do tratamento-experiment al simplesmente compensa seu maior custo e. portanto, os dois tratamentos sào considerados equivalentes.

3. Se $\omega \geq D_{S}$. o melhor benefício do tratamento-experimental compensa seu maior custo e, portanto. ele é considerado superior.

\subsection{Informação a Priori}

Ao realizar um ensaio. certamente estatístico possui alguma opiniào a respeito de $\omega$ e dos possíveis resultados deste ensaio. Na literatura bayesiana essa opiniào é chamada de grau de incerteza. Obviamente, o grau de incerteza a respeito do resultado de um dado ensaio nào só varia de pessoa para pessoa como. também. para a mesma pessoa. varia em funçào do conhecimento atual que ela possua sobre o assunto. ou seja, ele é subjetivo e pode variar com a aprendizagem. A informação a priori é vista como uma distribuiçào de probabilidade que descreve o grau de incerteza. Ela incorpora toda a informação externa referente ao ensaio. de uma maneira formal e direta.

O uso da fórmula de Bayes para a atualizaçào da priori após a observação dos 
dados nem sempre é simples em termos computacionais. Apesar de seu mecanismo ser bastante simples. as contas podem ficar extremamente complicadas. Devese mencionar. entretanto. que atualmente métodos de simulação tais como. por exemplo. amostrador de Gibbs e Monte Carlo tem enfrentado eficazmente esta dificuldade, alavancando a aplicação de métodos bayesianos a problemas reais.

O exemplo que iremos considerar neste trabalho envolve grupos de observaçòes binárias, ou seja, cada observaçào (resposta clínica de um paciente) possui apenas dois valores possiveis, que sảo "sucesso" ou "fracasso". Iremos supor que os pacientes de cada grupo sejam permutáveis em relaçào à resposta em questão (ver definição 3.1) e. sendo assim. as respostas podem ser sumarizadas através de $Y$, para representar o número de sucessos. e $(N-Y)$. para representar o número

de fracassos (onde $N$ é o tamanho do grupo de pacientes). Especificamente, estaremos envolvidos em um estudo sobre a proporção de sucessos e fracassos sob cada tratamento. Devido à extensa possibilidade de formas para a distribuição $\operatorname{Beta}(a, b)$ e a sua praticabilidade para atualização, ela é comumente utilizada como priori para proporções.

Definição 3.1 Dois ou mais pacientes sâo permutáueis para cocé em relação a resposta a ser dada a um certo tratamento quando voct̂ nào consegue distinguir. característica alguma nesses pacientes que tenha, na sua opiniäo. influência na resposta ao tratamento. Formalmente, a distribuiçào conjunta das respostas é invariante sob qualquer permutaçào dos pacientes.

\subsection{Problema Puro Associado}

Nesta seção, apresentaremos todas as características necessárias do problema puro associado ao problema de decisào estatística que desenvolveremos nas seções 
seguintes. Posteriormente. resolveremos este problema puro.

\subsubsection{Espaço Paramétrico}

O estadu da natureza é $\omega=P_{B}-P_{A}$. Como $P_{1}$ e $P_{B}$ são proporçòes. seus possiveis valores pertencem ao intervalo $[0.1]$ e. portanto, o espaço paramétrico para $\omega$ será $\Omega=[-1,1]$.

\subsubsection{Espaço de Decisões}

Devido ao objetivo da indústria farmacêutica, anteriormente especificado, o espaço de decisões será $D=\left\{d_{1}, d_{2}\right\}$, onde:

- $d_{1}$ simboliza "escolha do tratamento $A$ "

- $d_{2}$ simboliza "escolha do tratamento $B$ "

Admitiremos que a amplitude de equivalência seja dada por [0: 0.3). Faremos uma partiçào do espaço paramétrico $\Omega$ em 3 subconjuntos. $\Omega_{1}, \Omega_{2}$ e $\Omega_{3}$ da seguinte forma:

$$
\Omega_{1}=[-1: 0), \Omega_{2}=[0: 0.3)=\left[D_{l}, D_{S}\right) \text { e } \Omega_{3}=[0.3: 1] \text {. }
$$

Portanto,

- Se $\omega \in \Omega_{1}$, o tratamento-padrão é superior.

- Se $\omega \in \Omega_{2}$. os dois tratamentos são equivalentes. 
- Se $\omega \in \Omega_{3}$. o tratamento-experimental é superior.

Assim,

- $d_{1}$ seria apropriada se $\omega \in\left(\Omega_{1} \cup \Omega_{2}\right)$. enquanto que

- $d_{2}$ seria apropriada se $\omega \in\left(\Omega_{2} \cup \Omega_{3}\right)$.

\subsubsection{Função de Perda}

Para o tipo de problema que estamos tratando. utilizaremos uma variação da perda "0-k"1. A função de perda a ser considerada será clada por:

$$
L\left(\omega, d_{1}\right)= \begin{cases}0 & \text { se } \omega \notin \Omega_{3} \\ k_{1} & \text { se } \omega \in \Omega_{3}\end{cases}
$$

e

$$
L\left(\omega, d_{2}\right)= \begin{cases}k_{2} & \text { se } \omega \in \Omega_{1} \\ 0 & \text { se } \omega \notin \Omega_{1}\end{cases}
$$

Para o exemplo, usaremos $k_{1}=k_{2}=k=10$. No caso de se considerar algum dos dois erros (escolher o tratamento-padrào quando na verdade o tratamentoexperimental é melhor ou escolher o tratamento-experimental quando na verdade o tratamento-padrào é melhor) mais grave pode-se escolher $k_{1} \neq k_{2}$.

\footnotetext{
${ }^{1}$ A variaçào é devido à incorporação da amplitude de equivalencia. Perceba-se que, na regiào correspondente à ela, nenhuma perda é associada a qualquer decisão.
} 


\subsubsection{Distribuição a Priori}

Embora do nosso interesse resida na diferença entre as proporçoes $P_{A}$ e $P_{B}$. nào iremos especificar uma priori diretamente para ela. Especificaremos. ao invés disso, uma priori para cada proporçào.

A priori escolhida para $P_{A}$ é Beta(3.3) e para $P_{B}$ é Beta(3.3). Admitindo independência entre $P_{A}$ e $P_{B}$, a distribuição conjunta a priori para $\left(P_{A}, P_{B}\right)$ é determinada por:

$$
\frac{\Gamma(3+3)}{\Gamma(3) \Gamma(3)} p_{A}^{3-1}\left(1-p_{A}\right)^{3-1} \times \frac{\Gamma(3+3)}{\Gamma(3) \Gamma(3)} p_{B}^{3-1}\left(1-p_{B}\right)^{3-1}
$$

Denotaremos por $\xi_{0}$ a densidade a priori do vetor aleatório $\left(P_{A}, P_{B}\right)$.

\subsubsection{Solução para o Problema Puro}

Resolveremos o problema de decisão puro seguindo o princípio de Bayes. Como o espaço de decisões $D$ é finito. calcularemos separadamente o risco de cada uma das decisões $d_{i} \in D$.

$$
\begin{aligned}
\rho\left(\xi_{0} \cdot d_{1}\right) & =\mathbb{E}\left[L\left(\omega \cdot d_{1}\right)\right] \\
& =k \cdot \mathbb{P}_{\xi_{0}}[\omega \geq 0.3] \\
& =10 \mathbb{P}_{\xi_{0}}\left[\left(\dot{P}_{2}-P_{1}\right) \geq 0.3\right] \\
& =\frac{10 \Gamma(3+3) \Gamma(3+3)}{\Gamma(3) \Gamma(3) \Gamma(3) \Gamma(3)} \\
& \times \int_{0}^{0 . \tau} p_{1}^{3-1}\left(1-p_{1}\right)^{3-1}\left[\int_{p_{1}+0.3}^{1} p_{2}^{3-1}\left(1-p_{2}\right)^{3-1} \mathrm{~d} p_{2}\right] \mathrm{d} p_{1} \\
& =1.375 \tau \\
\rho\left(\xi_{0}, d_{2}\right) & =\mathbb{E}\left[L\left(\omega, d_{2}\right)\right]
\end{aligned}
$$




$$
\begin{aligned}
& =k \mathbb{P}_{\xi_{0}}[\omega<0] \\
& =10 \mathbb{P}_{\xi_{0}}\left[\left(P_{2}-P_{1}\right)<0\right] \\
& =\frac{10 \Gamma(3+3) \Gamma(3+3)}{\Gamma(3) \Gamma(3) \Gamma(3) \Gamma(3)} \\
& \times \int_{0}^{1} p_{1}^{3-1}\left(1-p_{1}\right)^{3-1}\left[\int_{0}^{p_{1}} p_{2}^{3-1}\left(1-p_{2}\right)^{3-1} \mathrm{~d} p_{2}\right] \mathrm{d} p_{1} \\
& =5
\end{aligned}
$$

O Risco de Bayes contra a priori $\xi_{0}$ é. portanto

$$
\begin{aligned}
\rho_{0}\left(\xi_{0}\right) & =\min \left[\rho\left(\xi_{0}, d_{1}\right): \rho\left(\xi_{0}, d_{2}\right)\right] \\
& =\min [1.3757: 5] \\
& =1.3757
\end{aligned}
$$

e a respectiva decisào de Bayes é $d_{1}$, que simboliza a escolha do tratamento $A$. Portanto, se nenhuma amostra fosse observada, a decisão a ser tomada seria escolher a droga-padrào (obviamente, neste caso, a determinação da melhor decisão considerou apenas a informação a priori e a funçào de perda).

A figura 3.1 mostra a distribuiçào a priori para $\left(P_{A}, P_{B}\right)$. O risco de $d_{1}$ nada mais é do que o volume sob a superfície da região onde $P_{B}-P_{A}>0.3$, ponderado pelo valor $k$. O risco de $d_{2}$ é o volume onde $P_{B}-P_{A}<0$. também ponderado por $k$. Devido aos mesmos parâmetros das duas prioris, a superfície é circularmente em $[0,1]^{2}$ simétrica. Devido à amplitude de equivalência e à funçào de perda escolhida, a área de risco para a decisào $d_{1}$ (onde $P_{B}-P_{A} \geq 0.3$ ) é menor que a área de risco para a decisào $d_{2}$ (onde $P_{B}-P_{A}<0$ ).

Obs: Note que. devido ao fato de $k_{1}=k_{2}=k_{3}$. a ponderaçào por $k$ torna-se irrelevante, podendo-se ter idéia da conclusão diretamente através da observação do gráfico da priori. 


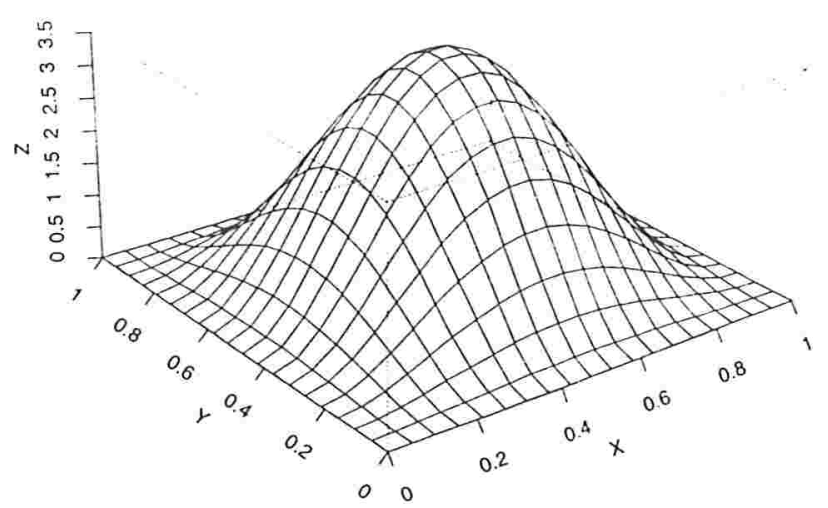

Figura 3.1: Priori para $\left(P_{A}, P_{B}\right)=($ X.Y $)$

\subsection{Características do Planejamento}

O ensaio a ser planejado envolverá um problema de decisào sequencial em grupos. Como um dos objetivos do ensaio sequencial é parar o ensaio tào logo os dados apontem para uma das decisões, é conveniente que o tamanho do grupo não seja muito grande. No exemplo observamos um grupo de tamanho 10 de cada vez. O custo de observar cada grupo de pacientes será fixado em 0.10 , ou seja, $c=0.01$ por paciente. ${ }^{2}$ Iremos supor que os grupos de pacientes sào permutáveis em relação ao vetor de respostas a ser observado. Em cada grupo de tamanho $2 N=10, N=5$ pacientes receberão a droga-padrão. enquanto que os $N=5$ restantes receberão a droga-experimental. A alocação dos tratamentos entre os

\footnotetext{
${ }^{2} \mathrm{~A}$ unidade de $c$ deve ser a mesma de $k$ da função de perda. Esta suposiçào de aditividade é crucial nas aplicaçōes de Teoria de Decisão
} 
pacientes nào será especificada (lembramos aqui que. como vimos no capítulo 1. o tipo de alocaçào utilizado não influencia no planejamento bayesiano e no tipo de análise bayesina do ensaio a ser feita portanto. podemos pensar que o estatístico utilizará aquele que considerar mais adequado). O planejamento considerará que o ensaio poderá ser interrompido após a observação de cada grupo de pacientes. sendo uma decisão terminal $d \in D$ então escolhida.

Se, por algum motivo, o ensaio for interrompido em algum outro momento que não corresponda a nenhum final de grupo. a análise bayesiana será feita com base na corrente distribuição a posteriori para $\left(P_{A} . P_{B}\right)$ incorporando as devidas perdas por decisào errada.

O vetor aleatório a ser observado na amostragem do primeiro grupo será denotado por $X_{1}=\left(Y_{1}, Z_{1}\right)$, onde $Y_{1}$ representa o número de sucessos na amostra do tratamento $A$, e $Z_{1}$ representa o número de sucessos na amostra do tratamento $B$. Como cada um dos tratamentos será dado a $N=5$ pacientes. temos o espaço amostral para $X_{1}$ dado por $\{0,1, \ldots, 5\} \times\{0,1, \ldots, 5\}$. Denotaremos por $\xi_{i j}$ a distribuição a posteriori para $\left(P_{A}, P_{B}\right)$, dado que $\left(Y_{1}=i \cdot Z_{1}=j\right)$ tenha sido observado e que $\xi_{0}$ tenha sido a distribuição a priori para $\left(P_{A} . P_{B}\right)$ considerada.

De maneira análoga, o vetor aleatório a ser observada na amostragem do segundo grupo será denotado por $X_{2}$ e a do terceiro grupo por $X_{3}$. O espaço amostral para $X_{2}$ e $X_{3}$ é o mesmo de $X_{1}$. Denotaremos por $\xi_{i, q q r}$ a distribuiçào a posteriori para $\left(P_{A}, P_{B}\right)$ dado que $\left(Y_{2}=q, Z_{2}=r\right)$ tenha sido observado e que $\xi_{i j}$ tenha sido a distribuição a priori para $\left(P_{A}, P_{B}\right)$ considerada. ou. equivalentemente, dado que $\left(Y_{1,2}=i+q \cdot Z_{1,2}=j+r\right)$ tenha sido obserrado (onde $Y_{1,2}$ representa o número de sucessos na amostra até o segundo grupo do tratamento $A$ e $Z_{1,2}$ do tratamento $B$ ) e que $\xi_{0}$ tenha sido a distribuição a priori para

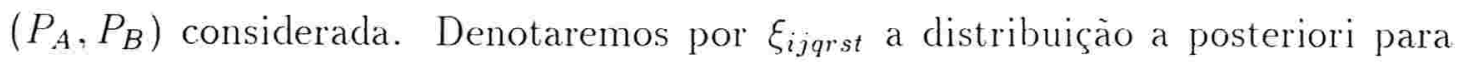


$\left(P_{A} \cdot P_{B}\right)$ dado que $\left(Y_{3}=s \cdot Z_{3}=t\right)$ tenha sido observado e que $\xi_{i j q r}$ tenha sido a distribuiçào a priori para $\left(P_{A} . P_{B}\right)$ consideradia. ou. equivalentemente. dado que $\left(Y_{1,2.3}=i+q+\therefore Z_{1.2 .3}=j+r+t\right)$ tenham sido obscrvado (onde $Y_{1.2 .3}$ representa o número de sucessos na amostra até o terceiro grupo do tratamento Ae $Z_{1,2,3}$ do tratamento $\left.B\right)$ e que $\xi_{0}$ tenhà sido a distribuiçào a priori para $\left(P_{A} \cdot P_{B}\right)$ considerada.

Resultado 3.1 Se a distribuiçào a priori para o parámetro $P_{A}$ é Beta(a.b) $\epsilon$ a distribuiçào condicional para $\left(Y \mid p_{A}\right)$ é Binomial $\left(X_{.}\right)$(onde $Y$ representa o número de sucessos do tratamento $A \mathrm{em}$ uma amostra de lamanho $\mathrm{X}$ ). então a distribuiçào a postcriori para $P_{A}$ será Beta! $\left.a+y \cdot b+(X-y)\right)$. onde y $\in(X-y)$ são o número de sucessos e o número de fracassos respectivamente obseriados na amostra.

Analogamente, a posteriori para $P_{B}$ será Bela $\left.c+z \cdot d+(\Lambda-z)\right)$ sendo a priori para $P_{B} B c t a(c, d)$ e $Z$ representando o número de sucessos do tratamento $B$ em uma amostra de tamanho $N$.

Uma grande vantagem da metodologia bayesiana é a consideração de distribuições preditivas. Para a construção do planejamento sequencial ótimo. vista no capítulo anterior. ela é fundamental.

Resultado 3.2 Sé a distribuição a priori para o parâmetro $P_{A}$ é Beta(a,b). denotada por $\xi_{A}($.$) . e para a distribuiçâo condicional para \left(Y \mid p_{A}\right) \dot{\epsilon}$ Binomial(.... $\left.p_{A}\right)$. então a distribuiçào preditiva para $Y$ (que tem suporte $y=\{0.1, \ldots . N\}$ ) será Beta-Binomial.

De fato,

$$
\mathbb{P}\left(X^{x} \mid \xi_{A}\right)=\int_{0}^{1} \frac{\Gamma(a+b)}{\Gamma(a) \Gamma(b)} p_{A}^{a-1}\left(1-p_{A}\right)^{b-1}
$$




$$
\begin{aligned}
& \times\left(\begin{array}{l}
x \\
y
\end{array}\right) p_{A}^{y}\left(1-p_{A}\right)^{N-y} \mathrm{~d} p_{A} \\
& =\left(\begin{array}{l}
x \\
y
\end{array}\right) \frac{\Gamma(a+b)}{\Gamma(a) \Gamma(b)} \frac{\Gamma(a+y) \Gamma(b+(X-y))}{\Gamma(a+b+N)} \\
& \times \int_{0}^{1} \frac{\Gamma(a+b+N)}{\Gamma(a+y) \Gamma(b+(N-y))} \\
& \times p_{A}^{a+y-1}\left(1-p_{A}\right)^{b+(N-y)-1} \mathrm{~d} p_{A} \\
& =\left(\begin{array}{c}
N \\
y
\end{array}\right) \frac{\Gamma(a+b) \Gamma(a+y) \Gamma(b+(N-y))}{\Gamma(a) \Gamma(b) \Gamma(a+b+N)}
\end{aligned}
$$

Resultado 3.3 Suponhamos que em um ensaio sequencial em grupos com priori Beta $(a, b)$ para $P_{A} \in \operatorname{Beta}(c, d)$ para $P_{B}$. a amostra do primeiro grupo tenha sido tomada e $X_{1}=\left(Y_{1}, Z_{1}\right)=(i, j)$ tenha sido observado. Considerando $P_{A} \in P_{B}$ independentes. temos:

- As distribuiçós a posteriori para $P_{A} \in P_{B}$ são denotadas por $\xi_{i}$ e $\xi_{j}$ respectivamente. A distribuiçào a posteriori conjunta para $\left(P_{A}, P_{B}\right)$ é denolada por $\xi_{i j} \in \ell$

$$
\begin{gathered}
\frac{\Gamma(a+b+N)}{\Gamma(a+i) \Gamma(b+(N-i))} p_{A}^{a+i-1}\left(1-p_{A}\right)^{b+N-i-1} \\
\times \frac{\Gamma(c+d+N)}{\Gamma(c+j) \Gamma(d+(N-j))} p_{B}^{c+j-1}\left(1-p_{B}\right)^{d+N-j-1}
\end{gathered}
$$

$\operatorname{para}\left(p_{A}, p_{B}\right) \in(0,1)^{2} e(i, j) \in\{0,1, \ldots, N\} \times\{0.1, \ldots, N\}$.

- A distribuicào preditiva para $\mathrm{X}_{2}=\left(\mathrm{Y}_{2}, Z_{2}\right)$ que assume calores (q.r) com 


$$
\begin{aligned}
& \text { suporte } \mathrm{em}\{0.1 \ldots . .1\} \times\{0.1 \ldots . .1\} \text { dada a posteriori } \xi_{i j} \epsilon \\
& \mathbb{P}\left(Y_{2}=q \cdot Z_{2}=r \mid \xi_{i, j}\right)= \\
& =\int_{0}^{1} \mathbb{P}\left(Y_{2}=q \mid p_{A}\right) \xi_{i}\left(p_{A}\right) \mathrm{d} p_{A} \times \int_{0}^{1} \mathbb{P}\left(Z_{2}=r \mid n_{B}\right) \xi_{j}\left(p_{B}\right) \mathrm{d} p_{B} \\
& =\text { (pelo resultado 3.2) } \\
& =\left(\begin{array}{l}
N \\
q
\end{array}\right) \frac{\Gamma(a+b+N) \Gamma(a+i+q) \Gamma(b+(N-i)+(N-q)}{\Gamma(a+i) \Gamma(b+N-i) \Gamma(a+b+N+N)} \\
& \times\left(\begin{array}{c}
N \\
r
\end{array}\right) \frac{\Gamma(c+d+N) \Gamma(c+j+r) \Gamma(d+(N-j)+(N-r)}{\Gamma(c+j) \Gamma(d+N-j) \Gamma(c+d+N+N)}(3.3)
\end{aligned}
$$

\subsection{Construção do Planejamento}

Nesta seção, iremos aproximar o procedimento de decisào sequencial de Bayes $\bigcap^{*}$ pelo procedimento de decisào sequencial $M$-truncado de Bayes $\gamma^{M \times x}$, utilizando $M=3$. Construiremos e apresentaremos o esquema completo para este ensaio.

\subsubsection{Etapa Inicial}

A primeira decisào a ser tomada é se a amostragem deve ser iniciada. Para isso, calcularemos o risco de continuaçào ótima na etapa inicial $\rho_{3}\left(\xi_{0}\right)$, que considera que a amostragem poderá prosseguir, no máximo, mais 3 etapas. Ele é dado por

$$
\rho_{3}\left(\xi_{0}\right)=\min \left[\rho_{0}\left(\xi_{0}\right), \mathbb{E}\left\{\rho_{2}\left[\xi_{0}\left(X_{1}\right)\right]\right\}+0.10\right]
$$


Mas

$$
\mathbb{E}\left\{\rho_{2}\left[\xi_{0}\left(X_{1}\right)\right]\right\}=\sum_{i=0}^{5} \sum_{i=0}^{5} \rho_{2}\left[\xi_{i j}\right] \mathbb{P}\left[\left(Y_{1}=i, Z_{1}=j\right) \mid \xi_{0}\right]
$$

Para cada uma das 36 possibilidades do somatório duplo da equaçào (3.5) devemos calcular o respectivo risco de continuaçào ótima $\rho_{2}\left[\xi_{i j}\right]$, que é dado por

$$
\rho_{2}\left(\xi_{i j}\right)=\min \left[\rho_{0}\left(\xi_{i, j}\right) \cdot \mathbb{E}\left\{\rho_{1}\left[\xi_{i, j}\left(X_{2}\right)\right]\right\}+0.10\right]
$$

além da probabilidade preditiva. dada pela equação (3.3) devidamente adaptada.

Calcularemos cada um dos $\rho_{0}\left(\xi_{i, j}\right)$ de maneira análoga ao cálculo de $\rho_{0}\left(\xi_{0}\right)$, detalhado na seção 3.5 .5 . diferindo por considerar como distribuição a priori para $\left(P_{A}, P_{B}\right)$ a posteriori $\xi_{i j}$.

Por sua vez, calcularemos cada uma das $\mathbb{E}\left\{\rho_{1}\left[\xi_{i j}\left(X_{2}\right)\right]\right\}$ utilizando a seguinte expressào (análoga a (3.5)):

$$
\mathbb{E}\left\{\rho_{1}\left[\xi_{i j}\left(X_{2}\right)\right]\right\}=\sum_{q=0}^{5} \sum_{r=0}^{5} \rho_{1}\left(\xi_{i j q r}\right) \mathbb{P}\left[\left(Y_{2}=q, Z_{2}=r\right) \mid X_{1}=(i, j)\right]
$$

Para calcularmos cada uma das 36 possibilidades do somatório duplo da equação (3.7) deveremos calcular o respectivo risco de continuaçào ótima $\rho_{1}\left(\xi_{i, j q r}\right)$. que é dado por

$$
\rho_{1}\left(\xi_{i j q r}\right)=\min \left[\rho_{0}\left(\xi_{i j q r}\right) \cdot \mathbb{E}\left\{\rho_{0}\left[\xi_{i j q r}\left(X_{3}\right)\right]\right\}+0.10\right]
$$

além da probabilidade preditiva. dada pela equaçào (3.3). devidamente adaptada.

Calcularemos cada um dos $\rho_{0}\left(\xi_{i j q r}\right)$ de maneira análoga ao cálculo de $\rho_{0}\left(\xi_{0}\right)$ ( a diferença, desta vez, será considerar como distribuiçào a priori para $\left(P_{A}, P_{B}\right)$ a posteriori $\xi_{\text {ijqr }}$ ). 
Para calcularmos cada uma das $\mathbb{E}\left\{\rho_{0}\left[\xi_{i j q r}\left(\mathrm{X}_{3}\right)\right]\right\}$. utilizaremos a seguinte expressào:

$$
\begin{aligned}
& \mathbb{E}\left\{\rho_{0}\left[\xi_{i j q r}\left(X_{3}\right)\right]\right\}= \\
& \quad \sum_{s=0}^{5} \sum_{t=0}^{5} \rho_{0}\left(\xi_{i j q r s t}\right) \mathbb{P}\left[\left(Y_{3}=s \cdot Z_{3}=t\right) \mid X_{1.2}=(i+q \cdot j+r)\right]
\end{aligned}
$$

Calcularemos cada $u m$ dos $\rho_{0}\left(\xi_{i, j q m n}\right)$ de maneira análoga ao cálculo de $\rho_{0}\left(\xi_{0}\right)$. Novamente. o cálculo da probabilidade preditiva segue da equasào (3.3) devidamente adaptada.

Desenvolvendo todos os cálculos indicados nas equaçòes acima. obtemos:

$$
\begin{aligned}
\rho_{3}\left(\xi_{0}\right) & =\min \left[\rho_{0}\left(\xi_{0}\right), \operatorname{iE}\left\{\rho_{2}\left[\xi_{0}\left(X_{1}\right)\right]\right\}+0.10\right] \\
& =\min [1.375 \tau: 0.417 \tau+0.10] \\
& =0.5177
\end{aligned}
$$

Portanto, a continuação ótima na etapa inicial é começar a amostragem, e seu risco é 0.5177 .

Obs: As contas necessárias para este planejamento foram realizadas através de uma rotina que elaborei utilizando o pacote Gauss.

\subsubsection{Etapa 1}

Suponhamos que a amostra do primeiro grupo tenha sido observada. Para cada uma das 36 possibilidades desta amostra devemos especificar se a amostragem deve ser interrompida na primeira etapa com a decisào de Bayes contra a respectiva posteriori $\xi_{i j}$ escolhida. ou se o segundo grupo de pacientes deve ser observado. 
Apresentaremos. como exemplo. as contas a serem feitas para o caso em que $X_{1}=(0,0)$ tenha sido observado.

Neste caso a informação a priori é atualizada pela informação $X_{1}=(0,0)$ e a corrente distribuiçào para $\left(P_{A}, P_{B}\right)$ é a posterior: $\varepsilon_{00}$. que é o produto entre a $\operatorname{Beta}(3,8)$ do tratamento $A$ e a $\operatorname{Beta}(3,8)$ do tratamento $B$. Para especificar se a amostragem deve ou nào ser continuada. calcularemos o risco de continuaçào ótima na etapa 1 dado que $X_{1}=(0,0)$ tenha sido observado (que considera que a amostragem poderá prosseguir, no máximo. mais 2 etapas). Ele é dado por:

$$
\rho_{2}\left(\xi_{00}\right)=\min \left[\rho_{0}\left(\xi_{00}\right) \cdot \mathbb{E}\left\{\rho_{1}\left[\xi_{00}\left(X_{2}\right)\right]\right\}+0.10\right]
$$

O valor de $\rho_{2}\left(\xi_{00}\right)$ já foi calculado quando necessário na equação (3.ĩ). Aproveitando os cáculos, temos:

$$
\begin{aligned}
\rho_{0}\left(\xi_{00}\right) & =\min \left[\rho\left(\xi_{00}, d_{1}\right) \cdot \rho\left(\xi_{00}, d_{2}\right)\right] \\
& =\min [0.5033: 5] \\
& =0.5033 \\
\rho_{2}\left(\xi_{00}\right) & =\min \left[\rho_{0}\left(\xi_{00}\right): \mathbb{E}\left\{\rho_{1}\left[\xi_{00}\left(X_{2}\right)\right]\right\}+0.10\right] \\
& =\min [0.5033: 0.3150+0.10] \\
& =0.4150
\end{aligned}
$$

Portanto, se $X_{1}=(0,0)$ for observado. a continuaçào ótima é prosseguir a amostragem, e seu risco é 0.4150 .

O esquema abaixo mostra a continuaçào ótima na etapa 1 para cada uma das 36 possibilidades de $X_{1}$. Nos casos en que a continuaçào ótima é interromper a amostragem, a respectiva decisào de Bayes é indicada. $Y_{1}$ e $Z_{1}$ representam o 
número de sucessos no tratamento $A$ e $B$. respectivamente. observados na amostragem do primeiro grupo.

- Se

$Y_{1}=0 \quad$ e $0 \leq Z_{1} \leq 3$ ou

$Y_{1}=1$ e $0 \leq Z_{1} \leq 4$ ou

$Y_{1}=2$ e $2 \leq Z_{1} \leq 5$ ou

$Y_{1}=3$ e $3 \leq Z_{1} \leq 5$ ou

$Y_{1}=4$ e $4 \leq Z_{1} \leq 5$ ou

$Y_{1}=5$ e $\quad Z_{1}=5$

então continue a amostragem.

- Se

$Y_{1}=0 \quad$ e $\quad 4 \leq Z_{1} \leq 5$ ou

$Y_{1}=1$ e $Z_{1}=5$

então pare a amostragem e escolha a decisão $d_{2}$.

- Se

$Y_{1}=2$ e $0 \leq Z_{1} \leq 1$ ou

$Y_{1}=3$ e $0 \leq Z_{1} \leq 2$ oul

$Y_{1}=4$ e $0 \leq Z_{1} \leq 3$ ou

$Y_{1}=5 \quad$ e $\quad 0 \leq Z_{1} \leq 4$

então pare a amostragem e escolha a decisào $d_{1}$.

\subsubsection{Etapa 2}

Através do esquema apresentado na etapa 1, vemos que, das 36 possibilidades para a primeira amostra, 17 delas especificam que a amostragem deva ser interrompida após a observaçào do primeiro grupo, enquanto que 19 especificam que 
a amostragem deva ser continuada. Cada uma dessas 19 possibilidades origina 36 novas possibilidades. totalizando 684 . Note porém que. como estamos assumindo que os grupos de pacientes são permutáveis (em relaçào ao vetor de respostas a ser observado). muitas dessas possibilidades são equivalentes. Por exmplo. observar $X_{1}=(0,0)$ e $X_{2}=(0.1)$ é equivalente a observar $X_{1}=(0.1)$ e $X_{2}=(0.0)$. Sào equivalentes, pois para efeito de verificar se amostragem deve ou nào ser continuada, a informação necessária da posteriori é a mesma: ${ }^{3}$ para ambas a posteriori é $\operatorname{Beta}(3,13)$ para o tratamento $A$ e $\operatorname{Beta}(4,12)$ para o tratamento $B$. Perceba que, com esta equivalência. o número de diferentes possibilidades é. no máximo, igual a $11^{2}=121$ (equivalente a pegar 10 pacientes para cada tratamento de uma só vez). Para verificar quais dessas 121 possibilidades sào realmente possíveis, basta seguir o seguinte raciocínio:

- Se $Y_{1}=0$. entào a amostragem deve ser continuada apenas se $Z_{1} \leq 3$. Suponha entào $Y_{1}=0$ e $Z_{1}=0$. Como $Y_{2}$ pode variar de 0 a 5 . valendo o mesmo para $Z_{2}$. as possibilidades provenientes para $Y_{1}=0$ e $Z_{1}=0$ são $Y_{1}+Y_{2}$ variando de 0 a 5 , ocorrendo o mesmo para $Z_{1}+Z_{2}$.

- Repetindo a etapa anterior para cada possibilidade de $Y_{1}$ e $Z_{1}$ que especifique que a amostragem deva ser continuada e aglutinando estes resultados, obtemos as possibilidades para $Y_{1}+Y_{2}$ e $Z_{1}+Z_{2}$.

Seguindo o raciocínio acima, verificamos que, para o nosso planejamento. existem 104 possibilidades para a amostra depois que o segundo grupo for observado. Para cada uma delas. devemos especificar se a amostragem deve ser interrompida na segunda etapa e a decisão de Bayes contra a posteriori $\xi_{i j q r}$ escolhida, ou se o terceiro grupo de pacientes deve ser observado.

\footnotetext{
${ }^{3}$ Considerando que nas duas ordens a amostragem teria seguido até a segunda etapa.
} 
Apresentaremos. como exemplo. as contas a serem feitas para o caso em que $X_{1}=(0.1)$ e $X_{2}=(0.0)$ tenha sido observado.

Neste caso a informaçào a priori $\xi_{01}$ é at ualizada com a informaçào $\mathrm{X}_{2}=(0.0)$. e a corrente distribuiçào para $\left(P_{A} . P_{B}\right)$ é a posteriori $\xi_{0100}$ qué ó o produto entre a Beta(3. 1:3) do tratamento $A$ e a Beta $(4,12)$ do tratimento B. Para especificar se a amostragem deve ser continuada. devemos calcular o risco de continuaçào ótima na etapa 2 dado que $\mathrm{X}_{1}=(0,0)$ e $\mathrm{X}_{2}=(0,1)$ tenham sido observados e que a amostragem poderá prosscguir. no máximo. mais uma ctapa:

$$
\rho_{1}\left(\xi_{0001}\right)=\min \left[\rho_{0}\left(\xi_{0001}\right), \mathbb{E}\left\{\rho_{0}\left[\xi_{0001}\left(X_{3}\right)\right]\right\}+0.10\right]
$$

O valor de $\rho_{1}\left(\xi_{0001}\right)$ já foi calculado quando necessário na equaçào (3.8). Aproveitando os cálculos, temos:

$$
\begin{aligned}
\rho_{0}\left(\xi_{0001}\right) & =\min \left[\rho\left(\xi_{0001}, d_{1}\right), \rho\left(\xi_{0001}, d_{2}\right)\right] \\
& =\min [0.4741,3.2566] \\
& =0.4741 \\
\rho_{1}\left(\xi_{0001}\right) & =\min \left[\rho_{0}\left(\xi_{0001}\right), \mathbb{E}\left\{\rho_{0}\left[\xi_{0001}\left(X_{3}\right)\right]\right\}+0.10\right] \\
& =\min [0.4741,0.3692+0.10] \\
& =0.4692
\end{aligned}
$$

Portanto, se $X_{1}=(0,0)$ e $X_{2}=(0,1)$ for observado. a continuaçào ótima é prosseguir a amostragem, e seu risco é 0.4692 .

O esquema abaixo mostra a continuaçào ótima na etapa 2 para cada uma das 104 possibilidade de $\mathrm{X}_{1,2}$ que atinjiram a segunda etapa. Nos casos em que a continuaçào ótima é interromper a amostragem, a respectiva decisào de Bayes é 


\section{Aplicação}

indicada. $Y_{1}+Y_{2}$ e $Z_{1}+Z_{2}$ representam o número de sucessos no tratamento A e no tratamento $B$. respectivamente. observados na amostragem do primeiro e segundo grupo conjuntamente.

- Se

$$
\begin{array}{ccc}
Y_{1}+Y_{2}=0 & \text { e } & Z_{1}+Z_{2}=0 \text { ou } \\
Y_{1}+Y_{2}=1 & \text { e } & 0 \leq Z_{1}+Z_{2} \leq 1 \text { ou } \\
Y_{1}+Y_{2}=2 & \text { e } & 0 \leq Z_{1}+Z_{2} \leq 2 \text { ou } \\
Y_{1}+Y_{2}=3 & \text { e } & 0 \leq Z_{1}+Z_{2} \leq 3 \text { ou } \\
Y_{1}+Y_{2}=4 & \text { e } & 0 \leq Z_{1}+Z_{2} \leq 4 \text { ou } \\
Y_{1}+Y_{2}=5 & \text { e } & 0 \leq Z_{1}+Z_{2} \leq 5 \text { ou } \\
Y_{1}+Y_{2}=6 & \text { e } & 0 \leq Z_{1}+Z_{2} \leq 6 \text { ou } \\
Y_{1}+Y_{2}=7 & \text { e } & 2 \leq Z_{1}+Z_{2} \leq 7 \text { ou } \\
Y_{1}+Y_{2}=8 & \text { e } & 3 \leq Z_{1}+Z_{2} \leq 8 \text { ou } \\
Y_{1}+Y_{2}=9 & \text { e } & 4 \leq Z_{1}+Z_{2} \leq 9 \text { ou } \\
Y_{1}+Y_{2}=10 & \text { e } & 5 \leq Z_{1}+Z_{2} \leq 10
\end{array}
$$

então pare a amostragem e escolha a decisão $d_{1}$.

- Se

$$
\begin{array}{ccc}
Y_{1}+Y_{2}=0 & \text { e } & 1 \leq Z_{1}+Z_{2} \leq 4 \text { ou } \\
Y_{1}+Y_{2}=1 & \text { e } & 2 \leq Z_{1}+Z_{2} \leq 5 \text { ou } \\
Y_{1}+Y_{2}=2 & \text { e } & 3 \leq Z_{1}+Z_{2} \leq 6 \text { ou } \\
Y_{1}+Y_{2}=3 & \text { e } & 4 \leq Z_{1}+Z_{2} \leq 7 \text { ou } \\
Y_{1}+Y_{2}=4 & \text { e } & 5 \leq Z_{1}+Z_{2} \leq 8 \text { ou } \\
Y_{1}+Y_{2}=5 & \text { e } & 6 \leq Z_{1}+Z_{2} \leq 9 \text { ou } \\
Y_{1}+Y_{2}=6 & \text { e } & 7 \leq Z_{1}+Z_{2} \leq 10 \text { ou } \\
Y_{1}+Y_{2}=7 & \text { e } & 8 \leq Z_{1}+Z_{2} \leq 10 \text { ou } \\
Y_{1}+Y_{2}=8 & \text { e } & 9 \leq Z_{1}+Z_{2} \leq 10 \text { ou } \\
Y_{1}+Y_{2}=9 \text { e } & Z_{1}+Z_{2}=10
\end{array}
$$


entào continue a amostragem.

- $\mathrm{Se}$

$Y_{1}+Y_{2}=0$ e $5 \leq Z_{1}+Z_{2} \leq \delta$ ou

$Y_{1}+Y_{2}=1 \quad$ o $\quad\left(j \leq Z_{1}+Z_{2} \leq 9\right.$ ou

$Y_{1}+Y_{2}=2$ e $\quad T \leq Z_{1}+Z_{2} \leq 10$ ou

$Y_{1}+Y_{2}=3$ ○ $\& \leq Z_{1}+Z_{2} \leq 10$ ou

$Y_{1}+Y_{2}=4$ e $9 \leq Z_{1}+Z_{2} \leq 10$ ou

$Y_{1}+Y_{2}=5$ e $\quad Z_{1}+Z_{2}=10$

entào pare a amostrageni e escolha a decisão $d_{2}$.

\subsubsection{Etapa 3}

Seguindo um raciocínio análogo ao apresentado na seçào 3.7.3. verificamos que, para nosso caso, existem 158 possibilidades para a amostra, depois que o terceiro grupo for observado. Como a amostragem será interrompida, com certeza, nesta etapa, para cada uma das 158 possibilidades devemos apenas especificar qual a decisão de Bayes contra a posteriori $\xi_{\text {ijgrst }}$ através do cálculo de $\rho_{0}\left(\xi_{\text {ijgrst }}\right)$.

As contas para cada $\rho_{0}\left(\xi_{i j q r s t}\right)$ já foram realizados quando foram necessários na equação (3.9). Aproveitando estes resultados, estabelecemos o esquema abaixo. $Y_{1}+Y_{2}+Y_{3}$ e $Z_{1}+Z_{2}+Z_{3}$ representam o número de sucessos nos tratamentos $A$ e $B$, respectivamente, observados na amostragem do primeiro, segundo e terceiro grupo conjuntaménte.

- Se

$$
\begin{array}{lll}
Y_{1}+Y_{2}+Y_{3}=0 & \text { e } & 1 \leq Z_{1}+Z_{2}+Z_{3} \leq 3 \text { ou } \\
Y_{1}+Y_{2}+Y_{3}=1 & \text { e } & 1 \leq Z_{1}+Z_{2}+Z_{3} \leq 4 \text { ou } \\
Y_{1}+Y_{2}+Y_{3}=2 & \text { e } & 1 \leq Z_{1}+Z_{2}+Z_{3} \leq 5 \text { ou }
\end{array}
$$




$$
\begin{array}{lll}
Y_{1}+Y_{2}+Y_{3}=3 & \text { e } & 1 \leq Z_{1}+Z_{2}+Z_{3} \leq 6 \text { ou } \\
Y_{1}+Y_{2}+Y_{3}=4 & \text { e } & 1 \leq Z_{1}+Z_{2}+Z_{3} \leq 7 \text { ou } \\
Y_{1}+Y_{2}+Y_{3}=5 & \text { e } & 1 \leq Z_{1}+Z_{2}+Z_{3} \leq 8 \text { ou } \\
Y_{1}+Y_{2}+Y_{3}=6 & \text { e } & 2 \leq Z_{1}+Z_{2}+Z_{3} \leq 9 \text { ou } \\
Y_{1}+Y_{2}+Y_{3}=7 & \text { e } & 3 \leq Z_{1}+Z_{2}+Z_{3} \leq 10 \text { ou } \\
Y_{1}+Y_{2}+Y_{3}=8 & \text { e } & 4 \leq Z_{1}+Z_{2}+Z_{3} \leq 11 \text { ou } \\
Y_{1}+Y_{2}+Y_{3}=9 & \text { e } & 5 \leq Z_{1}+Z_{2}+Z_{3} \leq 12 \text { ou } \\
Y_{1}+Y_{2}+Y_{3}=10 & \text { e } & 6 \leq Z_{1}+Z_{2}+Z_{3} \leq 13 \text { ou } \\
Y_{1}+Y_{2}+Y_{3}=11 & \text { e } & \imath \leq Z_{1}+Z_{2}+Z_{3} \leq 14 \text { ou } \\
Y_{1}+Y_{2}+Y_{3}=12 & \text { e } & 8 \leq Z_{1}+Z_{2}+Z_{3} \leq 15 \text { ou } \\
Y_{1}+Y_{2}+Y_{3}=13 & \text { e } & 9 \leq Z_{1}+Z_{2}+Z_{3} \leq 15 \text { ou } \\
Y_{1}+Y_{2}+Y_{3}=14 & \text { e } & 10 \leq Z_{1}+Z_{2}+Z_{3} \leq 15
\end{array}
$$

entào escolha a decisào $d_{1}$.

- $\mathrm{Se}$

$$
\begin{array}{lll}
Y_{1}+Y_{2}+Y_{3}=0 & \text { e } & 4 \leq Z_{1}+Z_{2}+Z_{3} \leq 9 \text { ou } \\
Y_{1}+Y_{2}+Y_{3}=1 & \text { e } & 5 \leq Z_{1}+Z_{2}+Z_{3} \leq 10 \text { ou } \\
Y_{1}+Y_{2}+Y_{3}=2 & \text { e } & 6 \leq Z_{1}+Z_{2}+Z_{3} \leq 11 \text { ou } \\
Y_{1}+Y_{2}+Y_{3}=3 & \text { e } & 7 \leq Z_{1}+Z_{2}+Z_{3} \leq 12 \text { ou } \\
Y_{1}+Y_{2}+Y_{3}=4 & \text { e } & 8 \leq Z_{1}+Z_{2}+Z_{3} \leq 13 \text { ou } \\
Y_{1}+Y_{2}+Y_{3}=5 & \text { e } & 9 \leq Z_{1}+Z_{2}+Z_{3} \leq 14 \text { ou } \\
Y_{1}+Y_{2}+Y_{3}=6 & \text { e } & 10 \leq Z_{1}+Z_{2}+Z_{3} \leq 15 \text { ou } \\
Y_{1}+Y_{2}+Y_{3}=7 & \text { e } & 11 \leq Z_{1}+Z_{2}+Z_{3} \leq 15 \text { ou } \\
Y_{1}+Y_{2}+Y_{3}=8 & \text { e } & 12 \leq Z_{1}+Z_{2}+Z_{3} \leq 15 \text { ou } \\
Y_{1}+Y_{2}+Y_{3}=9 & \text { e } & 13 \leq Z_{1}+Z_{2}+Z_{3} \leq 14 \text { ou } \\
Y_{1}+Y_{2}+Y_{3}=10 & \text { e } & 14 \leq Z_{1}+Z_{2}+Z_{3} \leq 15 \text { ou } \\
Y_{1}+Y_{2}+Y_{3}=11 & \text { e } & Z_{1}+Z_{2}+Z_{3}=15 \text { ou }
\end{array}
$$

entào escolha a decisào $d_{2}$. 
Com os esquemas feitos nas seçòes anteriores, juntamente com as probabilidades preditivas para cada possivel resultado da amostragem. podemos calcular a probabilidade do ensaio parar após a observação de cada um dos grupos.

A figura 3.2 mostra a distribuição de probabilidades do número de grupos a ser obsevado com a amostragem. Por exemplo, a àrea referente a "Etapa 1" representa a probalidlidade preditiva para os possíveis resultados da amostra do primeiro grupo que levariam a encerrar o ensaio depois que ele fosse observado.

Distr. Prob. do Numero de Grupos a ser Observado

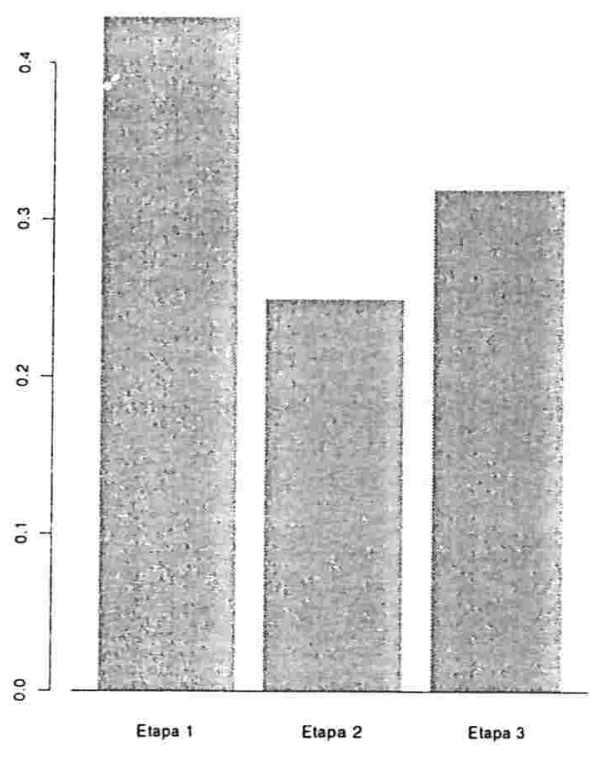

Figura 3.2: Histograma 


\subsection{Exemplos}

Nesta seção, apresentaremos alguns casos que poderiam ter acontecido se este ensaio fosse realizado na prática.

\subsubsection{Exemplo1}

Suponha que a amostragem tenha sido iniciada e que $Y_{1}=1$ e $Z_{1}=5$ tenham sido observados. Atualizando a priori com estes resultados, temos que a corrente distribuição para $P_{A}$ é $\operatorname{Beta}(4,7)$ e para $P_{B}$ é $\operatorname{Beta}(8,3)$.

A figura 3.3 mostra a corrente distribuição para $\left(P_{A}, P_{B}\right)$. Utilizando o esquema da seção 3.7.2, temos que, neste caso, a continuação ótima é interromper a amostragem.

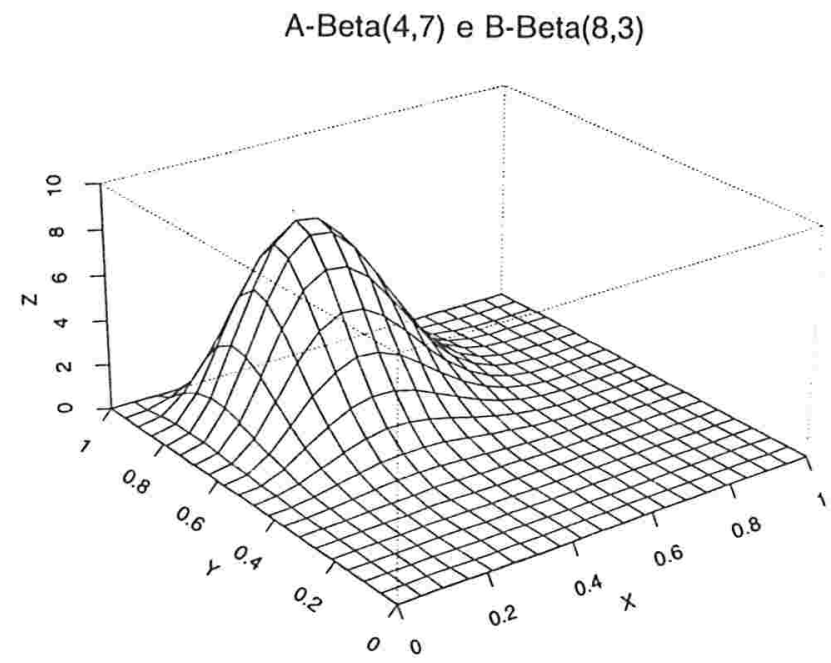

Figura 3.3: Posteriori para $\left(P_{A}, P_{B}\right)=(X, Y)$ 
Dado que a amostragem é interrompida após a observação do primeiro grupo temos:

$$
\rho_{0}\left(\xi_{15}, d_{1}\right)=4.61
$$

e

$$
\rho_{0}\left(\xi_{15}, d_{2}\right)=0 . \$ 9
$$

Portanto, a decisào de Bayes é $d_{2}$ com risco 0.89. A decisão terminal é que a indústria deve fabricar o tratamento-experimental e o Risco Total de Bayes a Posteriori contra $\xi_{15}$ é:

$$
R_{0}\left(\xi_{15}\right)=0.89+0.10=0.99
$$

\subsubsection{Exemplo 2}

Suponha que a amostragem tenha sido iniciada e que $Y_{1}=3$ e $Z_{1}=4$ tenham sido observados. Neste caso, a corrente distribuição para $P_{A}$ é Beta(6,5) e para $P_{B}$ é $\operatorname{Beta}(7,4)$.

A figura 3.4 mostra a corrente distribuição para $\left(P_{A}, P_{B}\right)$. Utilizando o esquema da seção 3.7 .2 , temos que, neste caso, a continuaçào ótima é prosseguir a amostragem, observando o segundo grupo de pacientes.

Suponha, agora, que $Y_{2}=1$ e $Z_{2}=0$ tenham sido observados. Neste caso, a corrente distribuição para $P_{A}$ é $\operatorname{Beta}(7,9)$ e para $P_{B}$ também é $\operatorname{Beta}(7,9)$. A figura 3.5 mostra a corrente distribuição $\left(P_{A}, P_{B}\right)$. Agora, a continuação ótima é interromper a amostragem. 
A-Beta(6,5) e B-Beta(7,4)

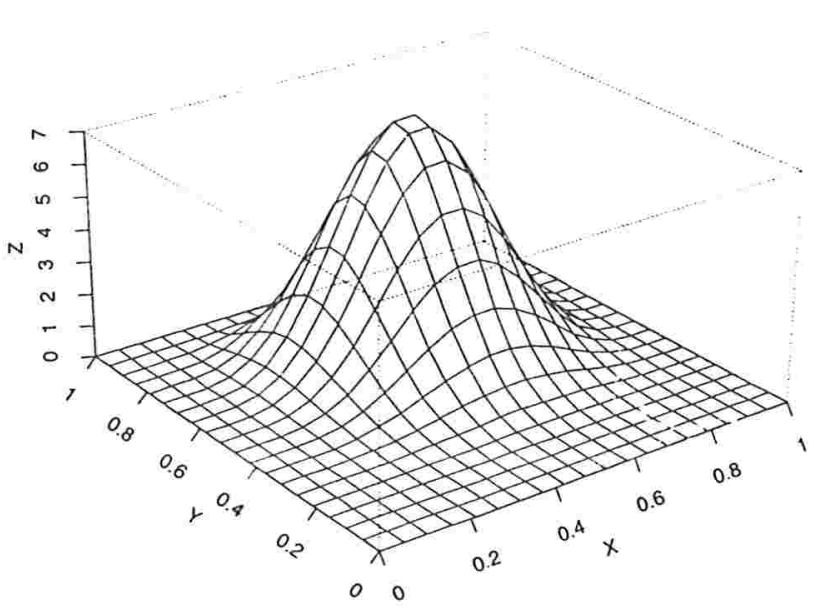

Figura 3.4: Posteriori para $\left(P_{A}, P_{B}\right)=(X, Y)$

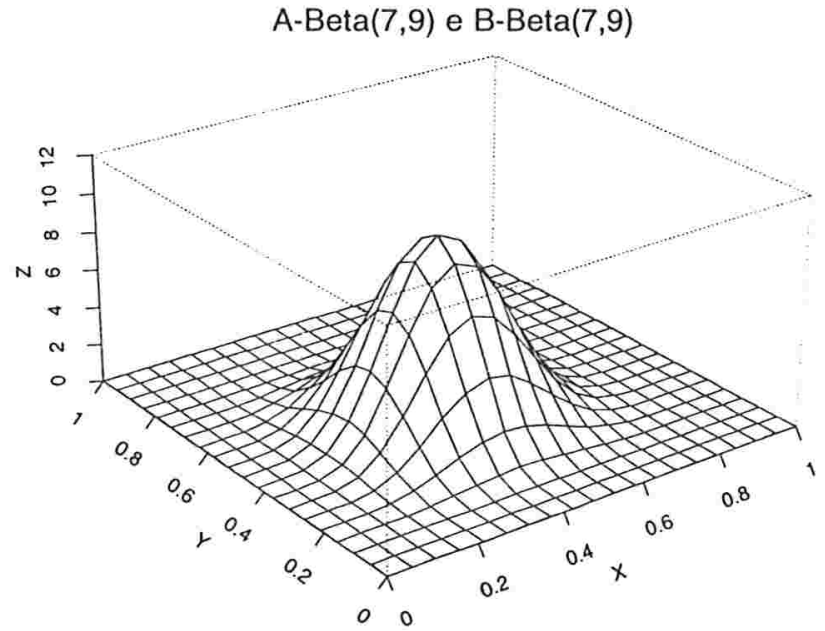

Figura 3.5: Posteriori para $\left(P_{A}, P_{B}\right)=(X, Y)$ 
Dado que a amostragem é interrompida após a observação do segundo grupo. temos:

$$
\rho_{0}\left(\xi_{3410}, d_{1}\right)=0.39
$$

e

$$
\rho_{0}\left(\xi_{\llcorner 410}, d_{2}\right)=5
$$

Portanto, a decisão de Bayes é $d_{1}$ com risco 0.39. A decisão terminal é que a indústria deve fabricar o tratamento-padrão e o Risco Total de Bayes a Posteriori contra $\xi_{3410}$ é:

$$
R_{0}\left(\xi_{3410}\right)=0.39+0.10+0.10=0.59
$$

\subsubsection{Exemplo 3}

Suponha que a amostragem tenha sido iniciada e que o mesmo resultado para a observação do grupo primeiro grupo do exemplo 2 tenha sido obtido. Suponha, então, que a amostragem tenha prosseguido e que $Y_{2}=1$ e $Z_{2}=1$ tenham sido observados. Neste caso, a corrente distribuição para $P_{A}$ é $\operatorname{Beta}(7,9)$ e para $P_{B}$ é $\operatorname{Beta}(8,8)$. A figura 3.6 mostra a corrente distribuição para $\left(P_{A}, P_{B}\right)$ na segunda etapa. Agora, a continuação ótima permanece sendo continuar a amostragem, observando o terceiro grupo de pacientes.

Suponha que $Y_{3}=1$ e $Z_{3}=2$ tenham sido observados. Neste caso, a corrente distribuição para $P_{A}$ é $\operatorname{Beta}(8,13)$ e para $P_{B}$ é Beta(10.11). A figura 3.7 mostra a corrente distribuição para $\left(P_{A}, P_{B}\right)$.

Dado que a amostragem é interrompida após a observaçào do terceiro grupo, temos:

$$
\rho_{0}\left(\xi_{341112}, d_{1}\right)=0.84
$$


e

$$
\rho_{0}\left(\xi_{3-41112} \cdot d_{2}\right)=2.62
$$

Portanto. a decisào de Bayes é $d_{1}$ com risco 0.84. A decisão terminal é que a indústria deve fabricar o tratamento-padrão e o Risco Total de Bayes a Posteriori col:tra $\xi_{341112}$ é:

$$
R_{0}\left(\xi_{341312}\right)=0.84+0.10+0.10+0.10=1.14
$$

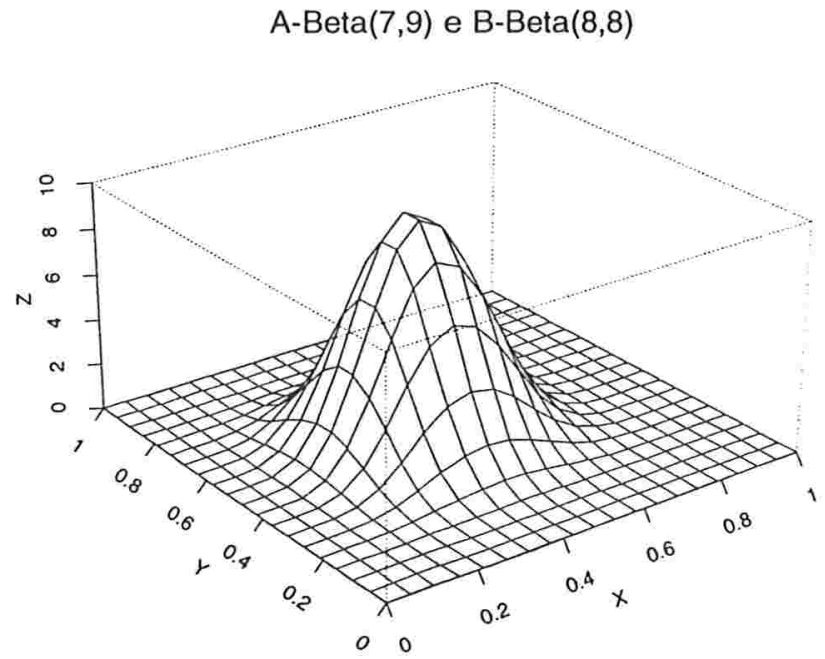

Figura 3.6: Posteriori para $\left(P_{A}, P_{B}\right)=(X, Y)$ 
A-Beta $(8,13)$ e B-Beta $(10,11)$

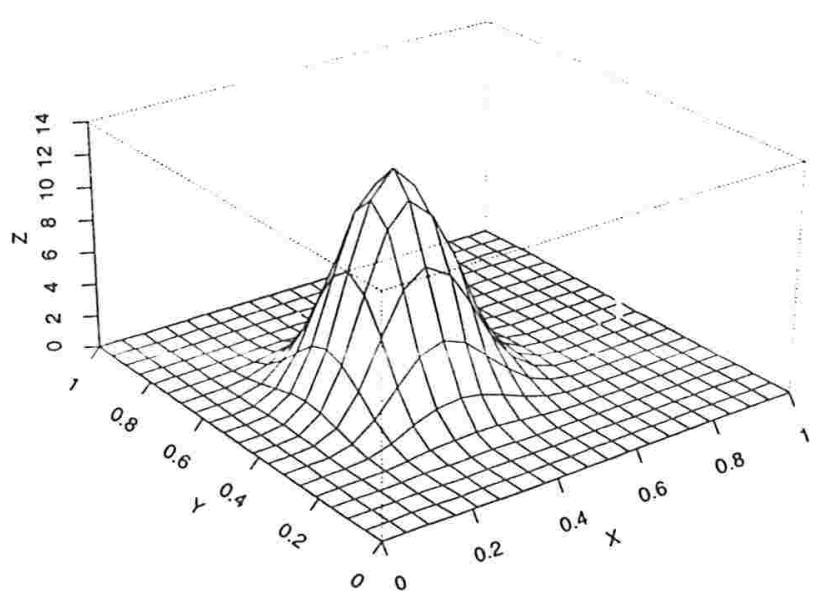

Figura 3.7: Posteriori para $\left(P_{A}, P_{B}\right)=(X, Y)$ 


\section{Comentários Finais}

A proposta deste trabalho foi apresentar uma maneira mais dinâmica e flexível para planejar e analisar um ensaio clínico. As questòes éticas que apresentamos no final do capítulo 1 sustentam a idéia de que ensaios clínicos não devem envolver análises que sejam muito dependentes de seus protocolos. A alocação de tratamentos entre os pacientes através de aleatorização, utilizandio algum mecanismo lotérico, compromete, indiscutivelmente, o compromisso com a ética individual. Um planejamento que não incorpora análises intermediárias ou não-programadas não possibilita que o ensaio seja interrompido tão logo os dados apontem para alguma conclusão, comprometendo, também, a ética coletiva. A análise que propusemos, sendo subordinada à abordagem bayesiana, não só é mais direta no sentido de se basear e apresentar uma distribuição a posteriori para o parâmetro de interesse, como também é mais flexível no sentido de não se preocupar em considerar o tipo de alocação e planejamento utilizados. Além disso ela permite a incorporação de informações externas ao ensaio. Com certeza. o tipo de alocação a ser feito deve ser bem estabelecido, tendo o cuidado para não introduzir vícios de alocação e com isso comprometer os resultados. O que não concordamos é que a aleatorização por mecanismo lotérico seja a única fonte (e infalível) de não introduzir vícios na alocação dos tratamentos. No momento em que consideramos os pacientes permutáveis em relação à resposta do estudo, por que deveríamos 
sortear tratamentos? Será que, neste momento, um sorteio é realmente tão mais eficiente no sentido de balancear fatores prognósticos desconsiderados ou nào observáveis do que outro tipo de alocação tal como a sistematizaçào ou a utilização de controles históricos? Ou mesmo cuidadosa alocaçào intencional? (ver Basu (1980) ou Inoue (1995)). E, de todo modo, porque o sorteio deve ser levado em conta após a amostragem. isto é. na análise?

A utilizaçào de nossa proposta de planejamento sequencial objetivou tornar o ensaio mais dinâmico, uma vez que ele pode ser interrompido após qualquer análise intermediária e, como estamos utilizando a abordagem bayesiana para a análise, o ensaio pode, na verdade, ser interrompido (ou prosseguido) a qualquer momento. A utilização de um planejamento sequencial faz com que o pesquisador tenha que decidir, após cada análise intermediária, se os dados até então obtidos são ou não suficientes para uma conclusão ou, equivalentemente, se a amostragem deve ou não ser interrompida. Seguimos a mesma linha de pensamento de Lindley quando ele discorda, na discussão do trabalho de Spiegelhalter et. al. (1994), que a incorporação de uma função de perda seja não-realística. Não só concordamos com Lindley em dizer que um planejamento sequencial utilizando Teoria da Decisão para ensaios clínicos é realístico como também é fundamental. Problemas de decisão estão intrinsicamente presentes no cotidiano da humanidade e, especificamente na área médica, estão presentes em todos os momentos. Como dizer, então, que é não-realístico um médico ter preferências e opiniões a respeito de perdas por decisões erradas? Porque essa assimetria entre priori e utilidade? Ou seja, porque opinião a priori é considerada realística e opinião sobre utilidade nào? A sugestão de incorporar a Teoria da Decisão no planejamento sequencial que apresentamos incorpora essas preferências por decisão errada e, objetivando minimizar a perda esperada, dita a regra de quando o ensaio deve ser interrompido.

Por outro lado, seguindo a proposta de Spiegelhalter et. al. (1994), fizemos uso 
da amplitude de equivalência, que é um conceito que precisa ser mais difundido. Acreditamos nisso devido ao seu adequamento com a realidade no sentido de incorporar na análise a idéia de equivalência não só onde a diferença entre os efeitos dos tratamento é nula.

A nossa primeira intenção com um planejamento sequencial bayesiano era ir atualizando a priori a cada nova informaçào (a cada resposta de um paciente). Com o decorrer do trabalho, consideramos que essa intenção nào era muito condizente nem com a área médica (onde o custo de observar e analisar um ensaio com pacientes sendo observados um a um é geralmeite mais alto do que quando pacientes são observados em grupo) e nem com a aplicabilidade estatística em relação à parte computacional (quanto mais análises intermediárias são realizadas, mais extensas tornam-se os cálculos necessários). O desenvolvimento com grupos foi uma alternativa que consideramos mais adequadà.

Acreditamos que os exemplos que apresentamos no final do capítulo 3 cumpriram o papel de ilustrar o planejamento e análise propostos. Apesar de ter sido planejado um ensaio que envolveria no máximo 30 pacientes, foi possível verificar que (se um tratamento é realmente mais eficiente que outro) o ensaio é normalmente interrompido antes de atingido o limite $\mathrm{M}$. Uma desvantagem da nossa proposta é que nem sempre a construção de um planejamento sequencial de Bayes utilizando Teoria da Decisão é computacionalmente simples. Na verdade, dependendo do tipo de dados a serem analisados e suas respectivas distribuições condicionadas ao parâmetro de interesse, as contas podem se tornar extremamente complicadas, mas evidentemente, com o contínuo desenvolvimento de hardware e software, esta desvantagem vai enfraquecendo. 


\section{Referências Bibliográficas}

[1] D. G. Altman. Practical Statistics for Medical Research. Chapman and Hall, 1991.

[2] P. Armitage, C. K. McPherson, and B. C. Rowe. Repeated significance tests on accumulating data. Journal Royal Statistical Society A, 132:235-244, 1969.

[3] D. Basu. Randomization analysis of experimental data: The Fisher randomization test (with discussion). J.A.S.A., 75:575-595, 1980.

[4] D. A. Berry. Interim analysis in clinical trials - the role of the likelihood principle. The American Statistician, 41:117-122, 1987.

[5] D. A. Berry. Statistical Methodology in the Pharmaceutical Sciences: Basic Principles in Designing and Analysing Clinical Studies. Marcel Dekker, Inc., 1990.

[6] D. A. Berry. A case for bayesianism in clinical trials. Statistics in Medicine, 12:1377-1393, 1993.

[7] D. A. Berry. Statistics A Bayesian Perspective. Duxbury Press, 1996.

[8] N. E. Breslow. Clinical trials. Encyclopedia of Statistical Sciences, 2:13-21, 1982. 
[9] D. P. Byar. R. M. Simon. II. T. Friedewald, J. J. Schlesselman. D. L. Demets, J. H. Ellemberg. M. H. Ciail. and J. H. Waer. Randomized clinical trials: Perspective on some recent ideas. New England J. Med.. 295:T-1-80. 1976.

[10] T. Colton. Statistics in Medicine. Little. Brown and Company. 1974.

[11] M. II. DeGirout. Optimal Stalistical Decisions. McCiraw-Hill Book Company. 1970.

[12] R. Doll and A. B. Hill. Lung cancer and other causes of death in relation to smoking. British Medical Journal, 2:1071, 1956.

[13] B. Freedman. Equipoise and the ethics of clinical research. Vew England J. Med., 317:141-145, 1987.

[14] C. Fried. Medical Experimentation: Personal Integrity and Social Policy. North-Holland. Amsterdam. 1974.

[15] L. Y. T. Inoue. Desenvolvimento e implementaçào do princípio da verossimilhança. Master's thesis. IME-USP, 1995.

[16] L. Y. T. Inoue and S. Wechsler. Inferência comparada: A violação do princípio da verossimilhança. Rev. Mat. Est., 12:19-31, 1994.

[17] R. J. Lewis and D. A. Berry. Group sequential clinical trials: A classical evaluation of bayesian decision-theoretic designs. Journal of the American Statistical Association. 89:1528-1534, 1994.

[18] D. V. Lindley. Making Decisions. John Wiley and Sons, 1971.

[19] D. Marquis. Leaving therapy to chance. Hastings Center Report. 13:40-47, 1983. 
[20] K. McPherson. On choosing the number of interim analysis in clinical trials. Statistics in Medicine. 1:25-36. 1982.

[21] P. C. O`Brien and T. R. Fleming. A multiple testing procedure for clinical trials. Biometrics. 35:549 556. 1979.

[22] C. A. B. Pereira and S. Wechsler. On the concept of p-ralue. Rebrape. $7: 159-17 \tau .1993$.

[23] S. J. Pocock. Group-sequential methods in the design and analysis of clinical trials. Biometrics. 64:191-199. 1977.

[24] H. Raiffa and R. Schlaifer. Applied Statistical Decision Theory. Harvard University Press. 1961.

[25] R. M. Royall. Ethics and statistics in randomized clinical trials (with discussion). Statistical Science, 6:52-88, 1991.

[26] J. J. Schlesselman. Case-Control Studies: Design. Conducl. Analysis. Oxford University Press, 1982.

[27] D. J. Spiegelhalter, L. S. Freedman, and M. K. B. Parmar. Bayesian approaches to randomized trials (with discussion). Journal Royal Statistical Society A, $157: 357-416,1994$.

[28] R. M. Veatch. A Theory of Medical Ethics. Basic Books. New York, 1981.

[29] J. H. Ware. Investigating therapies of potentially benefit: Ecmo (with discussion). Statistical Science, 4:298-340, 1989.

[30] L. J. Wei and S. Durham. The randomized play-the-winner rule in medical trials. Journal of American Statistical Association. 73:8:30-843, 1978. 